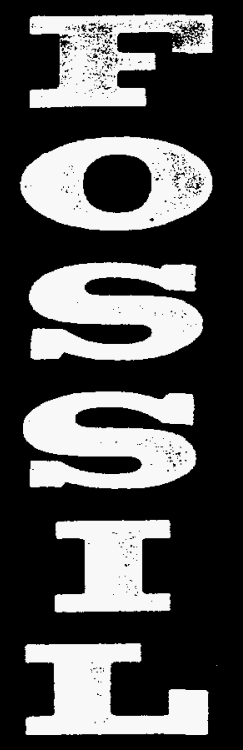

\title{
EVALUATION OF RESERVOIR WETTABILITY AND ITS EFFECT ON OIL RECOVERY
}

Annual Report

February 1, 1996 to January. 31, 1997

By

Jill S. Buckley

13
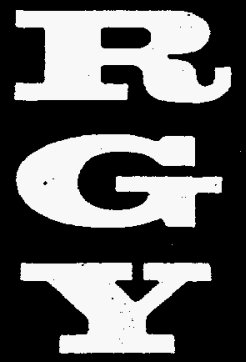

Performed Under Contract No. DE-FC22-96ID13421

March 1998

Perfo

New Mexico Petroleum Recovery Research Center New Mexico Institute of Mining and Technology

Socorro, New Mexico

\section{National Petroleum Technology Office U. S. DEPARTMENT OF ENERGY Tulsa, Oklahoma}




\section{DISCLAIMER}

This report was prepared as an account of work sponsored by an agency of the United States Govemment. Neither the United States Government nor any agency thereof, nor any of their employees, makes any warranty, expressed or implied, or assumes any. legal liability or responsibility for the accuracy, completeness, or usefulness of any information, apparatus, product, or process disclosed, or represents that its use would not infringe privately owned rights. Reference herein to any specific commercial product, process, or service by trade name, trademark, manufacturer, or otherwise does not necessarily constitute or imply its endorsement, recommendation, or favoring by the United States Government or any agency thereof. The views and opinions of authors expressed herein do not necessarily state or reflect those of the United States Government.

This report has been reproduced directly from the best available copy.

Available to DOE and DOE contractors from the Office of Scientific and Technical Information, P.O. Box 62, Oak Ridge, TN 37831; prices available from (615) 5768401 .

Available to the public from the National Technical Information Service, U.S. Department of Commerce, 5285 Port Royal Rd., Springfield VA 22161 


\title{
DOE/ID/13421- - T 3 \\ Distribution Category UC-122
}

Evaluation Of Reservoir Wettability And Its Effect On Oil Recovery

Annual Report

February 1, 1996 to January 31, 1997

\author{
By \\ Jill S. Buckley \\ March 1998 \\ Work Performed Under Contract No. DE-FC22-96ID13421
}

\author{
Prepared for \\ U.S. Department of Energy \\ Assistant Secretary for Fossil Energy \\ Jerry Casteel, Project Manager \\ National Petroleum Technology Office \\ P.O. Box 3628 \\ Tulsa, OK 74101
Prepared by:
New Mexico Petroleum Recovery Research Center
New Mexico Institute of Mining and Technology
801 Leroy Place
Socorro, New Mexico 87801

DISTRIBUTION OF THIS DOCUMENT IS UNLIMITED 


\section{DISCLAIMER}

Portions of this document may be illegible electronic image products. Images are produced from the best available original document. 


\section{TABLE OF CONTENTS}

TABLE OF CONTENTS ............................................................................................. ii

LIST OF FIGURES.......................................................................................................

LIST OF TABLES ….............................................................................................. viii

ACKNOWLEDGMENTS ................................................................................. ix

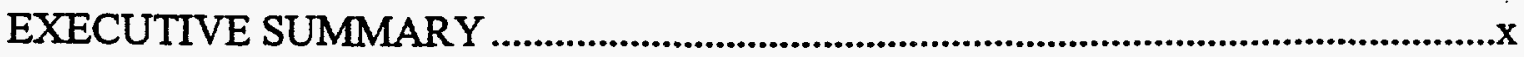

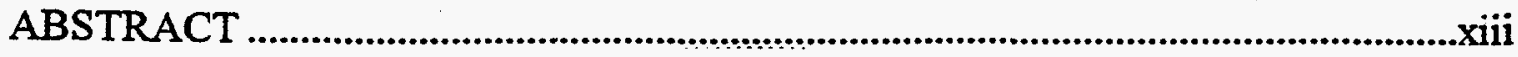

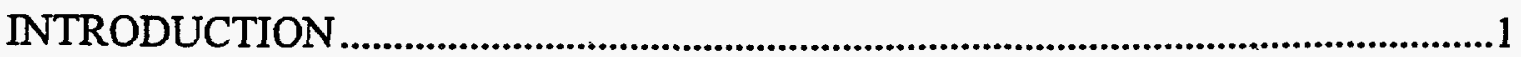

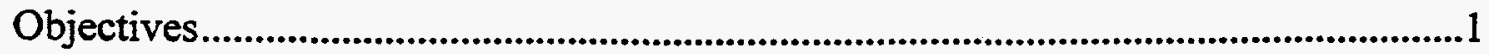

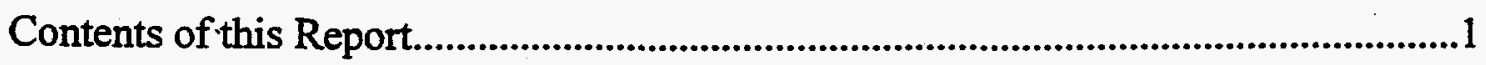

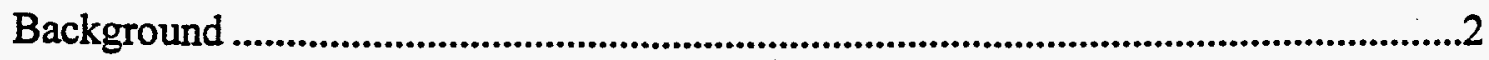

A conceptual model for development of mixed wetting................................................

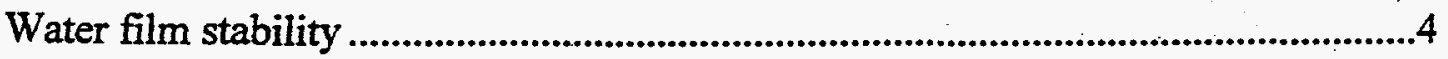

Crude oil components that can adsorb and alter wetting .......................................6

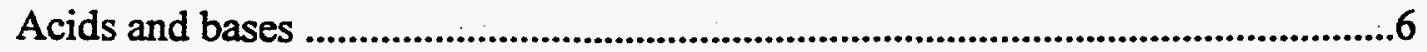

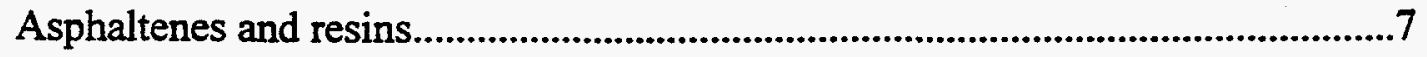

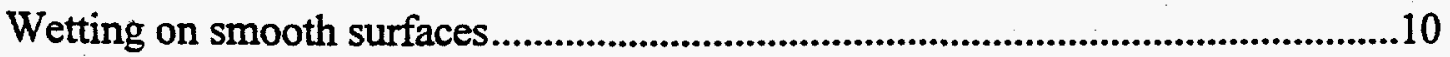

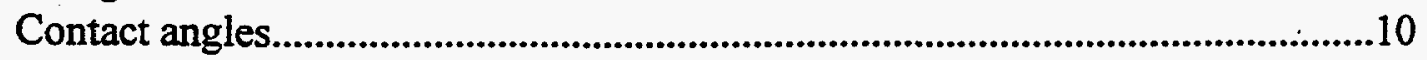

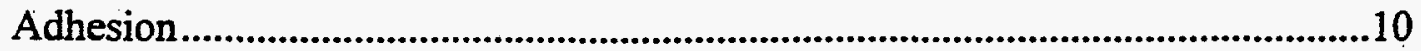

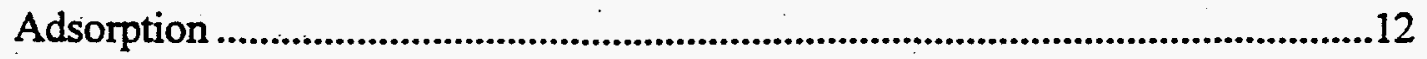

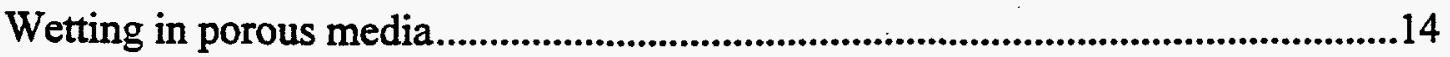

Standard core preparation procedures.........................................................14

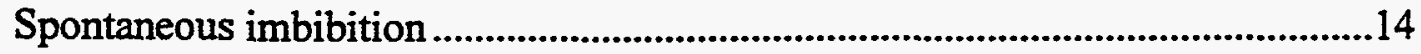

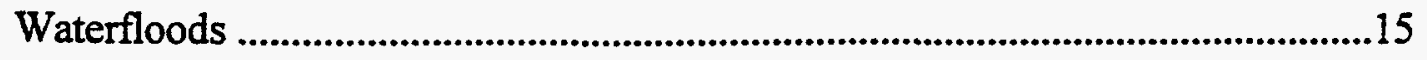

PART 1. CHEMICAL EVALUATION OF CRUDE OILS.........................................17

1.1 A Survey of Crude Oil Acid and Base Numbers ...................................................17

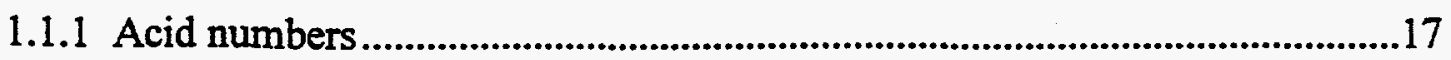

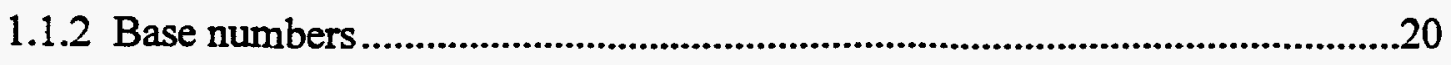

1.1.3 Relating acid and base numbers to alteration of wetting in cores..................24

1.2 Asphaltene Precipitation-Onset at Ambient Conditions....................................26

1.3 Mechanisms of COBR Interactions and Crude Oil Chemistry .............................31

1.3.1 Summary of proposed COBR interactions .....................................................31 


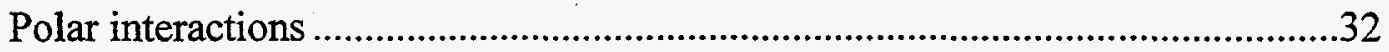

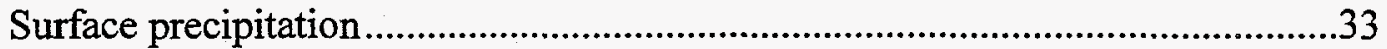

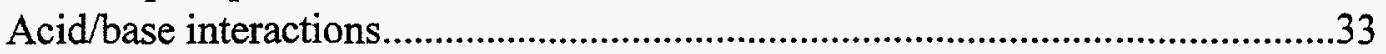

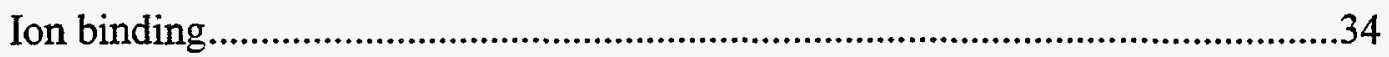

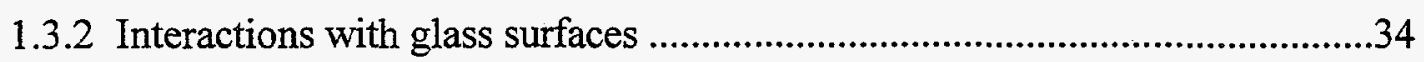

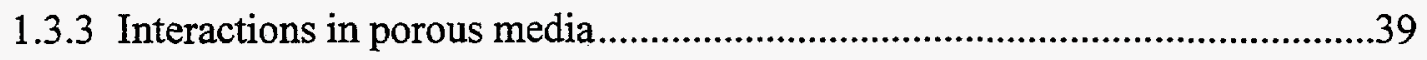

1.3.4 Effect of crude oil composition onwettability alteration ................................42

1.4 Asphaltene Precipitation-Onset at Controlled Temperature and Pressure ........43

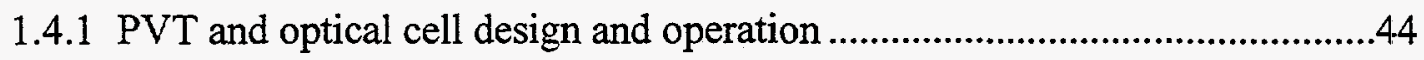

1.4.2 Results at controlled temperature and pressure ….........................................4.

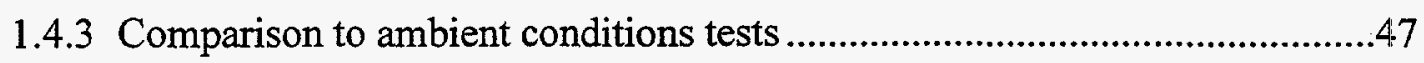

1.4.4 Rate and reversibility of asphaltene precipitate formation ............................48

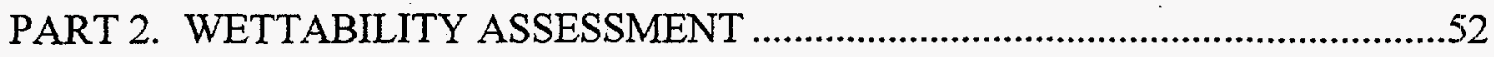

2.1 Interactions of Prudhoe Bay Crude Oil with Mica Surfaces .................................52

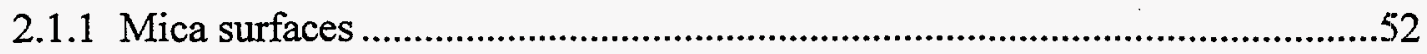

2.1.2 Experimental materials and methods .......................................................53

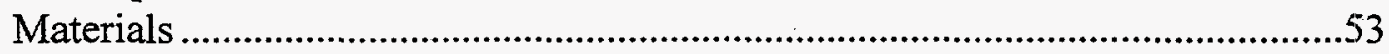

Characterizing crude oil-treated surfaces ..........................................................55

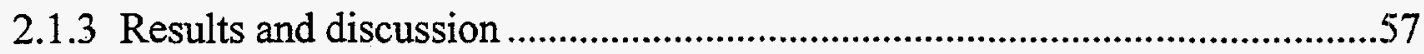

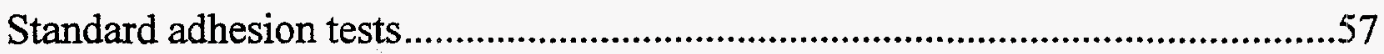

Changing wetting by adsorption........................................................................58

Reproducibility of contact angle measurements...................................................58

Adsorption on two mica minerals: muscovite and biotite ....................................59

Effect of aging time in crude oil....................................................................60

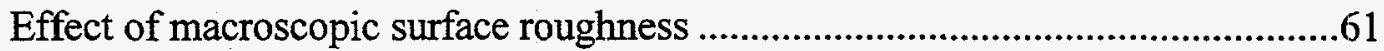

Brine composition effects...................................................................................62

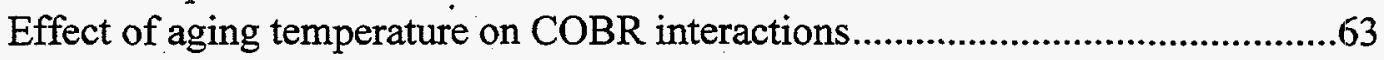

2.1.4 Conclusions of wettability study on mica surfaces.........................................65

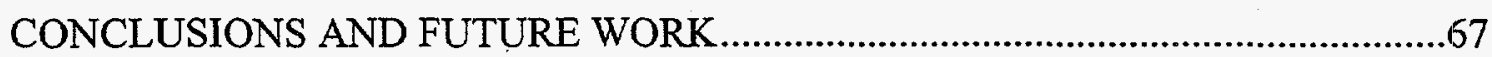

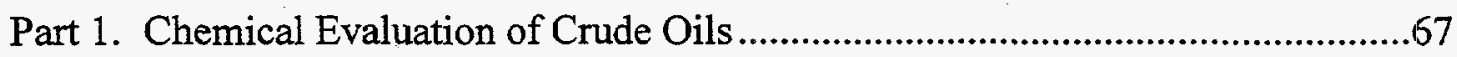

Part 2. Wettability Assessment .................................................................................69

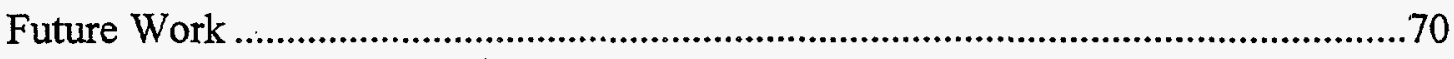

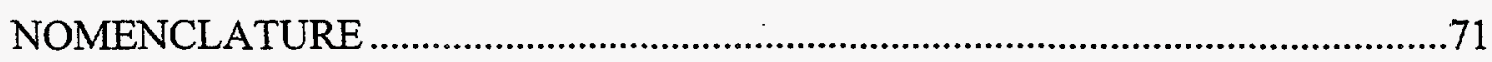

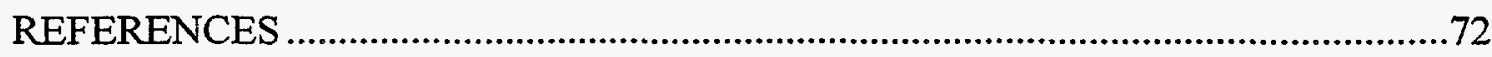




\section{LIST OF FIGURES}

Figure 1. Illustration of COBR interactions. When oil first enters the pore, it is the non-wetting fluid (a or b), with a film of water between the oil and mineral surface. Components from a crude oil can partition to the oil/water interface (c), and can adsorb and change wetting if the water film is unstable (d).

Figure 2. Regions of stability and instability of water films for drops of A-93 crude oil contacted with clean glass surfaces under brines of varying $\mathrm{pH}$ and $\mathrm{NaCl}$ concentration. Stable films result in non-adhesion whereas unstable films result in adhesion of the crude oil drop to the surface. In the region denoted as conditionally stable, low temperature adhesion and high temperature nonadhesion were observed. The disjoining pressure curves are illustrations only. Disjoining pressure was not measured in these experiments (after Buckley et al., 1997).

Figure 3. Zeta potentials of emulsions of Moutray crude oil in brines of varying $\mathrm{pH}$ and ionic strength. Markers show measured data; lines are calculated using an ionizable site group model with two ionizable species, one acidic and one basic with the properties shown above (after Buckley, et al., 1989).

Figure 4. SARA separation scheme divides crude oil into saturates, aromatics, resins (or polars), and asphaltenes.

Figure 5. Characteristics of asphaltenes precipitated by $n$-pentane or $n$-heptane. The darkest shaded area represents the properties of material insoluble in $n$-heptane. That material, plus some that is lower in either molecular weight, polarity, or aromaticity, is also insoluble in $n$-pentane (adapted from Long, 1981, and Cimino et al., 1995).

Figure 6. Variation in size of asphaltene aggregates with changes in solvent properties and temperature (measured by small angle neutron scattering, SANS experiments). Nominal volumes were calculated on the basis of reported particle dimensions. (after Buckley et al., 1997).

Figure 7. Contact angle is the angle between the tangent to the droplet at the three-phase line and the solid surface, measured here through the water phase.

Figure 8. Illustration of adhesion and non-adhesion between an oil droplet and a solid surface under water or brine.

Figure 9. A typical adhesion map delineates conditions of $\mathrm{NaCl}$ concentration and $\mathrm{pH}$ under which adhesion occurs. In this example, the crude oil is A-93. The test was performed at $80^{\circ} \mathrm{C} \ldots \ldots .12$

Figure 10. Standard procedures for adsorption and desorption tests.

Figure 11. Idealized capillary pressure vs. saturation curve, indicating the values used for calculation of Amott wettability indices $\left(I_{w}\right.$ and $\left.I_{0}\right)$ and the combined Amott-Harvey Index $I_{w-0}$.

Figure 12. Waterflood apparatus for constant rate experiments. .16

Figure 13. Comparison of crude oil titration with and without added stearic acid.

Figure 14. Titration of Moutray crude oil (sample 2), spiked with stearic acid solution. The graphical method used to find the inflection point is illustrated. 
Figure 15. Comparison of A-93 crude oil potentiometric titrations with and without added quinoline..... .21

Figure 16. Titration of A-93 crude oil plus quinoline, illustrating graphical determination of the inflection point.

Figure 17. Acid and base numbers of selected crude oils.

Figure 18. Relationship between acid and base numbers and the Amott index to water for Berea sandstone cores exposed to brine and to six different crude oils.

Figure 19. Schematic illustration of the onset of precipitation test procedure.

Figure 20. Refractive index of mixtures of a sample of crude oil from Prudhoe Bay with isooctane, plotted as a function of the volume fraction of the mixture that is crude oil. Open circles have no microscopically visible precipitate. Precipitate is observed in the mixtures indicated by the closed symbols.

Figure 21. Accuracy of the linear extrapolation is demonstrated by mixtures of Lagrave crude oil and $n$ heptane.

Figure 22. Deviation from linearity can be severe, as shown for a crude oil from the Ventura field. $\mathrm{RI}_{\text {oil }}$ was confirmed using mixtures of oil and toluene.

Figure 23. Mixtures of ST-86 and $n$-heptane are free of precipitate for all volume fractions of oil. .30

Figure 24. Mechanisms of interaction between crude oil components and solid surfaces. .32

Figure 25. Glass surfaces, treated with crude oils in the absence of water. Polar interactions result in intermediate in wetting.

Figure 26. Contact angles (measured on glass surfaces treated with synthetic reservoir brine and A-93 crude oil) show that oil mixtures with poorer solvent quality have greater wettability altering tendency.

Figure 27. Density and RI are both rough measures of an oil's solvent power. Rankings by API gravity (a) and $\Delta_{\mathrm{RI}}(\mathrm{b})$ are similar, with some significant differences for SQ-95 and Tensleep.

Figure 28. Brine composition can have a dominant effect on oil/solid interactions by the acid/base mechanism (after Liu and Bụckley, 1997).

Figure 29. Illustration of the summary notation used in Table 4.

Figure 30. Rate of imbibition of brine into Berea sandstone cores after they were aged for 9-12 days with three different crude oil samples.

Figure 31. When crude oils are grouped by API gravity, trends in wetting alteration that depend on acid and base numbers can be differentiated from the effects of oil solvent properties.

Figure 32. $\mathrm{P}_{\mathrm{RI}}$ of A-93 varies with carbon chain length of $n$-paraffin precipitants. Tests at ambient conditions show a minimum value for $n$-heptane.

Figure 33. Adapted Ruska 2370 PVT apparatus configured for charging the pump cell with oil. Volume is controlled by movement of the pump cell piston. 
Figure 34. Optical cell designed for observation of oil samples for detection of onset of asphaltene precipitation.

Figure 35. Comparison of ambient and PVT results for onset of precipitation from A-93 crude oil as a function of carbon chain length of the precipitant.

Figure 36. Asphaltene precipitation is reversible near the onset point. Temperatures at which particles disappear depends on composition and on precipitant.

Figure 37. Layered structure of muscovite (after Grim, 1953).............................................................52

Figure 38. X-ray diffraction patterns of muscovite and biotite. .................................................................55

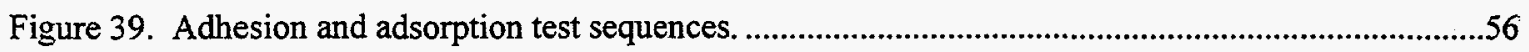

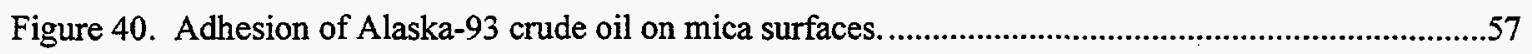

Figure 41. Adhesion of Alaska-93 crude oil on glass surfaces (after Buckley et al, 1997)........................57

Figure 42. Decane/water advancing and receding contact angles measured on brine and crude oil-treated muscovite.

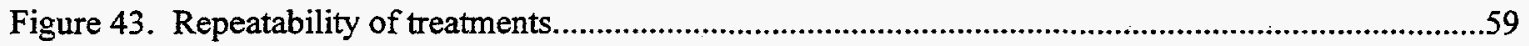

Figure 44. Comparison of contact angles on treated muscovite and biotite surfaces..................................59

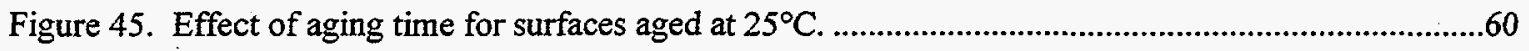

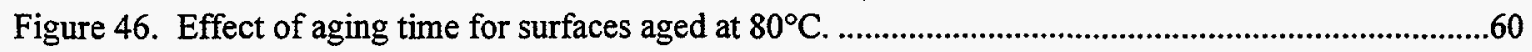

Figure 47. Effects of macroscopic roughness on contact angles. ........................................................61

Figure 48. Wettability alteration by Alaska- 93 crude oil aged at $25^{\circ} \mathrm{C}$ - effects of brine composition. .......62

Figure 49. Advancing angles measured on mica surfaces aged in Alaska-93 at 25,60 , and $80^{\circ} \mathrm{C} \ldots \ldots \ldots \ldots . . .63$

Figure 50. Effects of aging temperature on glass surfaces (after Buckley, 1996).....................................64

Figure 51. Glass and mica interactions are similar for aging at $25^{\circ} \mathrm{C}$, but not at $80^{\circ} \mathrm{C}$............................65 


\section{LIST OF TABLES}

Table 1. Acid and Base Numbers

Table 2. Wetting Alteration of Berea Sandstone Cores by Selected Crude Oils

Table 3. RI and $\mathrm{P}_{\mathrm{RI}}$ Data for Mixtures of Crude Oils with $n$-Heptane.

Table 4. Mechanisms of Interaction between Crude Oils, Brine, and Solid Surfaces

Table 5. Onset of Precipitation from A-93 Crude Oil and Paraffinic Precipitants

Table 6. Disappearance Temperatures for Mixtures of Paraffins and A-93 Near Onset of Precipitation ....49

Table 7. Crude Oil Properties. .53

Table 8. $\mathrm{pH}$ and Salinity of Aqueous Solutions .54

Table 9. Properties of Mica Samples .54 


\section{ACKNOWLEDGMENTS}

This work is supported by the US Department of Energy under Cooperative Agreement DEFC22-96ID13421 and by industrial support from Mobil, Norsk Hydro, and Unocal.

Crude oil samples were supplied by Arco, Elf Aquitaine, and Statoil.

Acid and base numbers were measured by Stephanie Monsterleet, Visiting Scientist.

Ambient conditions tests of asphaltene precipitation were conducted by Sue Von Drasek, graduate student in Geochemistry, and Mary Downes, undergraduate in Biology.

We thank Ruska Instruments for the loan of the Model 2370 mercury-free PVT apparatus. The optical cell was designed and built by Dr. Kay Brower, Chemistry Professor Emeritus at New Mexico Tech. Measurements were made by Jianxin Wang, graduate student in Petroleum Engineering.

The study of adhesion and adsorption of crude oils on mica was the thesis work of Ling Liu, M.S. student in Chemistry. We thank Yu Liu for her advice and encouragement.

We are grateful to Norman Morrow of the University of Wyoming, George Hirasaki of Rice University, Ken Sorbie of Heriot-Watt University, and John Lievois and Robbie Lansangan of Premier Instruments for many helpful discussions. 


\section{EXECUTIVE SUMMARY}

We report on the first year of the project, "Evaluation of Reservoir Wettability and its Effect on Oil Recovery." The objectives of this five-year project are (1) to achieve improved understanding of the surface and interfacial properties of crude oils and their interactions with mineral surfaces, (2) to apply the results of surface studies to improve predictions of oil production from laboratory measurements, and (3) to use the results of this research to recommend ways to improve oil recovery by waterflooding. During the first year of this project we have focused on understanding the interactions between crude oils and mineral surfaces that establish wetting in porous media.

Mixed-wetting can occur in oil reservoirs as a consequence of the initial fluid distribution. Water existing as thick films on flat surfaces and as wedges in corners can prevent contact of oil and mineral. Water-wet pathways are thus preserved. Depending on the balance of surface forces-which depend on oil, solid, and brine compositionsthick water films can be either stable or unstable. Water film stability has important implications for subsequent alteration of wetting in a reservoir.

On surfaces exposed to oil, the components that are likely to adsorb and alter wetting can divided into two main groups: those containing polar heteroatoms, especially organic acids and bases; and the asphaltenes, large molecules that aggregate in solution and precipitate upon addition of $n$-pentane and similar agents. In order to understand how crude oils interact with mineral surfaces, we must first gather information about both these classes of compounds in a crude oil. Test procedures used to assess the extent of wetting alteration include adhesion and adsorption on smooth surfaces and spontaneous imbibition into porous media. Part 1 of this project is devoted to determining the mechanisms by which crude oils alter wetting.

Petroleum Acids and Bases: Standard acid and base number non-aqueous potentiometric titration procedures were modified and 22 crude oil samples were tested. The range of acid numbers, in units of $\mathrm{mg} \mathrm{KOH} / \mathrm{g}$ of oil, was from a high of 0.66 to a low 
of 0.09. Base numbers varied over an even larger range, from a high of 5.19 to a low of $0.24 \mathrm{mg} \mathrm{KOH} / \mathrm{g}$ of oil. Prudhoe Bay crude oil, for which a substantial amount of wettability data is available, has a high base number and low acid number; the opposite extreme, high acid number and low base number, is exemplified by Moutray crude oil.

The Onset of Asphaltene Precipitation: In this study, the approach used to characterize the asphaltenes differed from those used in many earlier studies. Rather than focus on the amount of asphaltene that precipitates in standard ASTM tests, this project concentrates on the solvent environment in each oil. We quantify solvent properties by refractive index (RI) measurements. Refractive index is related to the surface forces between asphaltene aggregates. It is linearly related to component volume fractions of components in mixtures of crude oil, solvents, and precipitants. The onset of precipitation provides a point of comparison from one sample to another, and the difference between that point and the oil's RI measures stability of the asphaltenes in the stock tank oil. The onset of asphaltene precipitation with addition of $n$-heptane was measured at ambient conditions for nine oil samples. Onset testing has been extended to conditions of higher temperatures and pressures; volatile precipitants can now be tested along with the effects of temperature and pressure. Lagrave crude oil from France, for which some wettability test data are available, is a particularly poor solvent for its asphaltenes.

Mechanisms of Interaction: Four distinct categories of interaction mechanisms have been identified that can be demonstrated to occur when crude oils contact solid surfaces. In the absence of water, polar interactions can occur between the compounds in the oil that contain polar heteroatoms and mineral surfaces. These interactions are fairly nonspecific, producing intermediately wetted surfaces. If an oil is a poor solvent for its asphaltenes, surface precipitation can occur. This mechanism is probably most influential just before the onset of precipitation, causing surfaces to become quite oil-wet. Attractive forces can be either enhanced or limited by the presence of water. Acid/base interactions account for $\mathrm{pH}$-dependent adhesion and for electrophoretic mobilities of emulsified crude oil droplets. In the presence of divalent or multivalent ions, specific 
interactions, here referred to as ion-binding interactions can occur. These can be very strong interactions, and are characterized by high-hysteresis surfaces. Specific instances when each of these mechanisms is dominant have been identified in tests using crude oils of different acid number, base number, and solvent quality.

Wetting Assessment: Part 2 of this project is devoted to improved assessment of wetting. A baseline study of crude oil interactions with mica surfaces is reported. Mica is attractive for use as a solid substrate because it is easy to produce molecularly smooth surfaces by cleavage of mica plates, because its structure is well known, and because it is the subject of many other surface studies. Trends of wettability alteration are comparable to those reported previously for glass surfaces, but there are some significant differences as well, especially at elevated temperature.

During the first year of this project, we have made some very encouraging advances in explaining the mechanisms by which crude oils can alter wetting and in developing methods for characterizing crude oils and their interactions with mineral surfaces. Plans for next year include extension of asphaltene precipitation tests to an increased range of temperatures and pressures, and to more volatile precipitants. We will focus on explaining some of the differences observed between glass and mica in their interactions with crude oils. A new study will be initiated into visualization of imbibition into mixed-wet media with simple geometries. 


\begin{abstract}
We report on the first year of the project, "Evaluation of Reservoir Wettability and its Effect on Oil Recovery." The objectives of this five-year project are (1) to achieve improved understanding of the surface and interfacial properties of crude oils and their interactions with mineral surfaces, (2) to apply the results of surface studies to improve predictions of oil production from laboratory measurements, and (3) to use the results of this research to recommend ways to improve oil recovery by waterflooding.

During the first year of this project we have focused on understanding the interactions between crude oils and mineral surfaces that establish wetting in porous media. As background, mixed-wetting and our current understanding of the influence of stable and unstable brine films are reviewed. The components that are likely to adsorb and alter wetting are divided into two groups: those containing polar heteroatoms, especially organic acids and bases; and the asphaltenes, large molecules that aggregate in solution and precipitate upon addition of $n$-pentane and similar agents. Finally, the test procedures used to assess the extent of wetting alterationtests of adhesion and adsorption on smooth surfaces and spontaneous imbibition into porous media-are introduced.
\end{abstract}

In Part 1, we report on studies aimed at characterizing both the acid/base and asphaltene components. Standard acid and base number procedures were modified and 22 crude oil samples were tested. Our approach to characterizing the asphaltenes is to focus on their solvent environment. We quantify solvent properties by refractive index measurements and report the onset of asphaltene precipitation at ambient conditions for nine oil samples.

Four distinct categories of interaction mechanisms have been identified that can be demonstrated to occur when crude oils contact solid surfaces: polar interactions can occur on dry surfaces, surface precipitation is important if the oil is a poor solvent for its asphaltenes, and acid/base and ion-binding interactions occur in the presence of water. Specific instances when each of these mechanisms is dominant can be identified using crude oils of different acid number, base number, and solvent quality.

Part 2 of this project is devoted to improved assessment of wetting. We report on a baseline study of crude oil interactions with mica surfaces that shows wettability alteration characteristics that are comparable to those reported previously for glass surfaces. Mica has advantages over amorphous glass that make it a better choice as a standard surface for wettability testing, especially for tests at high temperatures. 


\section{INTRODUCTION}

\section{Objectives}

The objectives of this five-year project are threefold:

1. achieve improved understanding of the surface and interfacial properties of crude oils and their interactions with mineral surfaces,

2. apply the results of surface studies in the laboratory to improve predictions of oil production, and

3. use the results of this research to recommend ways to improve oil recovery by waterflooding.

Both existing methods of wettability assessment and new methods developed in the course of this research will applied to advance our understanding of oil reservoir wettability and how wetting affects oil recovery.

\section{Contents of this Report}

This report details the results of the first year of this five-year project. Studies are divided into three main areas that are aligned with the project's objectives.

The report begins with a review of mixed-wetting and shows how it may develop because of crude oil/brine/rock (COBR) interactions in reservoir rocks. Standard methods of wettability assessment are included in this brief review.

Advances during year one of this project are presented specifically in studies of acid/base interactions, for which standard tests of crude oils are being developed, and in the area of asphaltene chemistry. Measurements of refractive index of oils and their mixtures with solvents and precipitants help to quantify the onset of asphaltene precipitation. Chemical characteristics of crude oils are shown to relate to the mechanisms by which they can alter the wetting of solid surfaces. 
In Part 2 of this project, the effects of COBR interactions on wetting alteration of specific materials are the focus with the aim of eventually being able to apply an understanding of the interaction mechanisms to predict their effect on wettability of materials of interest. Individual minerals and various core materials will be tested over the course of this project. During year one, interactions between crude oils and mica surfaces have been studied and are reported here.

Part 3 of this project, is concerned with applying the lessons learned from our studies of COBR interactions and wetting alteration to improvements in waterflood oil recovery. Part 3 will begin in year two and extend throughout the remainder of the project.

\section{Background}

It is now generally recognized that while most clean rock-forming mineral surfaces are strongly water-wet, interactions with components in crude oil can alter wetting. The most likely wettability condition in an oil reservoirs is something other than strong water wetness. An extensive literature now exists on the questions of reservoir wettability and how best to measure it. The early literature is thoroughly surveyed in a series of reviews by Anderson (1986 and 1987); more recent developments are covered by Morrow (1990), Cuiec (1991), and Buckley (1996).

Wettability is widely recognized as an important, if elusive, part of the physical description of an oil reservoir. Fluid distribution and the course of immiscible displacements, like waterflooding, are controlled by the wetting properties of pore surfaces within reservoir rocks. In order to interpret the results of laboratory core floods with respect to the reservoir, the core test samples must have a wetting condition that is analogous to the in situ reservoir condition. As yet, there is no way to ensure that this condition is met.

In this project, we will focus on illuminating the interactions between oil components and rock-forming minerals in the presence of brine. Some of the reasons for 
taking this approach are apparent from the background on crude oil/brine/rock interactions presented in this section. Given the range of interactions that can occur between solids and components from crude oil, mixed-wet conditions seem likely. Evidence from the field of freshly recovered cores that can imbibe both water and oil supports the assumption that mixed wetting is important in naturally occurring oil reservoirs. In this context, the term mixed wetting is intended to imply that not all pore surfaces have the same wetting. These differences might arise because of the distribution of various pore lining minerals (dalmation or fractional wetting as suggested by Brown and Fatt, 1956) or because of limitations imposed by the initial fluid distribution (as suggested first by Salathiel, 1973). Both of these situations are included in the definition of mixed wetting.

It is important to note that multiphase flow through mixed-wet porous media is influenced both by the degree of wetting and the distribution of wetting. The effect of wetting in mixed-wet media cannot be inferred by interpolations between strongly waterwet and strongly oil-wet studies. Thus a more fundamental picture of the distribution and degree of wetting is essential to development of the ability to predict oil recovery from surface studies.

\section{A conceptual model for development of mixed wetting}

Among the many possibilities for reservoir wetting, mixed-wetting of the type first described by Salathiel (1973) may be the most likely. This is a consequence of the initial fluid distribution governed by conditions that are initially water-wet, and subsequent crude oil/brine/rock (COBR) interactions. Figure 1 is a simple illustration of the sequence of events that may occur when crude oil invades a water-filled pore. The pore space is represented as a brine-filled capillary tube of triangular cross section into which the oil moves as the non-wetting phase. If the oil phase is a pure hydrocarbon, such as decane, interactions are restricted to dispersion forces; water is held as a film at the drained solid surface (Fig. 1a). At equilibrium, disjoining pressure in the water film equal to the capillary pressure across the oil/bulk water interface. Access to the solid surface may be restricted by a stable film of water as shown in Fig. 1b. Polar 
components in the crude oil adsorb at the oil/water interface of both the bulk water and the thin film as shown in Fig. 1c. If the film is unstable, it breaks, exposing solid surface to the components at the brine/oil interface as illustrated in Fig. 1d. Whether or not the water film is stable has been the subject of earlier studies. The interactions that can occur in the absence of a stable water film and how these interactions vary for different oils as a function of their composition are the focus of the studies in Part 1 of this project.

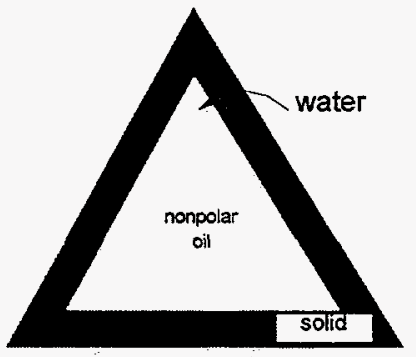

a. Water films are stable with nonpolar oil.

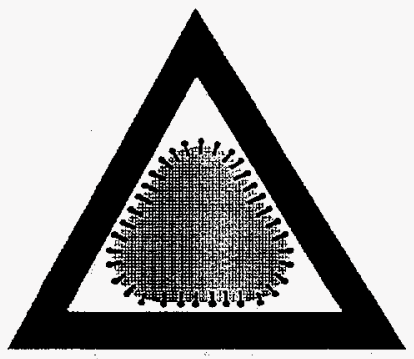

c. Large polar compounds adsorb at the oilbrine interface.

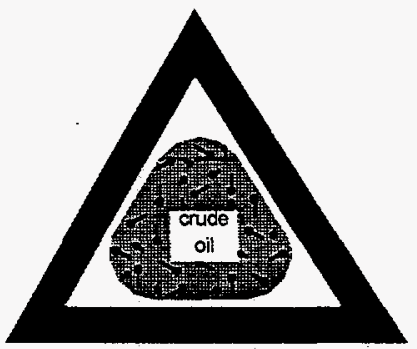

b. Crude oil invades a water-wet pore.

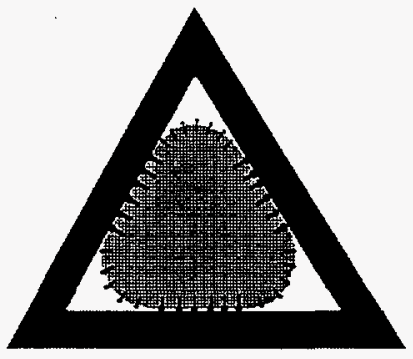

d. If the water film is unstable, adsorption of targe polar compounds can proceed.

Figure 1. Illustration of COBR interactions. When oil first enters the pore, it is the nonwetting fluid ( $a$ or $b$ ), with a film of water between the oil and mineral surface. Components from a crude oil can partition to the oil/water interface (c), and can adsorb and change wetting if the water film is unstable (d).

\section{Water film stability}

The stability of thin water films between oil and solid depends on DLVO and other forces arising from properties of the solid/brine and oil/brine interfaces (Buckley $e t$ al., 1989). In previous studies of COBR interactions we have shown that regions of stability and instability can be delineated by observing adhesion (or non-adhesion) to a smooth solid surface of a drop of crude oil under brine (Buckley et al., 1997). Figure 2 shows these regions of stability and instability for A-93 crude oil from Prudhoe Bay and 
clean borosilicate glass surfaces. Standard adhesion tests (by procedures explained later in this review) were used to define those regions where brine $\mathrm{pH}$ and $\mathrm{NaCl}$ concentration produced stable and unstable water films. Comparison of adhesion tests at room temperature with tests at elevated temperature $\left(80^{\circ} \mathrm{C}\right)$ showed that there is a region of brine composition where stability depends on temperature. In most cases, adhesion was observed at low temperature, whereas the high temperature tests showed non-adhesion.

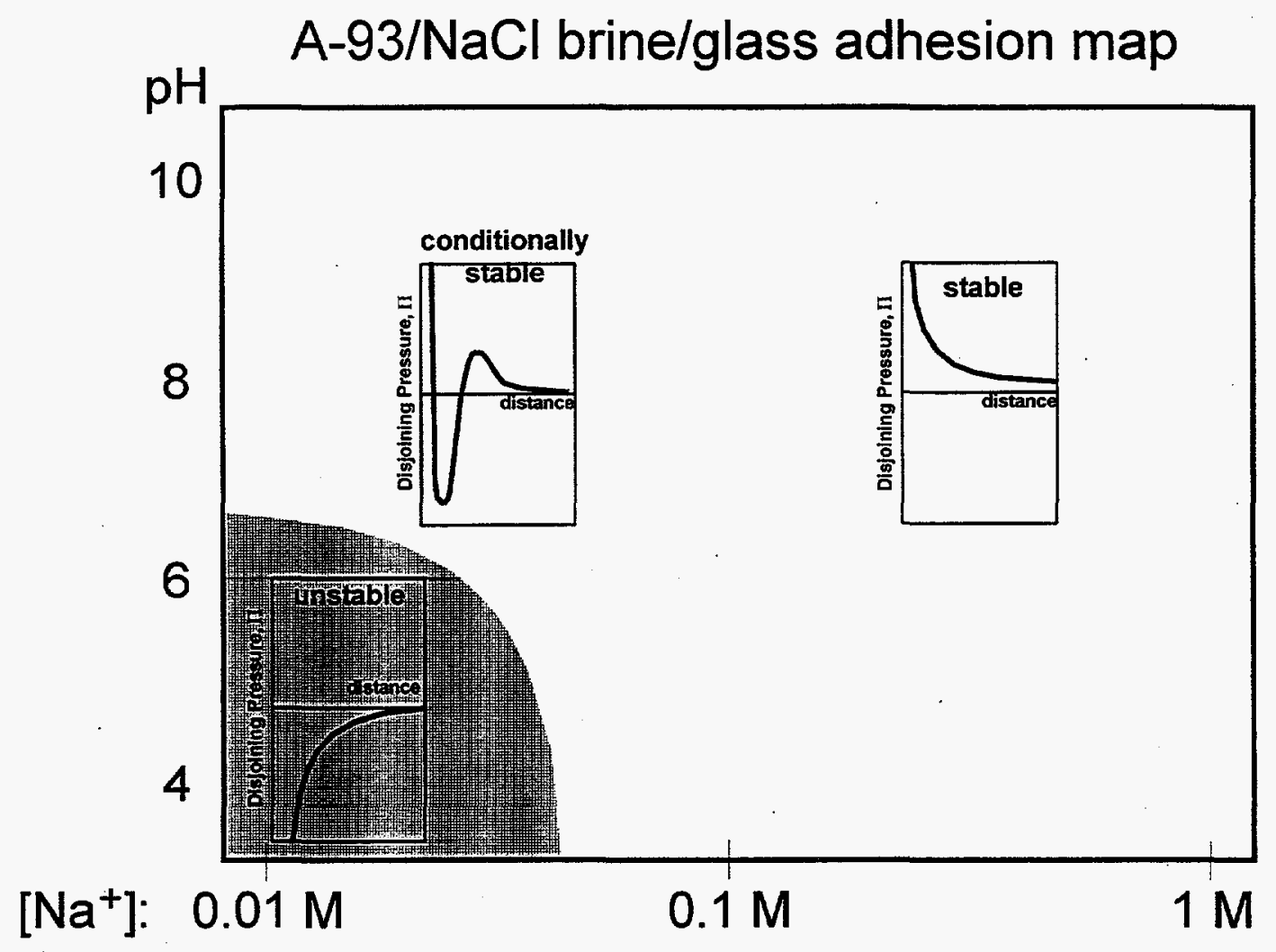

Figure 2. Regions of stability and instability of water films for drops of A-93 crude oil contacted with clean glass surfaces under brines of varying $\mathrm{pH}$ and $\mathrm{NaCl}$ concentration. Stable films result in non-adhesion whereas unstable films result in adhesion of the crude oil drop to the surface. In the region denoted as conditionally stable, low temperature adhesion and high temperature nonadhesion were observed. The disjoining pressure curves are illustrations only. Disjoining pressure was not measured in these experiments (after Buckley et al., 1997). 


\section{Crude oil components that can adsorb and alter wetting}

\section{Acids and bases}

The strong $\mathrm{pH}$ dependence exhibited by crude oils in their adhesion to solid surfaces (e.g., Fig. 2) is evidence for the contribution of acidic and basic species in the oil to adhesion phenomena. Buckley et al. (1989) showed that electrophoretic mobility of emulsified crude oil droplets in brine could be modeled by assuming reasonable surface concentrations of as few as one type of acidic and one basic species (Fig. 3).

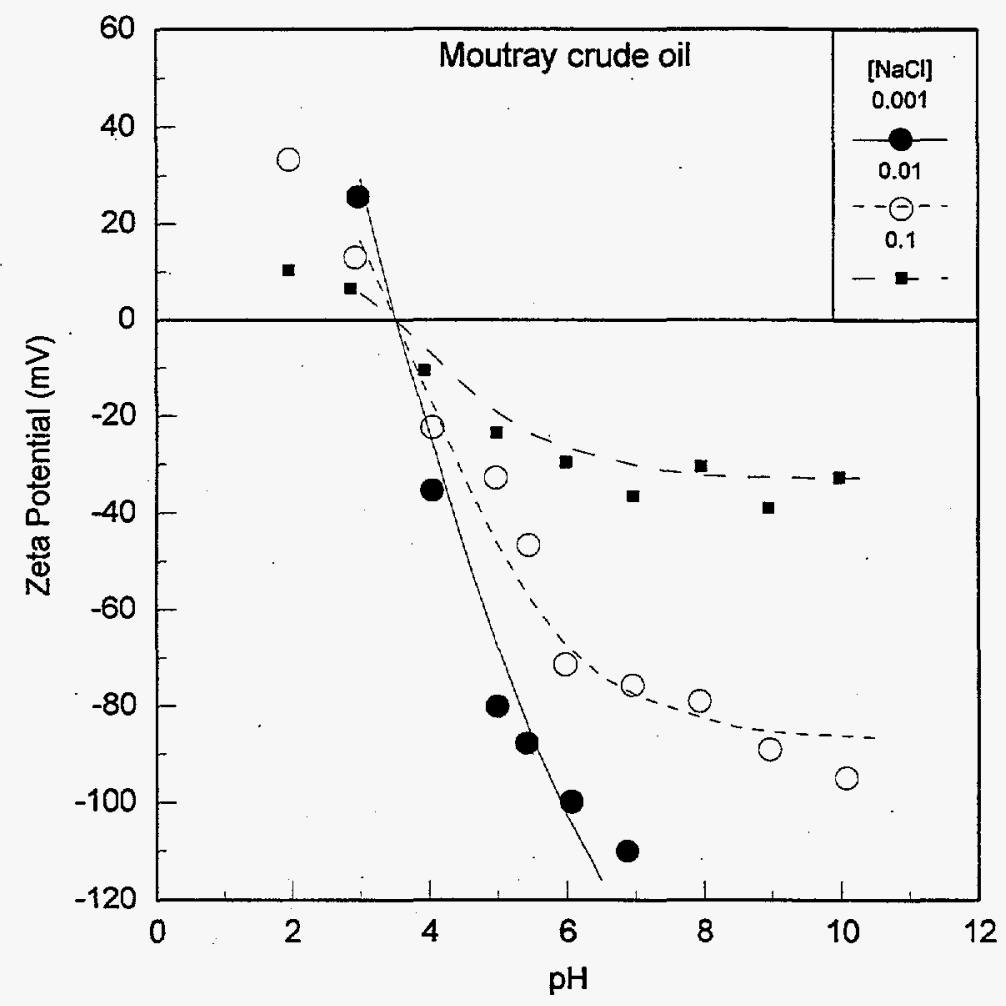

\begin{tabular}{|cc|cc|}
\hline \multicolumn{2}{|c|}{ Acidic sites } & \multicolumn{2}{c|}{ Basic sites } \\
\hline $\begin{array}{c}\text { Number of } \\
\text { sites } / \mathrm{m}^{2}\end{array}$ & $\mathrm{pK}_{\mathrm{a}}$ & $\begin{array}{c}\text { Number of } \\
\text { sites } / \mathrm{m}^{2}\end{array}$ & $\mathrm{pK}_{\mathrm{a}}$ \\
$4 \times 10^{17}$ & 4 & $1 \times 10^{17}$ & 6 \\
\hline
\end{tabular}

Figure 3. Zeta potentials of emulsions of Moutray crude oil in brines of varying $\mathrm{pH}$ and ionic strength. Markers show measured data; lines are calculated using an ionizable site group model with two ionizable species, one acidic and one basic with the properties shown above (after Buckley, et al., 1989). 


\section{Asphaltenes and resins}

Crude oils are complex mixtures of hundreds of components ranging in size from one carbon atom to one hundred or even more. Beyond the first few members of each homologous series, individual species cannot be readily separated and identified by standard techniques. Instead, crude oils are often characterized by dividing components into a few groups based on physical and chemical separations.

One of many such separation schemes is shown in Fig. 4 (adapted from ASTM D2007-80). Some of the heaviest, most polar components are insoluble in low molecular weight paraffins. If one volume of crude oil is mixed with 40 volumes of $n$-pentane, the resulting precipitate is defined as the asphaltene fraction of the oil. The remainder of the oil can be separated chromatographically on the basis of polarity, with saturates as the least polar fraction followed by the aromatic hydrocarbons. The final fraction, called resins or polars, consists of hydrocarbons with small percentages of polar heteroatoms (mainly oxygen, nitrogen, and sulfur).

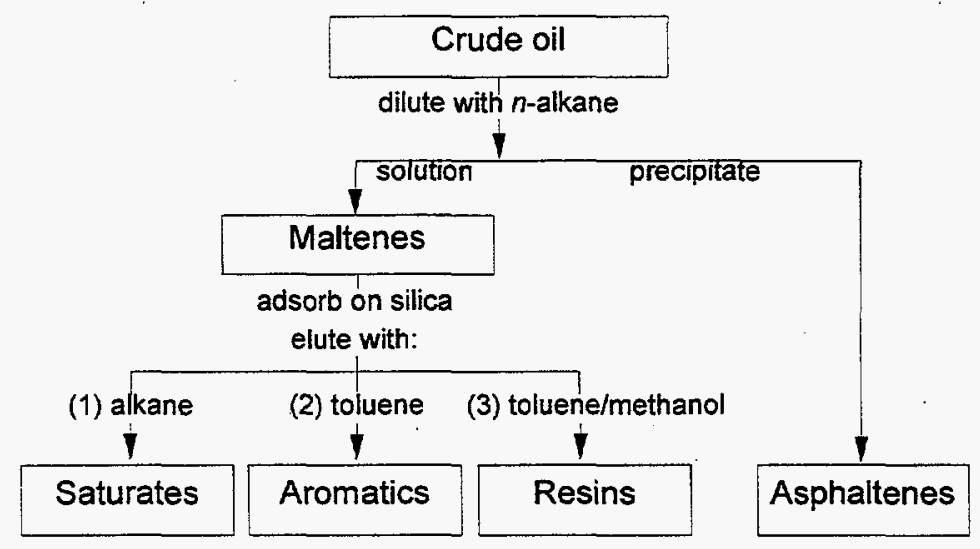

Figure 4. SARA separation scheme divides crude oil into saturates, aromatics, resins (or polars), and asphaltenes.

An oil composed only of saturates and aromatics would be non-wetting relative to water on most clean mineral surfaces. Hence, attention with respect to wetting has focused on the asphaltene and resin fractions, both of which have polar components that can adsorb on silica and other mineral surfaces. These include a continuum of high 
molecular weight crude oil species. Chemical compositions of either asphaltenes or resins depend on the source crude oil as well as the method by which the fractions were separated from the remainder of the oil. The distinction between them is based on solubility. The molecules that precipitate in response to addition of different diluting agents represent a balance of polarity, aromaticity, and molecular weight (Long, 1981; Cimino et al., 1996), as shown schematically by the various shaded areas in Fig. 5. Reported molecular weights are usually for aggregates, rather than single molecules, and vary from a low of around 1000 Daltons to highs in the hundreds of thousands of Daltons (Speight et al., 1985).

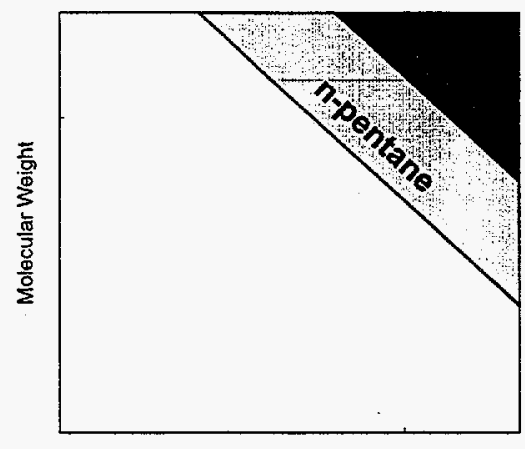

Polarity \& Aromaticity

Figure 5. Characteristics of asphaltenes precipitated by $n$-pentane or $n$-heptane. The darkest shaded area represents the properties of material insoluble in $n$ heptane. That material, plus some that is lower in either molecular weight, polarity, or aromaticity, is also insoluble in $n$-pentane (adapted from Long, 1981, and Cimino et al., 1995).

While the absolute molecular weight of molecules in the asphaltene fraction is difficult to measure, the ratio of elements is fairly consistent for asphaltenes from a wide range of sources (Speight, 1991) and, on average, can be represented by an empirical formula which, for the $n$-pentane precipitate, is $\mathrm{C}_{100} \mathrm{H}_{115} \mathrm{~N}_{1} \mathrm{~S}_{3} \mathrm{O}_{2}$. The hydrogen to carbon ratio indicates a high degree of aromaticity; nitrogen content varies only a little, while oxygen and sulfur are more variable. None of these polar constituents is present in sufficient quantity to confer significant water solubility on such large organic molecules, but the extent of polar functionality may well contribute to the affinity of these molecules for the oil/brine interface. 
Both asphaltenes and resins exist in crude oil as aggregates. The colloidal nature of asphaltenes was postulated in early studies by Nellensteyn (1938) and by Pfeiffer and Saal (1940). More recently, measurements with small-angle x-ray (SAXS) and neutron (SANS) scattering (Espinat and Ravey, 1993; Thiyagarajan, 1995) have demonstrated the changes in aggregation size with changes in temperature or solvent. Figure 6 shows nominal volumes measured by these techniques for asphaltenes from two different oils (Safanya and Maya) dissolved in various solvents. The volumes were calculated directly from the published size parameters to allow a rough comparison between results from investigators who have interpreted their data using different models for particle shapes (including disks, rods, and spheres). As shown in Fig. 6a, asphaltene aggregates dissolved in toluene were observed to increase in size with increasing fractions of a precipitant ( $n$-heptane) added to the mixture. Figure $\mathbf{6 b}$ shows the opposite effect of adding resins which are good asphaltene solvents. Increasing temperature (Figs. 6c and d) also decreased the size of aggregates.
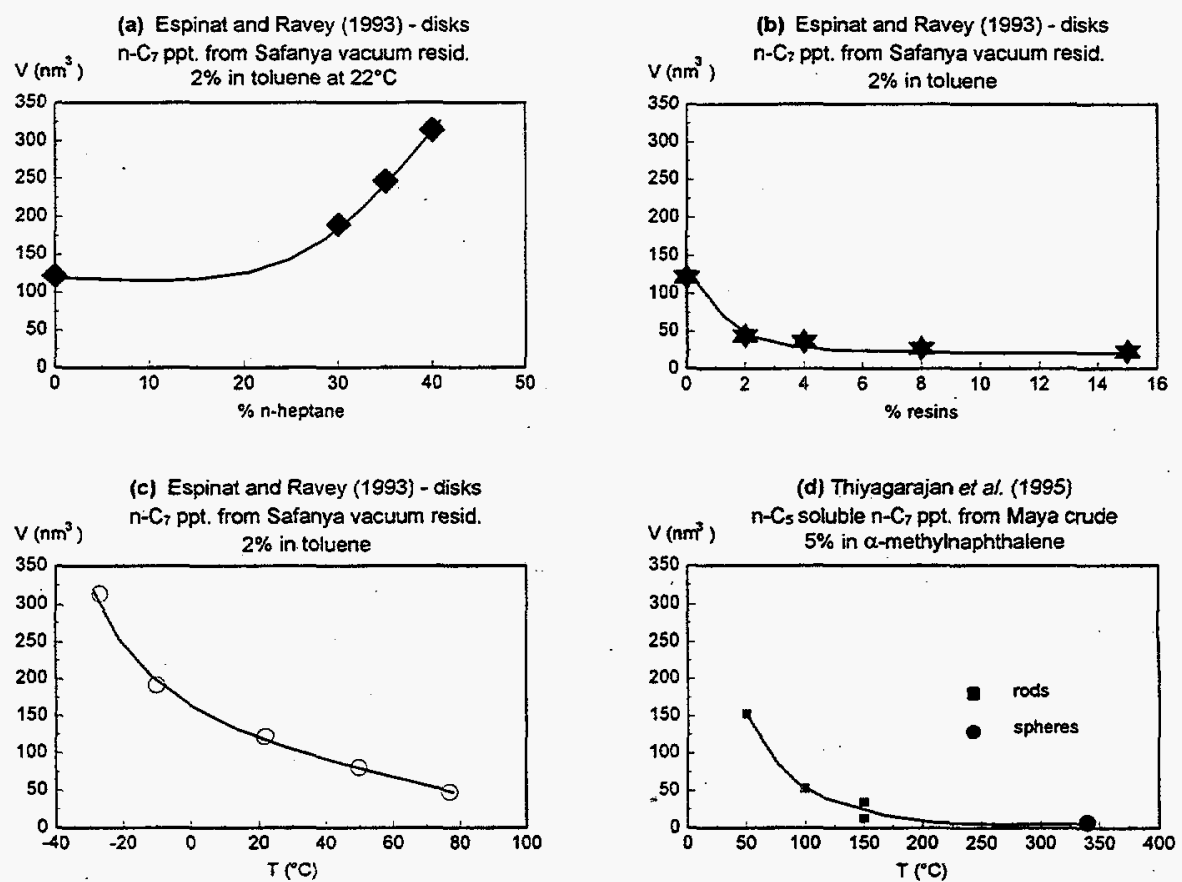

Figure 6. Variation in size of asphaltene aggregates with changes in solvent properties and temperature (measured by small angle neutron scattering, SANS experiments). Nominal volumes were calculated on the basis of reported particle dimensions. (after Buckley et al., 1997) 


\section{Wetting on smooth surfaces}

\section{Contact angles}

The most fundamental measure of wetting is a contact angle between two fluids which partially wet a solid surface, as shown in Fig. 7. By convention, we measure the angle through the water phase. In practice, equilibrium contact angles are never measured with crude oil because there can be hysteresis between water advancing and water receding conditions caused by roughness in the surface and by chemisorption and physisorption between oil components and the solid surface. Contact angles are measured in our laboratory by the captive drop technique (Gaudin, 1964).

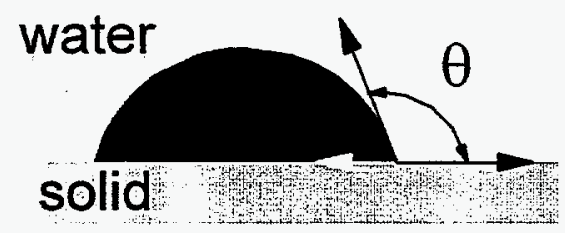

Figure 7. Contact angle is the angle between the tangent to the droplet at the threephase line and the solid surface, measured here through the water phase.

\section{Adhesion}

Observations of large hysteresis between receding and advancing conditions led to development of an adhesion test first described by Morrow, et al. (1986) and given a rational basis in DLVO theory by Buckley, et al. (1989). The test itself is deceptively simple. A drop of oil is formed under water at the tip of either a microburet or syringe held as rigidly as possible to avoid vibration during changes in drop volume. The volume of the oil droplet can vary, but it is usually quite small (a few $\mu$ l or less). Variations in contact angle with drop volume are of secondary importance in these measurements. The oil droplet is allowed to contact a smooth solid surface, also submerged in the aqueous phase. After some period of contact between oil and solid (usually two minutes), the drop is drawn back into the needle or buret tip. At that stage, very different phenomena have been observed, as illustrated in Fig. 8, for the two extremes of possible outcomes. 


\section{Nonadhesion}

Form oil drop.

Contact with surface.
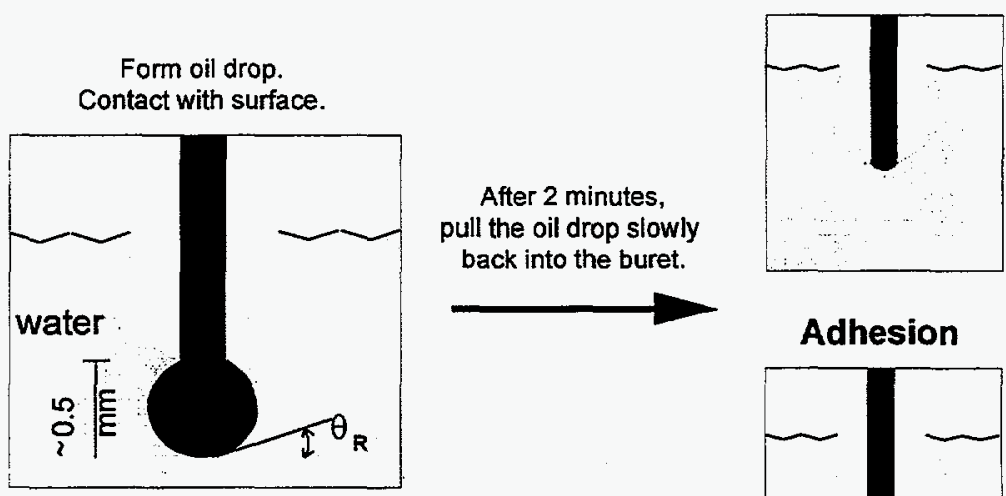

Adhesion

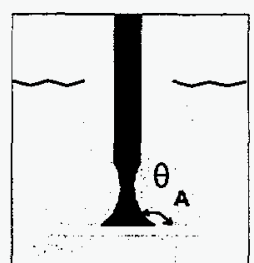

Figure 8. Illustration of adhesion and non-adhesion between an oil droplet and a solid surface under water or brine.

When the oil drop does not adhere, there is very little difference between advancing and receding contact angles $\left(\theta_{\mathrm{A}}\right.$ and $\theta_{\mathrm{R}}$, respectively). At the other extreme, the three-phase contact line is pinned, and, as the volume of the oil drop is reduced, the shape of the drop is distorted, as shown in the case labeled adhesion. Further reduction in the drop volume results in separation of the adhering drop from the oil in the buret. Drops of oil up to about $0.5 \mu \mathrm{l}$ in volume may remain on the surface. Using this simple distinction between adhering and non-adhering conditions, a map of brine compositions can be made with distinctions drawn between areas of adhesion and non-adhesion. A typical example is shown in Fig. 9. Intermediate conditions are often observed in which very small droplets adhere, or $\theta_{\mathrm{A}}$ is high and a larger oil droplet adheres. With time, however, the contact angle begins to decrease and eventually the drop is released and floats to the surface. 


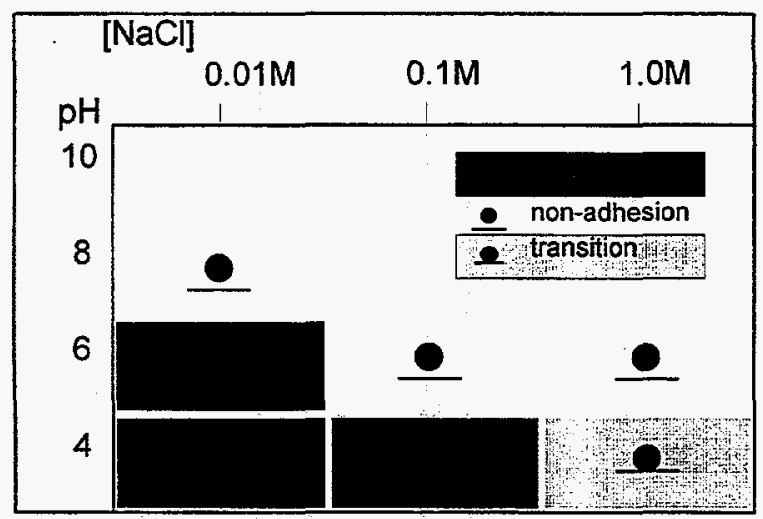

Figure 9. A typical adhesion map delineates conditions of $\mathrm{NaCl}$ concentration and $\mathrm{pH}$ under which adhesion occurs. In this example, the crude oil is A-93. The test was performed at $80^{\circ} \mathrm{C}$.

Of course, this arbitrary division according to the extremes of adhesion and nonadhesion is an oversimplification. A great deal of additional detail can be observed in these tests. The three-phase line is not always pinned, but may slip at a well-defined advancing contact angle. The volume and final contact angle of adhering drops can vary. In principle, the adhering drop might spread. This situation has been observed only once (i.e., for one crude oil in contact with a single brine composition) in many hundreds of these measurements with dozens of different crude oils. Variations in the standard procedure, for example allowing longer contact times, can provide additional information, but the standard procedure provides a fixed starting point in this universe of variables.

\section{Adsorption}

In order to observe much longer periods of interaction between smooth solid surfaces, brines, and crude oils, a second standard test has been developed (Buckley and Morrow, 1991; Liu and Buckley, 1997). An outline of the standard procedure adopted for this adsorption test is shown in Fig. 10. 


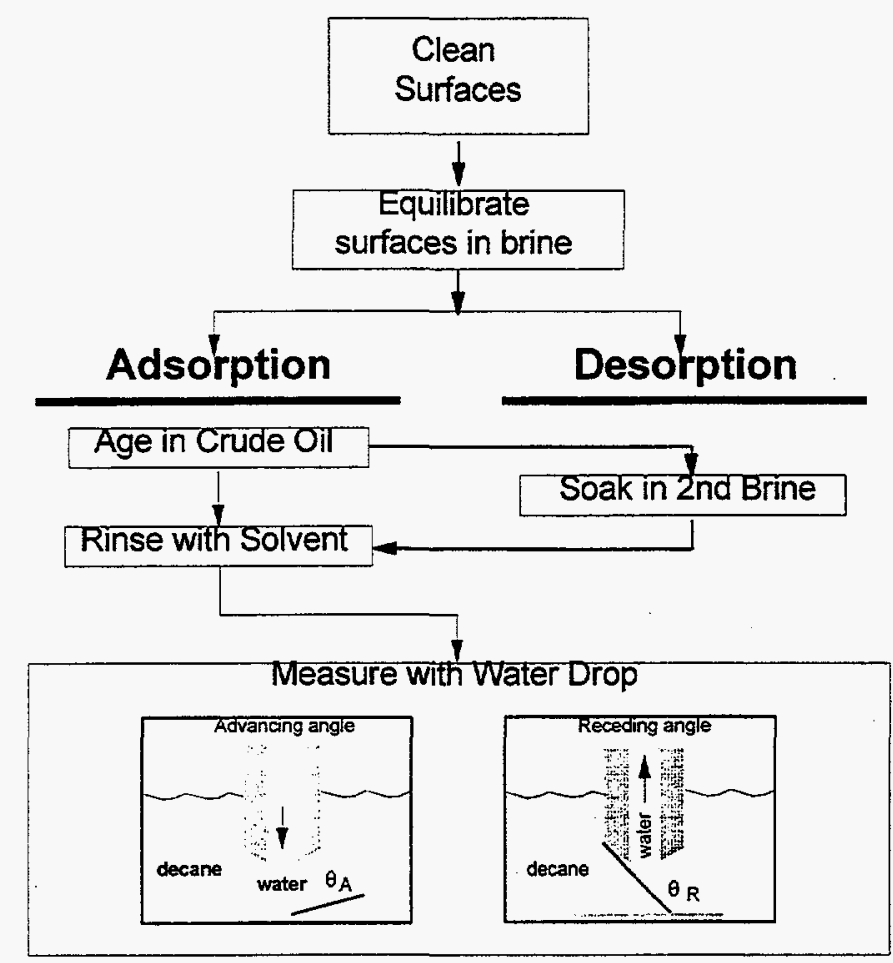

Figure10. Standard procedures for adsorption and desorption tests.

After cleaning and equilibrating in brine, the solid pieces are removed and allowed to drain, but not to dry, before being immersed in crude oil. Variables include brine and oil compositions, aging time, and temperature. At the end of the oil-aging period, samples are removed and washed gently with solvent to remove bulk oil. Toluene has been used as the standard solvent; cyclohexane gives nearly the same results. Fluids that are poor asphaltene solvents-decane, for example - are avoided since they make the surfaces uniformly oil-wet. After washing, the treated surface is immersed in just such a poor asphaltene solvent so that further changes do not occur as water advancing and receding contact angles are measured (Fig. 10).

An additional step, immersing the treated surface in another brine solution and aging it again, shows the extent to which the adsorbed components can be removed. Desorption varies with time, temperature, and brine composition. 


\section{Wetting in porous media}

\section{Standard core preparation procedures}

Cylindrical cores are cut with a diamond core bit using tap water for cooling. The cores are allowed to dry for several days in an oven at $80^{\circ} \mathrm{C}$, after which nitrogen permeabilities are measured. Selected core plugs are saturated under vacuum in degassed brine and allowed to equilibrate in the brine phase for one week at ambient temperature. At the end of this equilibration time, absolute permeability to brine is measured. Synthetic and outcrop cores thus prepared are strongly water-wet and are ready for use in various kinds of experiments.

For alteration of core wettability, the brine-saturated cores are flooded with crude oil to establish an initial water saturation. An initial measurement of oil permeability is made. The value of initial water saturation, aging time, and aging temperature are the main variables associated with the extent of wetting alteration at this stage. Cores with oil and connate water are submerged in crude oil in a sealed beaker and stored either in an oven or in a water bath at the designated aging temperature. At the end of the aging period, the oil aged in the core is displaced with fresh oil (either the same crude oil of a refined oil) and permeability to oil is remeasured with connate water in place.

\section{Spontaneous imbibition}

The use of imbibition measurements to characterize wettability in cores has been common since a test was proposed by Amott (1959) that compared the amount of a phase imbibed spontaneously with the amount of that phase taken up by the same core in a forced displacement. While this is strictly an empirical measure that can be affected by many experimental details, it does provide a framework for comparisons from one sample to another and even from one rock type to another. The procedure used here is similar to that suggested by Cuiec (1991). It combines spontaneous imbibition with viscous forced displacement in a core flood, as opposed to the gravity-driven centrifuge displacement recommended by Amott. An idealized capillary pressure curve is shown in Fig. 11 with 
the saturations used to calculate wetting parameters indicated. Since only endpoint saturations are used, measurement of $P_{c}$ is not required.

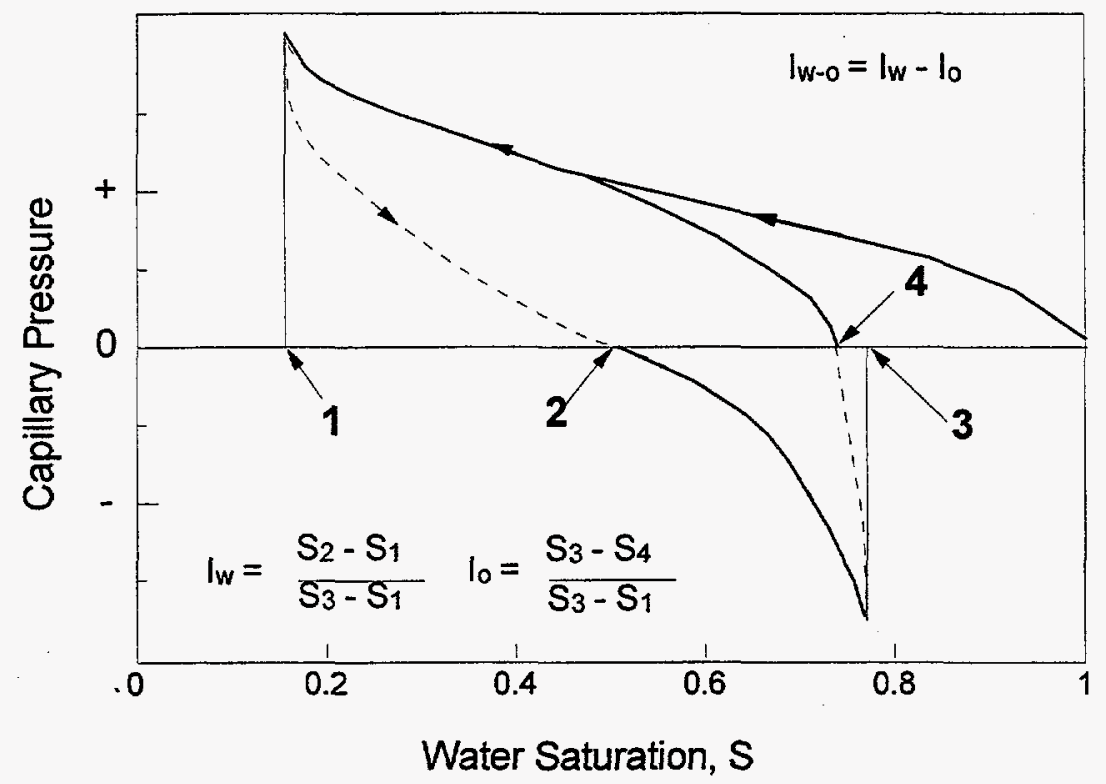

Figure 11. Idealized capillary pressure vs. saturation curve, indicating the values used for calculation of Amott wettability indices $\left(I_{w}\right.$ and $\left.I_{0}\right)$ and the combined Amott-Harvey Index $I_{w-0}$.

All steps shown by solid lines in Fig. 11 are viscous displacements with the core confined in a Hassler holder. In the spontaneous imbibition steps (dotted lines), all core surfaces are exposed to the imbibing fluid. Imbibition is monitored either gravimetrically or volumetrically.

\section{Waterfloods}

Waterfloods are performed at constant flow rate with the core confined in a Hassler holder as illustrated in Fig. 12 with about 300 psi of confining pressure provided by nitrogen. Pressure is monitored with a transducer upstream of the core. The outlet pressure is atmospheric. 


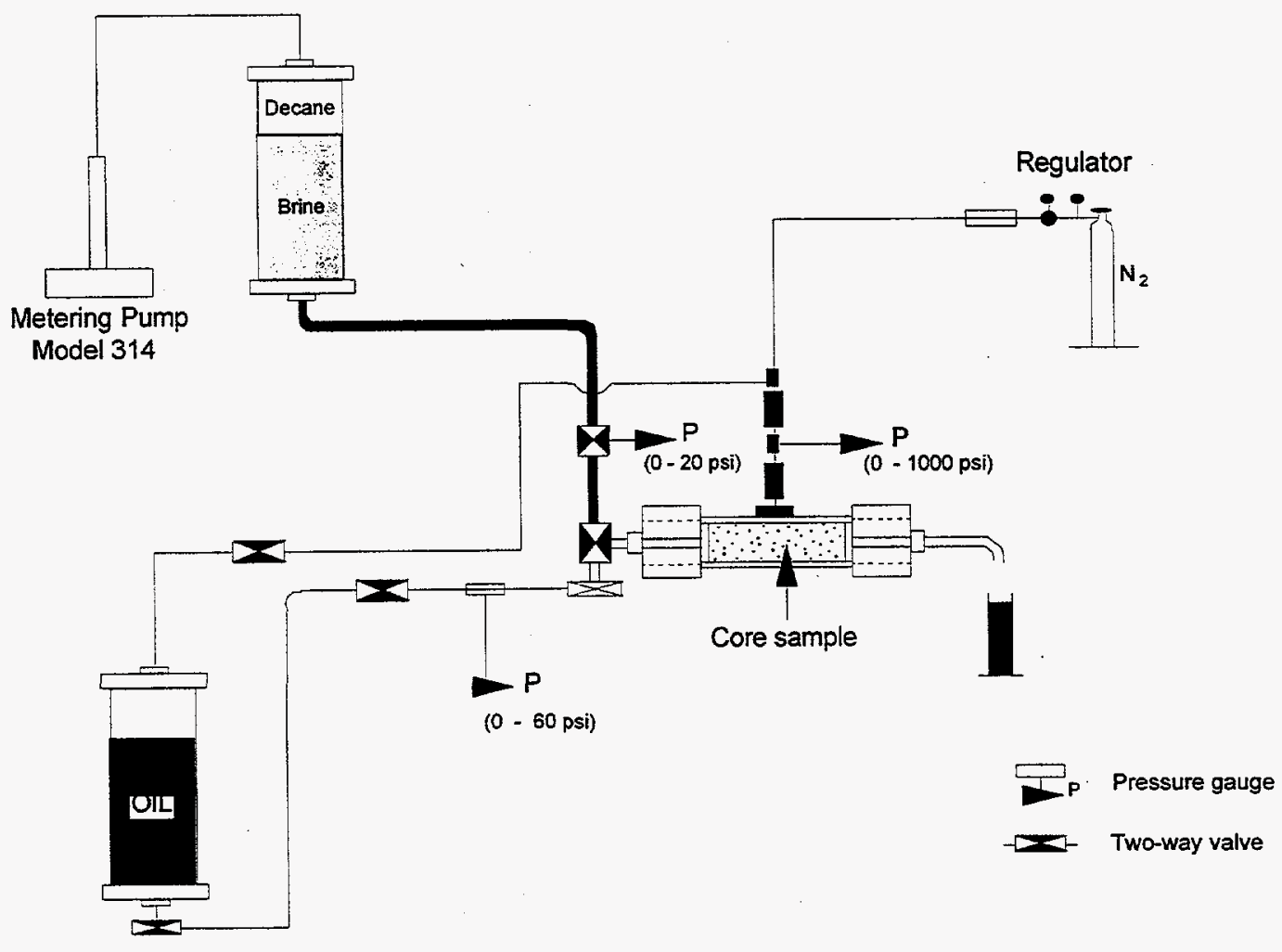

Figure 12. Waterflood apparatus for constant rate experiments. 


\section{PART 1. CHEMICAL EVALUATION OF CRUDE OILS}

\subsection{A Survey of Crude Oil Acid and Base Numbers}

Acid and base numbers are routinely used to characterize the polar components of crude oils. Since many of the interfacial properties of crude oils in contact with water appear to be traceable to acidic and basic functionality of interfacial species, it is of interest to measure these standard quantities to see how they are related to oil/brine/solid interfacial properties. Some relationship is to be expected, but not necessarily a simple one.

\subsubsection{Acid numbers}

Method ASTM-D664-89 was used for the determination of the acid number of crude oils. ASTM-D664-89 involves a potentiometric titration of a sample of crude oil (on average 2 to $5 \mathrm{~g}$ ) dissolved in a mixture of toluene, isopropanol and water (50/49.5/0.5\% by volume). The titration uses a $0.1 \mathrm{~N}$ solution of $\mathrm{KOH}$ as titrant to determine the acid number. Contrary to the ASTM recommendation, the titration did not completely exclude contact with air. The possibility of carbon dioxide contamination was addressed by purging the isopropanol with nitrogen before dissolving the $\mathrm{KOH}$ and by making a fresh solution of $\mathrm{KOH}$ every two weeks.

This method does not always give a sharp inflection point. Spiking the crude oil with a known amount of stearic acid in titration solvent $(1 \mathrm{ml}$ of $0.1 \mathrm{M})$ forced a good inflection. The acid number was then determined by difference, subtracting out the effect of the added stearic acid. This spiking procedure was verified via comparisons of spiked and unspiked titrations using oils which gave good inflections, similar to the base number titrations. Fig. 13 shows an example. The acid numbers agreed within experimental error. The result for one oil was further verified by comparing with the result obtained by Triton Analytics. 


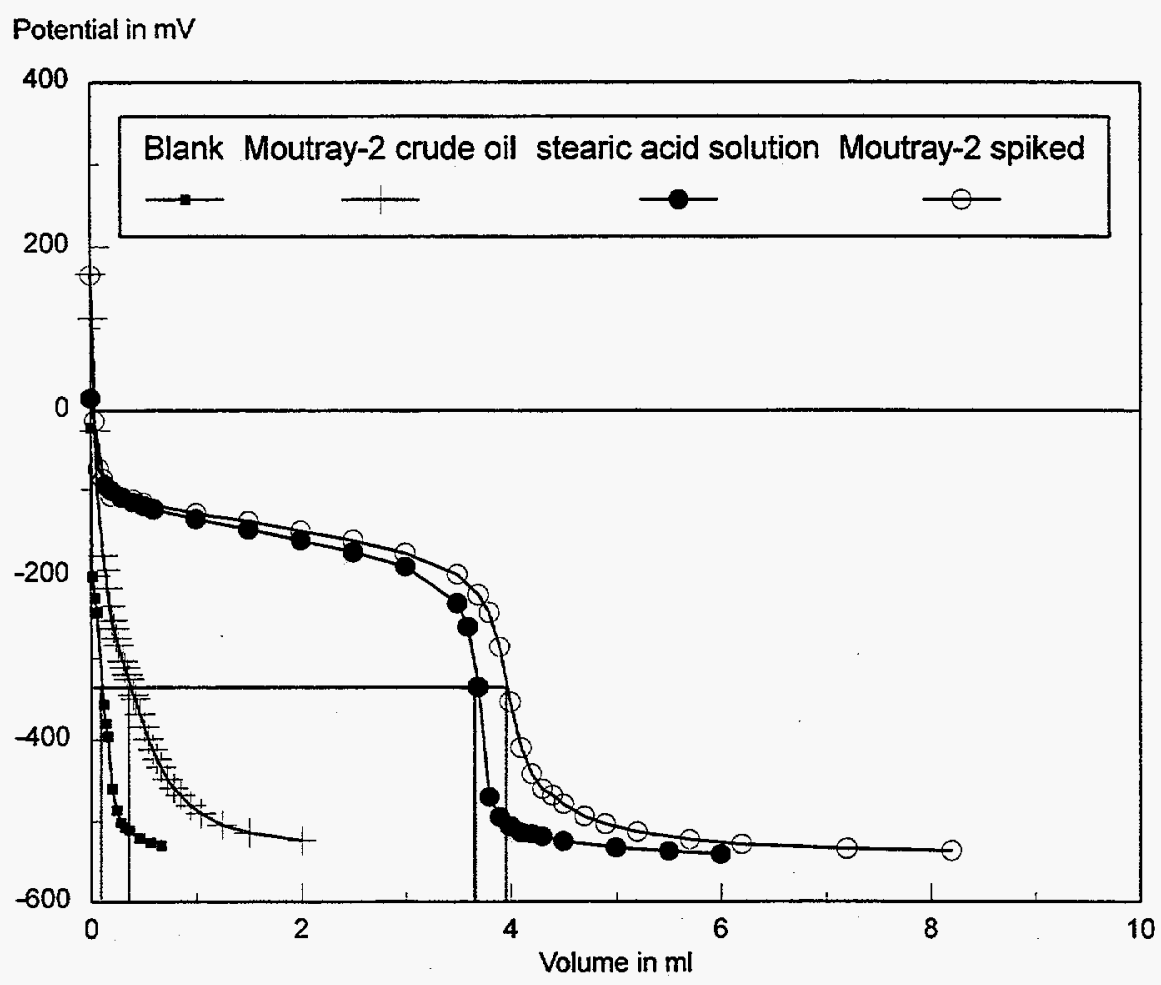

Figure 13. Comparison of crude oil titration with and without added stearic acid.

Ross half-cell electrodes (the calomel electrode was filled with $\mathrm{KCl}$ electrolyte) were used, with an Orion pH/ISE meter model 520A. Titrant was added from a $25 \mathrm{ml}$ buret in increments of about $0.1 \mathrm{ml} / \mathrm{min}$. The increment size was reduced to about 0.02 $\mathrm{ml} / \mathrm{min}$ near the inflection point. For each sample, the solution was allowed to stabilize for 10 minutes before taking the first measurement. The end point was always observed between a potential of -300 and $-400 \mathrm{mV}$. The end point was determined using the graphic method illustrated in Fig. 14. 


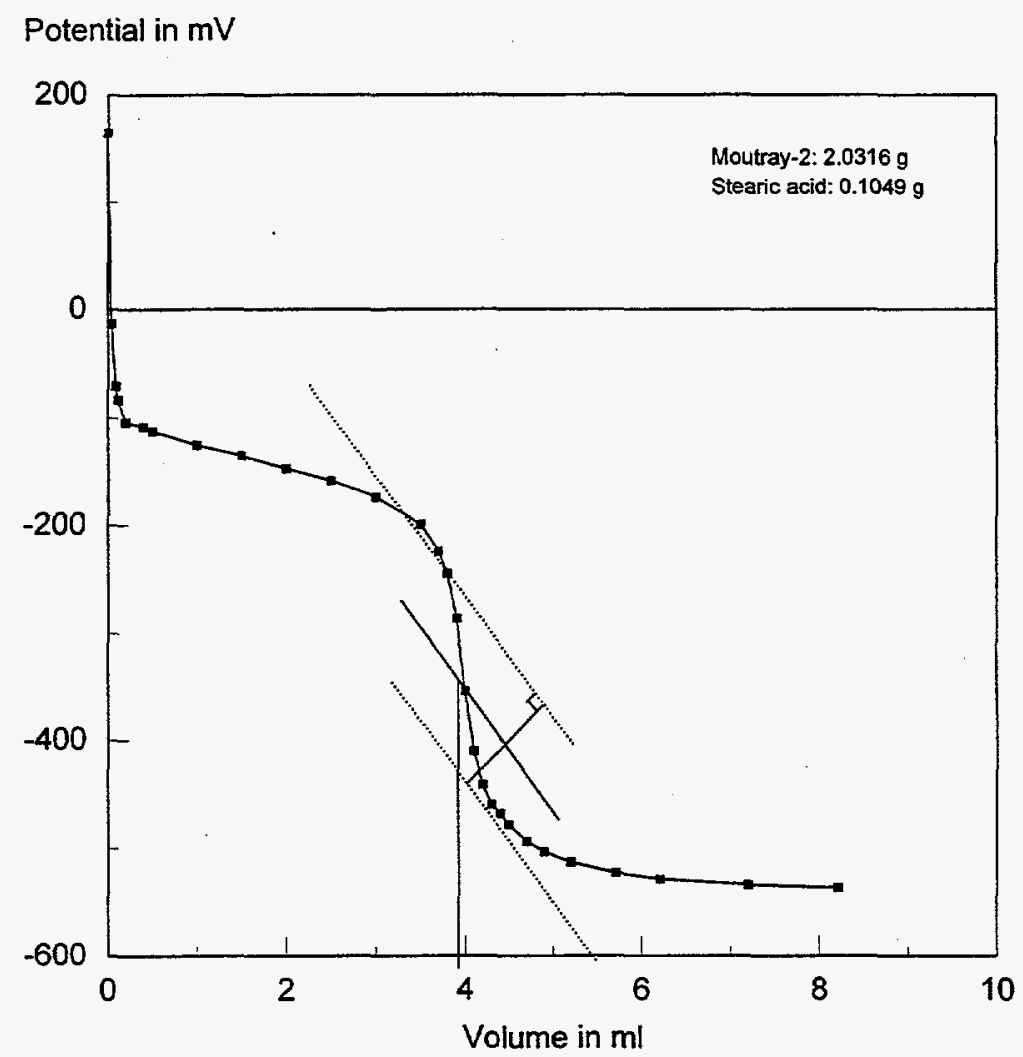

Figure 14. Titration of Moutray crude oil (sample 2), spiked with stearic acid solution. The graphical method used to find the inflection point is illustrated.

The acid number $N_{A}$ in units of $\mathrm{mg}$ of $\mathrm{KOH}$ per gram of sample was calculated using Eqn. 1:

$$
N_{A}=\frac{56.1(E-F) N_{b}}{S}
$$

where $E=$ equivalence point of the sample (ml)

$F \quad=$ equivalence point of the blank ( $\mathrm{ml})$

$N_{b}=$ normality of the $\mathrm{KOH}$ solution (equivalents $/ \mathrm{L}$ ), and

$S=$ sample size $(\mathrm{g})$

Several difficulties were encountered in the determination of the acid number.

- Some of the oils did not fully dissolve in the titration solvent. For example, with crude oil A-93, 2\% precipitate was obtained by filtration at the beginning and end of the titration. 
- During the titration of the blank, the potentials did not stabilize; they first went down quickly then back up again. The problem was not encountered in the solutions spiked with stearic acid.

- Acid numbers are very small for some of the oils tested. These had to be titrated many times to achieve statistically significant results.

\subsubsection{Base numbers}

Method ASTM-D2896-88 was adapted for the determination of the base number of crude oils. ASTM-D2896-88 involves a potentiometric titration of a sample of crude oil (on average 1 to $3 \mathrm{~g}$ ) dissolved in $40 \mathrm{ml}$ methyl isobutyl ketone. The titration uses perchloric acid at $0.025 \mathrm{~N}$ as titrant to determine the base number.

The standard method does not give a sharp inflection point. To improve the analysis, the crude oil was spiked with a known amount of quinoline in decane $(1 \mathrm{ml}$ of $0.08 \mathrm{M}$ ) following the procedure of Dubey and Doe (1993). The presence of quinoline forced a good inflection. The base number was then determined by difference, subtracting out the effect of the added quinoline. The spiking procedure was verified by comparing spiked and unspiked titrations using oils which gave good inflections (see Fig. 15). The base numbers agreed within experimental error. The result for one oil was further verified by comparing with the result obtained by an independent lab (Triton Analytics Corp.). 


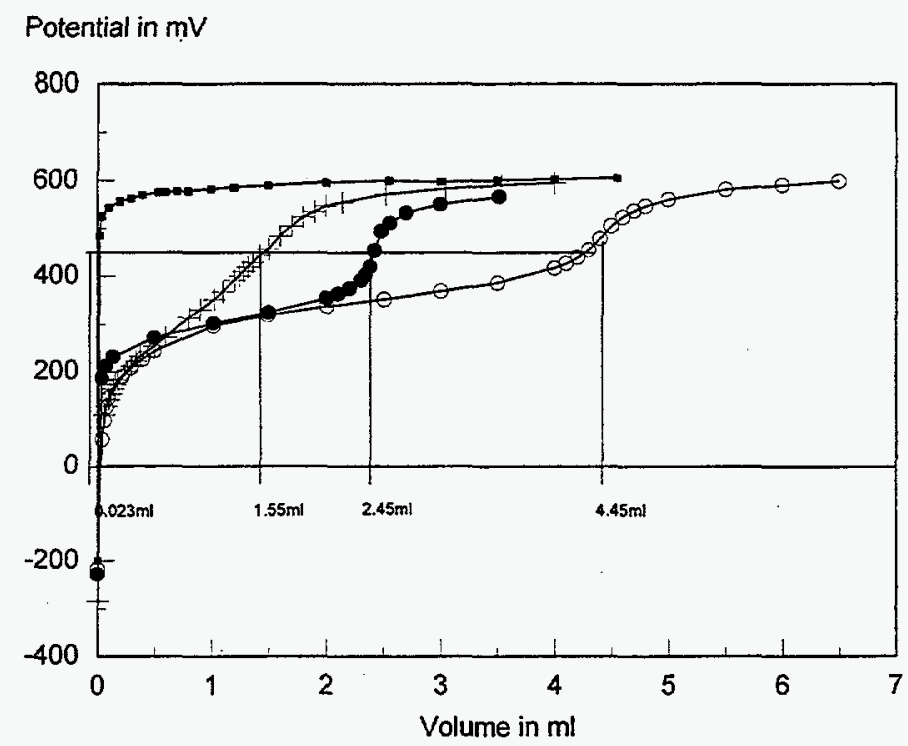

Blank A-93 crude oil Quinoline solution A-93 spiked

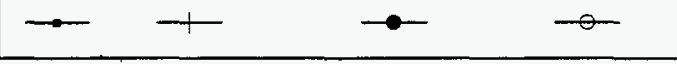

Figure 15. Comparison of A-93 crude oil potentiometric titrations with and without added quinoline.

For the potentiometric titration a combination $\mathrm{pH}$ electrode filled with a saturated solution of sodium perchlorate in isopropanol was used, with an Orion $\mathrm{pH} / \mathrm{ISE}$ meter model 520A. Titrant was added from a $25 \mathrm{ml}$ buret in increments of about $0.1 \mathrm{ml} / \mathrm{min}$. The increment size was reduced to about $0.02 \mathrm{ml} / \mathrm{min}$ near the inflection point. For each sample, the solution was left 10 minutes to stabilize before taking the first measurement. The end point was always observed between a potential of 400 and $500 \mathrm{mV}$. The end point was determined graphically, as illustrated in Fig. 16. 


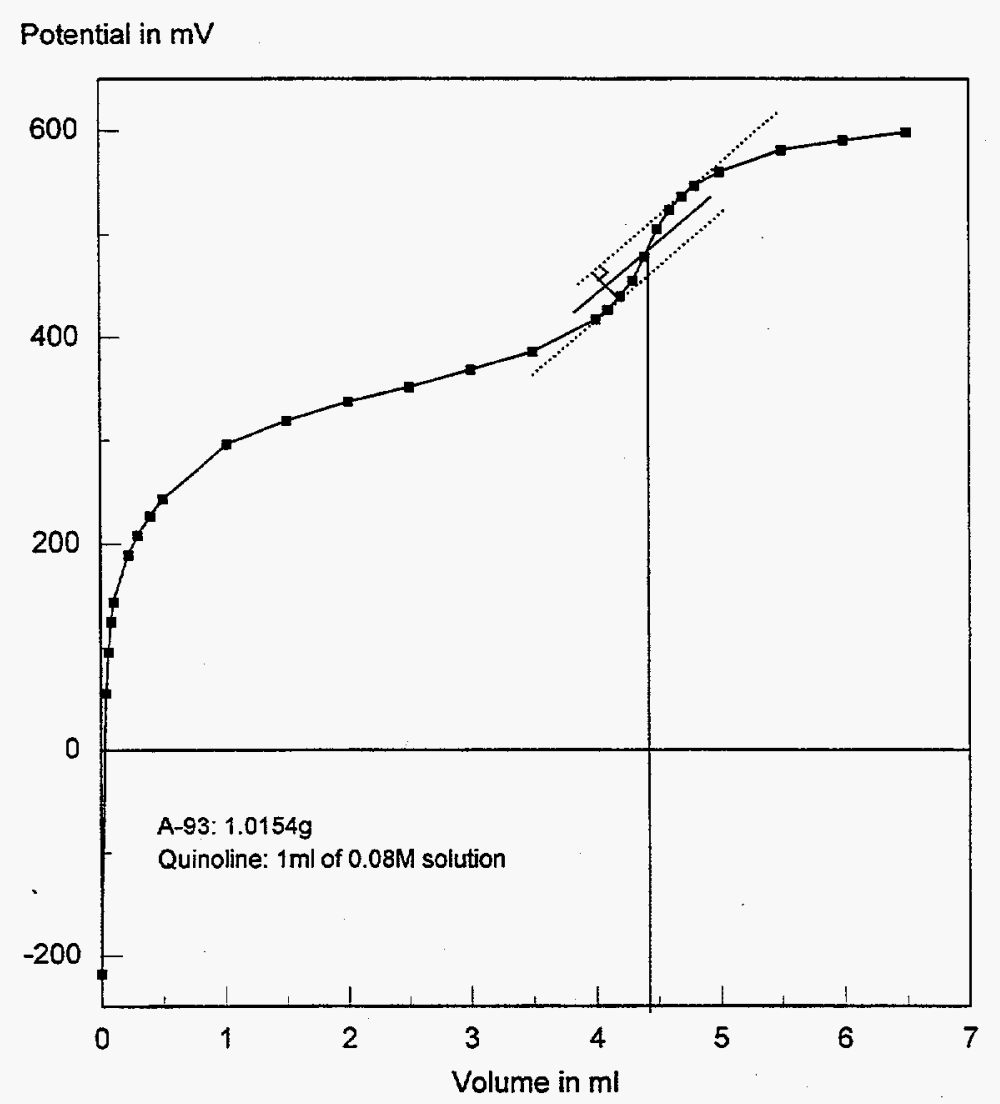

Figure 16. Titration of A-93 crude oil plus quinoline, illustrating graphical determination of the inflection point.

The base number, $N_{B}$ in units of $\mathrm{mg}$ of $\mathrm{KOH}$ per gram of sample, was calculated using Eqn. 2:

$$
N_{B}=\frac{56.1(E-F) N_{a}}{S}
$$

where $E=$ equivalence point of the sample (ml)

$F=$ equivalence point of the blank (ml)

$\mathrm{Na}=$ normality of the $\mathrm{HClO}_{4}$ solution (equivalents/L), and

$S=$ sample size $(\mathrm{g})$

For determination of the A-93 asphaltene base number, the same method was used, but the sample size was smaller ( 0.1 to $0.2 \mathrm{~g}$ ) and the asphaltenes were dissolved in a toluene/MIBK mixture $(25 \mathrm{ml} / 15 \mathrm{ml})$. 
Results of both acid and base number measurements for 22 crude oil samples are summarized in Table 1.

\begin{tabular}{|l|c|c|}
\hline \multicolumn{3}{|c|}{ Table 1. Acid and Base Numbers } \\
\hline \multicolumn{1}{|c|}{ Crude Oil } & $\begin{array}{c}\text { Acid \# } \\
\text { (mg KOH/g oil) }\end{array}$ & $\begin{array}{c}\text { Base \# } \\
\text { (mg KOH/g oil) }\end{array}$ \\
\hline A-90 & $0.24 \pm 0.04^{*}$ & $1.99 \pm 0.09$ \\
A-93 & $0.14 \pm 0.04^{*}$ & $2.42 \pm 0.33$ \\
A-93** & $0.12 \pm 0.02$ & $2.80 \pm 0.08$ \\
A-93 n-C asphaltenes $_{\text {A-93 } n-C_{6} \text { maltenes }}$ & unable to measure* & $9.82 \pm 0.44$ \\
A-95 & $0.18 \pm 0.02$ & $1.38 \pm 0.03$ \\
Brookhaven & $0.24 \pm 0.05^{*}$ & $2.20 \pm 0.01$ \\
California & $0.18 \pm 0.03$ & $0.46 \pm 0.05$ \\
CS & $0.39 \pm 0.03^{*}$ & $5.19 \pm 0.10$ \\
Dagang & $0.33 \pm 0.03$ & $1.16 \pm 0.18$ \\
EMSU & $0.66 \pm 0.08^{*}$ & $4.67 \pm 0.17$ \\
Lagrave & $0.55 \pm 0.02$ & $0.80 \pm 0.04$ \\
Maljamar & $0.29 \pm 0.02^{*}$ & $0.65 \pm 0.02$ \\
Moutray & $0.12 \pm 0.04$ & $0.72 \pm 0.06$ \\
NBU & $0.55 \pm 0.10$ & $0.81 \pm 0.09$ \\
Schuricht & $0.16 \pm 0.03$ & $0.96 \pm 0.01$ \\
Spraberry & $0.09 \pm 0.03$ & $0.97 \pm 0.06$ \\
ST-86 & $0.28 \pm 0.12^{*}$ & $2.09 \pm 0.06$ \\
ST-87 & $0.32 \pm 0.02$ & $2.83 \pm 0.05$ \\
ST-88 & $0.48 \pm 0.06$ & $1.07 \pm 0.07$ \\
ST-89 & $0.29 \pm 0.06$ & $1.17 \pm 0.01$ \\
SQ-94 & $0.24 \pm 0.01$ & $0.53 \pm 0.06$ \\
SQ-95 & $0.10 \pm 0.01 *$ & $0.92 \pm 0.01$ \\
Tensleep & $0.45 \pm 0.05^{*}$ & $0.24 \pm 0.14$ \\
Wassan & $0.16 \pm 0.03^{*}$ & $0.62 \pm 0.03$ \\
\hline
\end{tabular}

* some precipitate observed during measurement

**measured by Triton Analytics, no precipitate reported 


\subsubsection{Relating acid and base numbers to alteration of wetting in cores}

Not all of the crude oils represented in Table 1 have been tested for their tendency to alter wetting. Those that have, have been tested under conditions that are sometimes comparable, and sometimes quite different. Factors that have been identified as affecting wetting alteration for a given rock/oil pair include the connate brine (ionic composition and $\mathrm{S}_{\mathrm{wi}}$ ) as well as the aging conditions (time and temperature). The closest comparisons have been chosen from the available literature and from unpublished data. These are summarized in Table 2. Initial water saturations vary by only five percent. Aging temperatures are all 80 or $88^{\circ} \mathrm{C}$, well above the range of temperatures where small differences might be expected to be significant. Aging times also are long enough (10 to 15 days) that there should not be major differences in wettability because of differences in aging time. The brines vary significantly, although none are very low salinity and all have some divalent calcium ion.

\begin{tabular}{|c|c|c|c|c|c|c|c|c|c|}
\hline \multirow[b]{2}{*}{ Oil } & \multicolumn{3}{|c|}{ Brine (\%) } & \multirow{2}{*}{$\begin{array}{l}\mathrm{S}_{\mathrm{wi}} \\
(\%)\end{array}$} & \multicolumn{2}{|c|}{ Aging Conditions } & \multirow[b]{2}{*}{$I_{w}$} & \multirow[b]{2}{*}{$I_{0}$} & \multirow[b]{2}{*}{ Reference } \\
\hline & $\mathrm{NaCl}$ & $\mathrm{CaCl}_{2}$ & other salts & & time (days) & $\mathrm{T}\left({ }^{\circ} \mathrm{C}\right)$ & & & \\
\hline ST-86 & 4 & 0.5 & - & 25 & 10 & 80 & 0.6 & 0.0 & $\begin{array}{c}\text { Jadhunandian } \\
\text { (1990) }\end{array}$ \\
\hline Schuricht & 2.5 & 0.5 & - & 29 & 15 & 80 & 0.52 & - & $\begin{array}{l}\text { Villard et al. } \\
\quad(1993)\end{array}$ \\
\hline $\begin{array}{l}\text { Sulimar } \\
\text { Queen }\end{array}$ & 19.7 & 0.4 & $\begin{array}{cl}\mathrm{NaHCO}_{3} & 0.02 \\
\mathrm{Na}_{2} \mathrm{SO}_{4} & 0.3 \\
\mathrm{MgCl}_{2} & 2.6\end{array}$ & 29 & 14 & 80 & 0.48 & 0.0 & \\
\hline A-93 & 2.1 & 0.03 & $\begin{array}{cc}\mathrm{KCl} & 0.01 \\
\mathrm{MgCl}_{2} & 0.01\end{array}$ & 25 & 10 & 88 & $0.45^{* *}$ & $\therefore$ & $\begin{array}{l}\text { Morrow et al., } \\
\text { (1994) }\end{array}$ \\
\hline Lagrave & - & 2 & - & 25 & 14 & 80 & 0.34 & * & $\begin{array}{l}\text { Morrow et al. } \\
\quad(1994)\end{array}$ \\
\hline Moutray & 4 & 0.5 & - & 24 & 10 & 80 & 0.32 & 0.03 & $\begin{array}{c}\text { Jadhunandan } \\
\text { (1990) }\end{array}$ \\
\hline \multicolumn{10}{|c|}{ " Not measured, but probably close to zero } \\
\hline
\end{tabular}


Figure 17 summarizes acid and base number data for a selected suite of crude oils that includes those in Table 2, plus some related samples from Prudhoe Bay (A-90 and A-95). Wetting of the Berea cores after exposure to brine and oil is indicated by spontaneous imbibition of either water or oil, compared to the amount the saturation of that same phase can be shifted by forced displacement. These measurements result in Amott indices to water and oil, $I_{w}$ and $I_{o}$, respectively (Amott, 1959). None of these cores imbibed significant amounts of oil $\left(I_{o} \leq 0.03\right)$. Figure 18 shows the acid and base numbers of the oils in Table 2 , cross plotted with $I_{w}$.

(a) Acid numbers

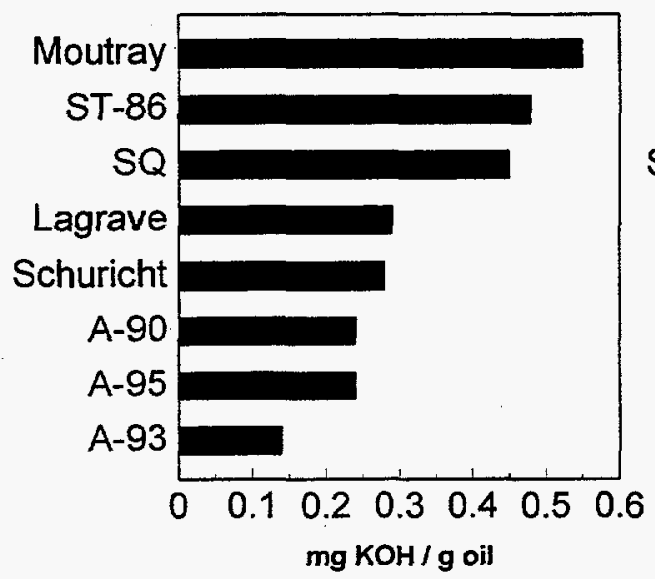

(b) Base numbers

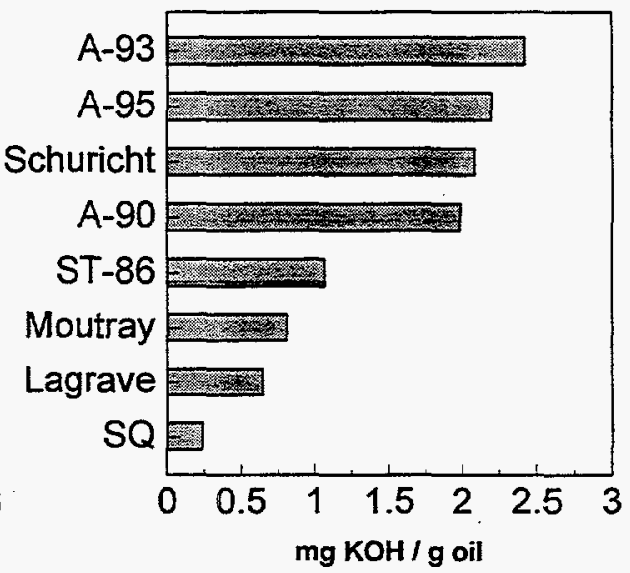

Figure 17. Acid and base numbers of selected crude oils.

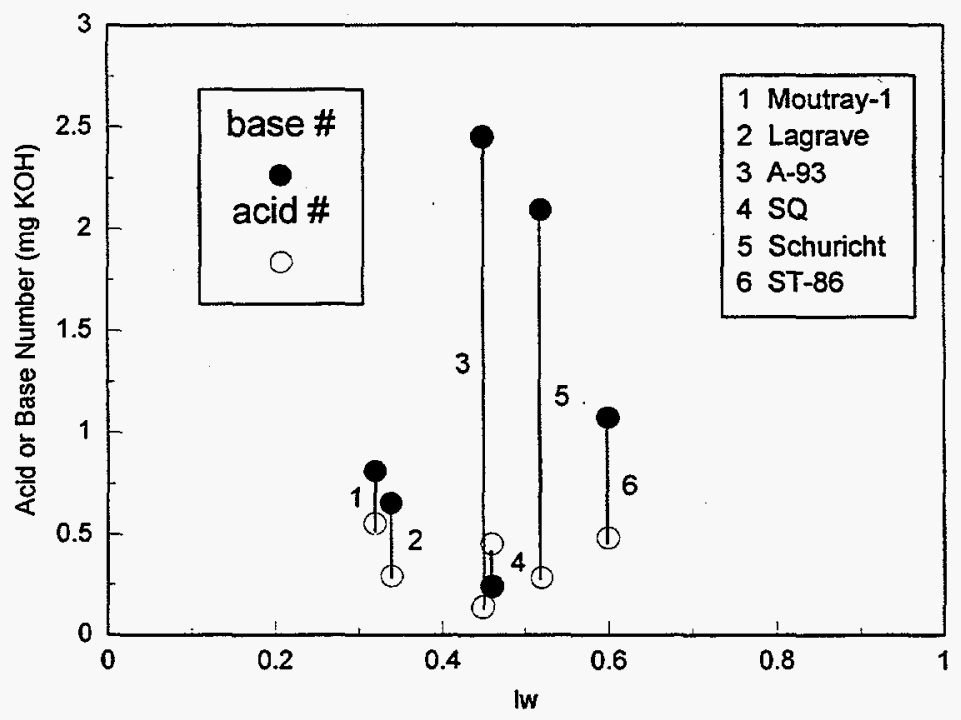

Figure 18. Relationship between acid and base numbers and the Amott index to water for Berea sandstone cores exposed to brine and to six different crude oils. 
While no obvious correlation between either acid number or base number and the extent of wetting are immediately apparent, we will revisit this data in Section 1.3, after closer examination of the asphaltenes and their solvent environment.

\subsection{Asphaltene Precipitation-Onset at Ambient Conditions}

The asphaltenes are implicated in wetting, but only recently has the connection between wetting alteration and the solvent environment of the asphaltenes begun to be established (Buckley et al., 1997; Tang et al., 1996). The amount of asphaltene in an oil is less important than the fact that it is present and in what solvent environment. The evidence suggests that as the oil becomes a poorer asphaltene solvent, its tendency to make surfaces more oil-wet increases. Solubility parameters cannot be measured directly. SAXS and SANS measurements give a direct measure of the asphaltene aggregate size (as shown in Fig. 6), reflecting changes with solvent quality, but these methods require sophisticated equipment and data interpretation, and they are not readily applied to black oils.

Instead, refractive index can be used to quantify solvent quality (Buckley, 1996). Refractive index (RI) measurements are used in tandem with observations of the onset of precipitation. The onset of asphaltene precipitation is readily observed microscopically at relatively low magnification (at most $45 \mathrm{X}$ ). Asphaltene can usually be distinguished from other solids in the oil, especially paraffin, because it is amorphous. Crystalline wax appears as bright spots under polarized light, whereas asphaltenes are completely dark.

The use of RI to quantify the state of the asphaltenes can best be explained by a few simple illustrations. Figure 19 is a schematic outline of the procedure. In Fig. 20, $\mathrm{RI}$ is plotted as a function of the volume fraction of oil in a mixture of oil and precipitant. Small amounts of isooctane can be mixed with A-93 without causing precipitation. RI's of mixtures that remain free of asphaltene precipitate are indicated by open circles. In sufficiently high concentration, isooctane causes asphaltene to precipitate from A-93 crude oil. Those mixtures containing precipitate are indicated by filled circles. We have shown previously that precipitation occurs at an RI that is characteristic for each 
oil/precipitant pair. Addition of solvents, for example toluene or $\alpha$-methyl naphthalene, affects the volume fraction, but not the $\mathrm{RI}$ at which precipitation occurs.

(1) Mix crude oil, solvents, and precipitants

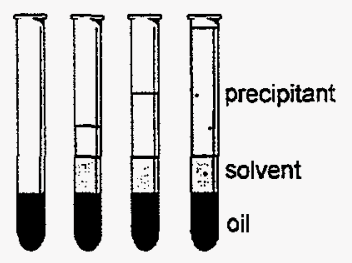

(2) Observe

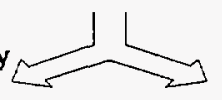

(3) Measure refractive index $(\mathrm{RI})$
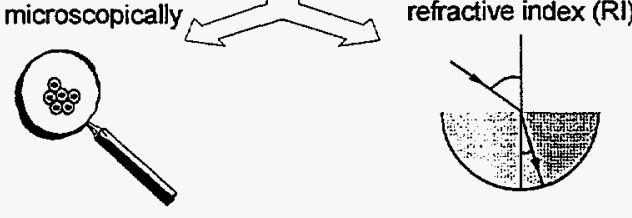

Figure 19. Schematic illustration of the onset of precipitation test procedure.

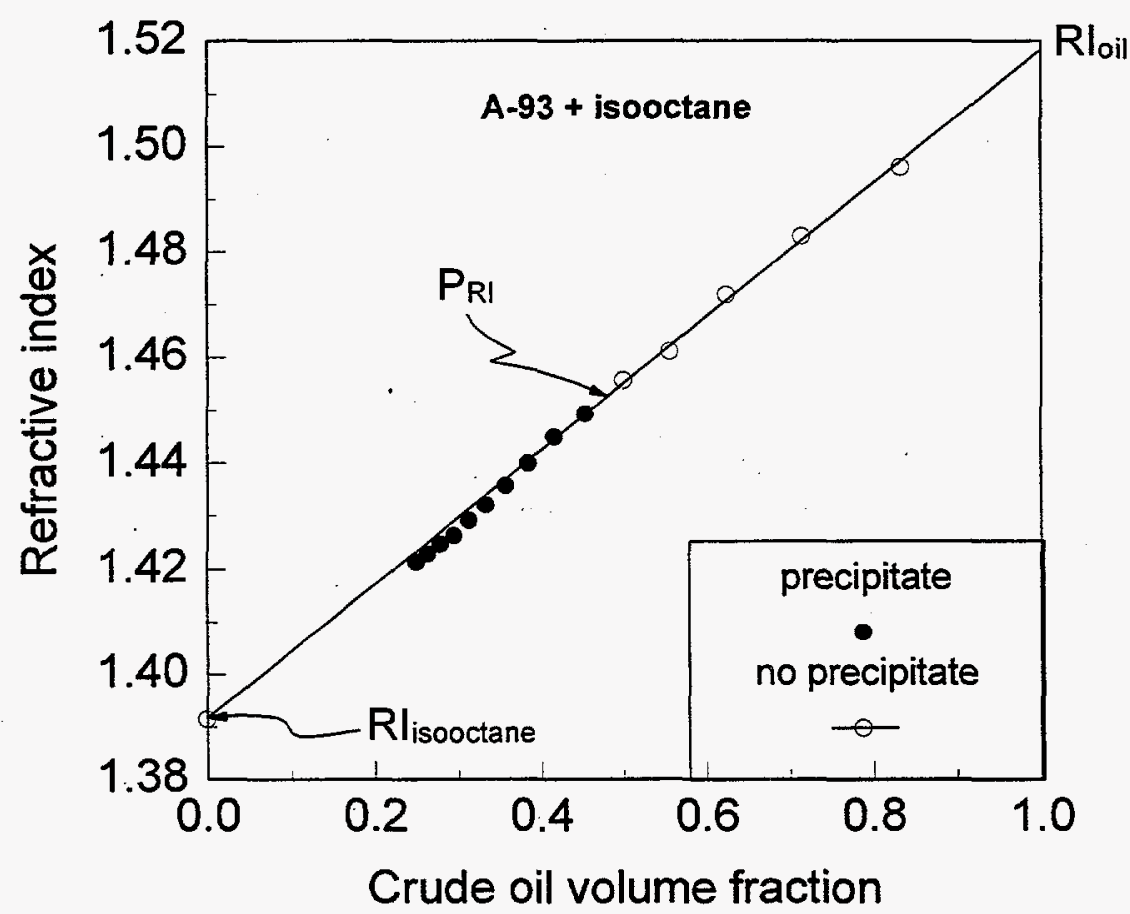

Figure 20. Refractive index of mixtures of a sample of crude oil from Prudhoe Bay with isooctane, plotted as a function of the volume fraction of the mixture that is crude oil. Open circles have no microscopically visible precipitate.

Precipitate is observed in the mixtures indicated by the closed symbols. 
The $\mathrm{RI}$ at the onset of precipitation, $\mathrm{P}_{\mathrm{RU}}$, is about 1.45 for $\mathrm{A}-93$ and isooctane. $\mathrm{RI}$ of the stock-tank oil cannot be accurately measured if the oil is too opaque. It can, however, be estimated by linear extrapolation of the mixture RI's. Only the precipitate free mixtures and pure isooctane are used in this extrapolation. Once precipitation occurs, mixture RI's can deviate from the linear relationship. Figure 21 shows a case where RI can be measured directly, confirming that the relationship is linear and the estimate of $\mathrm{RI}_{\text {oil }}$ is accurate.

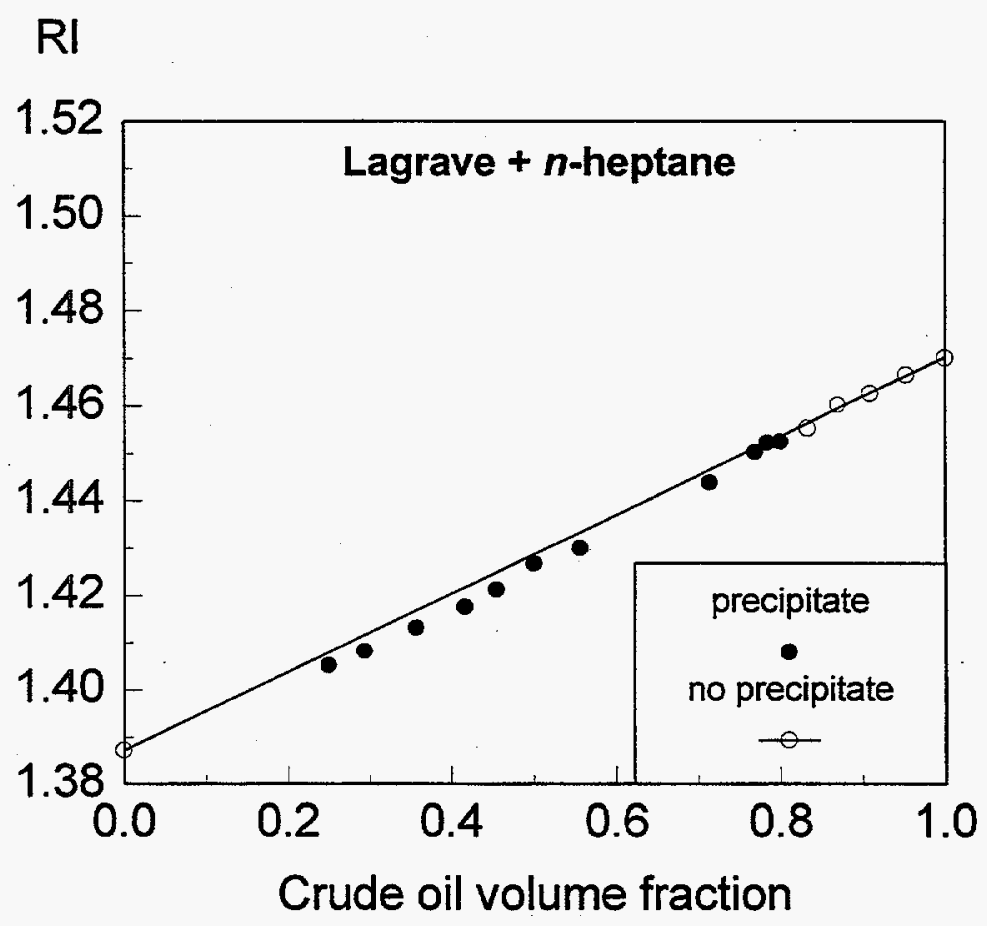

Figure 21. Accuracy of the linear extrapolation is demonstrated by mixtures of Lagrave crude oil and $n$-heptane.

The oil sample in Fig. 22 shows extreme deviation from linearity when precipitation has occurred. Separation of precipitate from the oil could also be observed in the bulk solution without the aid of a microscope. The range of precipitate-free solutions was limited, so $\mathrm{RI}_{\mathrm{oil}}$ was confirmed by mixing oil and toluene. 


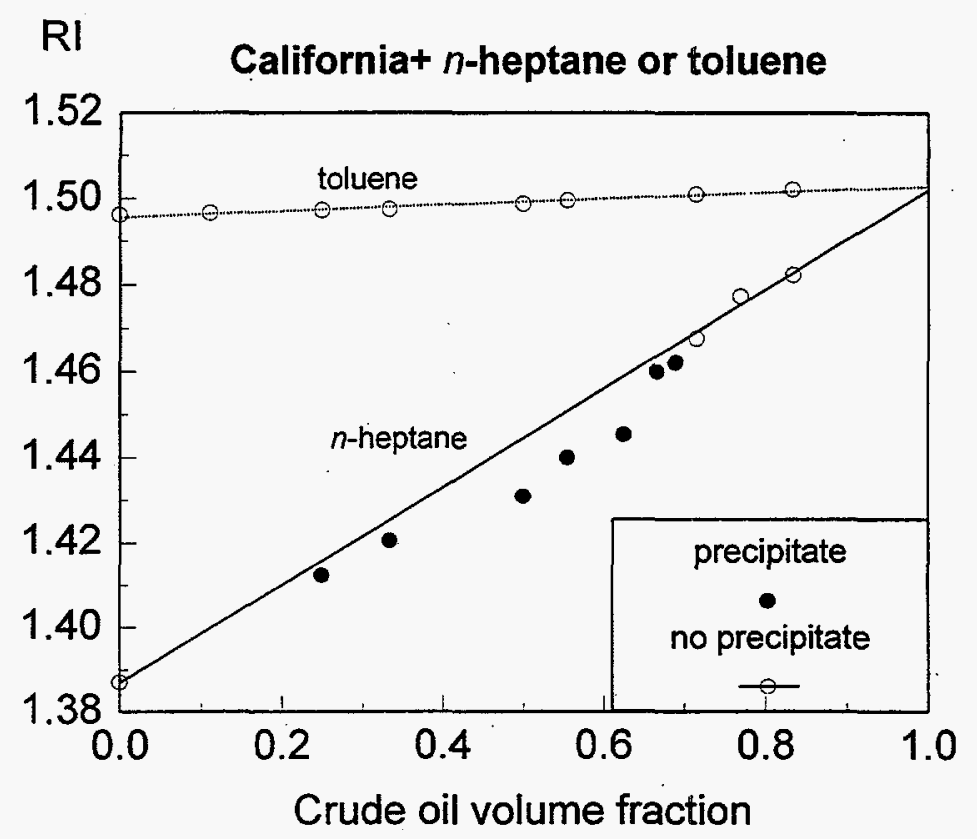

Figure 22. Deviation from linearity can be severe, as shown for a crude oil from the Ventura field. $\mathrm{RI}_{\mathrm{oil}}$ was confirmed using mixtures of oil and toluene.

From the two points, $\mathrm{RI}_{\text {oil }}$ and $\mathrm{P}_{\mathrm{R}}$, we can then define a measure of the stability of the asphaltenes:

$$
\Delta_{R I}=R I_{o i l}-P_{R I}
$$

Data for nine crude oil samples are summarized in Table 3. Also shown for each oil is its API gravity and the amount of asphaltene precipitated with $n$-pentane in the standard ASTM test.

\begin{tabular}{|l|c|c|c|c|c|c|}
\hline \multicolumn{7}{|c|}{ Table 3. RI and $P_{\mathrm{RI}}$ Data for Mixtures of Crude Oils with $n$-Heptane } \\
\hline Crude Oil & $\begin{array}{c}\text { API } \\
\text { gravity } \\
\left({ }^{\circ}\right)\end{array}$ & $\begin{array}{c}n \text { - } \mathrm{C}_{5} \\
\text { asphaltenes } \\
(\%)\end{array}$ & $\mathrm{RI}$ & $\mathrm{f}_{\mathrm{V}, \mathrm{oil}}$ at pptn & $\mathrm{P}_{\mathrm{RI}}$ & $\Delta_{\mathrm{RI}}=\left(\mathrm{RI}_{\mathrm{oil}}-\mathrm{P}_{\mathrm{RI}}\right)$ \\
\hline A-93 & 25.5 & 10.9 & 1.522 & 0.43 & 1.446 & 0.076 \\
A-95 & 25.2 & 5.0 & 1.518 & 0.43 & 1.445 & 0.074 \\
California & 28.5 & & 1.503 & 0.70 & 1.465 & 0.038 \\
EMSU & 32.0 & 1.2 & 1.484 & 0.43 & 1.429 & 0.055 \\
Lagrave & 41.3 & 3.8 & 1.470 & 0.82 & 1.454 & 0.016 \\
Moutray & 35.2 & 1.8 & 1.484 & 0.45 & 1.432 & 0.052 \\
Schuricht & 24.6 & 9.9 & 1.514 & 0.47 & 1.448 & 0.066 \\
SQ-95 & 37.2 & 2.9 & 1.476 & 0.16 & 1.402 & 0.074 \\
Tensleep & 31.2 & 3.4 & 1.486 & $>1.00$ & 1.490 & -0.004 \\
\hline
\end{tabular}


Stability of the asphaltenes in these various oils can be judged from the $\Delta_{\mathrm{RI}}$ values in the right column. The most stable (highest $\Delta_{\mathrm{RI}}$ ) are the Prudhoe Bay oils (A-93 and A95) and a sample from the Sulimar Queen reservoir in SE New Mexico (SQ-95). Least stable is the Tensleep, which-perhaps coincidentally-is cited as the oil-wet capillary pressure example in Craig's waterflooding monograph (1971); Tensleep oil has asphaltene precipitate in our laboratory sample. The precipitate disappears if toluene is mixed with the oil. Next in instability by this measure is Lagrave, reported to have significant asphaltene production problems (Garland, 1989).

There are oils that do not produce any sign of asphaltene precipitation in tests with $n$-heptane. One such oil from the North Sea is shown in Fig. 23. Linearity is maintained over the whole range of mixtures. Some other oils in this category tested with the $n$-heptane procedure include NBU and Spraberry.

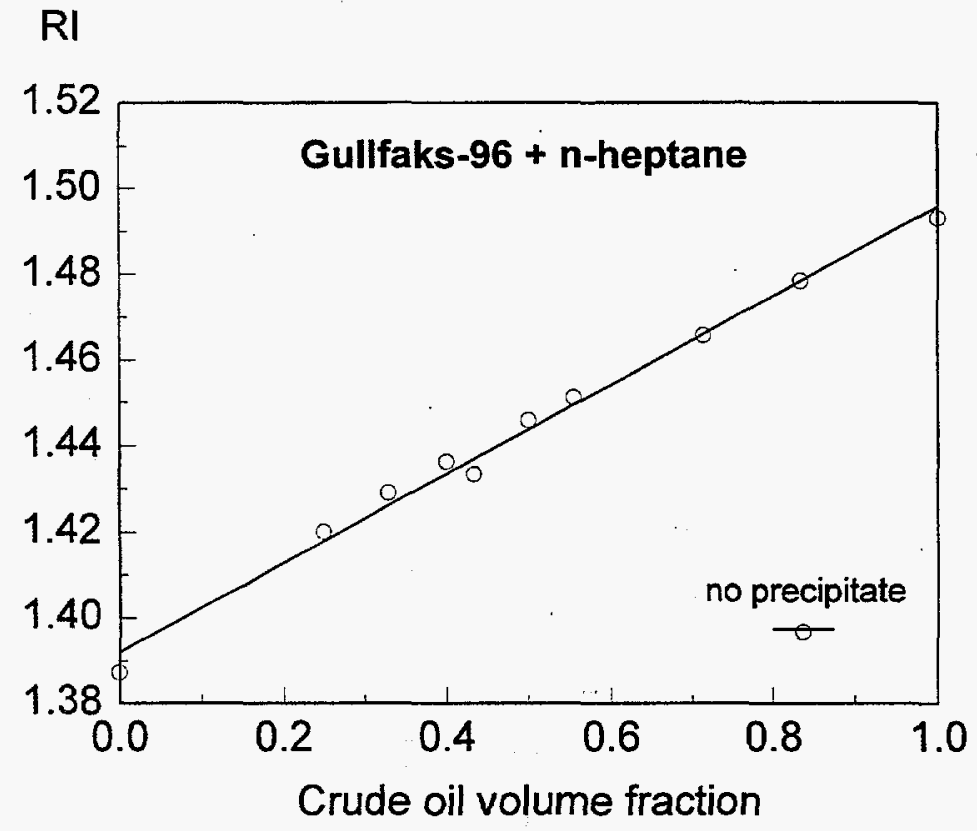

Figure 23. Mixtures of ST-86 and $n$-heptane are free of precipitate for all volume fractions of oil. 


\subsection{Mechanisms of COBR Interactions and Crude Oil Chemistry}

Using the acid/base and asphaltene solvent quality observations presented in Sections 1.1 and 1.2, we can now consider the mechanisms by which crude oils adsorb onto mineral surfaces. Much of the contact angle, adhesion, and core data analyzed in this section is from studies that have been conducted in earlier projects, both here and in other laboratories. The objective of this section is to explanation the accumulated information, in light of the chemical oil characterizations.

It is particularly difficult to unravel the interaction mechanisms from core tests because of the coupled effects of wetting and pore morphology. The strategy here is to concentrate first on interactions of crude oils and their components with smooth solid surfaces in the presence or absence of brine and then extend the explanations to cores. While this discussion of interaction mechanisms transcends the boundaries of Part 1 , it is introduced at this point mainly because of the key importance of considering together the acid/base and solvent quality observations to explain COBR interactions.

The mechanisms identified here are representative of physisorption on amorphous silica surfaces. These observations may well apply, with due consideration to differences in surface charge and surface chemistry, to a variety of minerals, especially other oxides. It should be noted, however, that there are circumstances in which other mechanisms will dominate. One example is chemisorption of carboxylic acids on hematite surfaces (Peck et al., 1966). Bearing in mind that exceptions will be encountered, it is still important to understand the more general mechanisms by which crude oils can alter the wetting of high energy oxide surfaces.

\subsubsection{Summary of proposed COBR interactions}

Four main categories of crude oil/brine/rock interactions have been identified, as illustrated in Fig. 24. They include:

- polar interactions that predominate in the absence of a water film between oil and solid, 
- surface precipitation, dependent mainly on crude oil solvent properties with respect to the asphaltenes,

- acid/base interactions that control surface charge at oil/water and solid/water interfaces, and

- ion binding or specific interactions between charged sites and higher valency ions.

(a) typical crude oil components with polar functionality<smiles>[R]c1ccncc1</smiles><smiles>[R]C1C=CC(C(=O)O)=CC1[R]</smiles>

(c) acid/base interactions

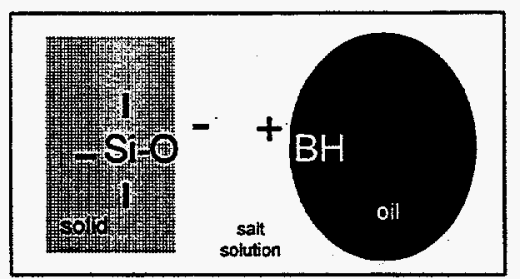

(b) surface precipitation

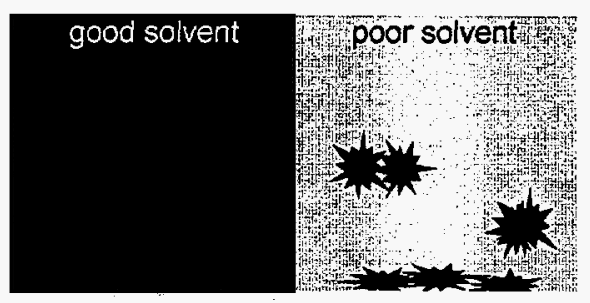

(d) ion-binding

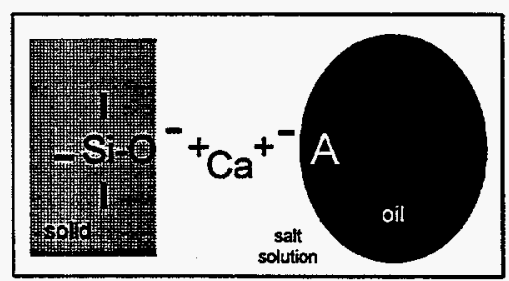

Figure 24. Mechanisms of interaction between crude oil components and solid surfaces.

\section{$\underline{\text { Polar interactions }}$}

Adsorption of asphaltenes directly from oil onto mineral surfaces has often been reported. Some important variables that affect adsorption onto clay minerals in the absence of water include the type of clay and its exchangeable cations, nitrogen content of the oil, and the solvent in which the polar compounds are dissolved (Clementz, 1976, 1982; Czarnecka and Gillott, 1980). Monolayer adsorption was reported (Dubey and Waxman, 1991), except in nitrobenzene, a polar solvent. The thickness of the monolayer depended on the solvent from which it was adsorbed. Studies designed to separate out the effects of acidic and basic components (Denekas 
et al., 1959) or various distillation fractions (Cuiec, 1986) in different lithologies have mainly demonstrated the complexity of the interactions involved in these adsorption processes. The adsorbed material is enriched in nitrogen, oxygen, and sulfur and is higher in molecular weight than the oil from which it comes (Akhlaq, et al., 1996). Two of the many types of functional groups that are likely to be involved in polar interactions are suggested in Fig. 24a. The variety of ways in which these species can interact with surfaces are grouped together here under the general heading of polar interactions to distinguish them from interactions between ionic species.

Direct measurements of surface forces between dry mica surfaces immersed in crude oil (Christenson and Israelachvili, 1987) showed slow adsorption of high molecular weight material. Water advancing contact angles on dry glass surfaces, after treatment with several different crude oils or with a solution of asphaltenes in toluene, have been reported to be in the range from 60 100 (Liu and Buckley, 1997; Buckley et al., 1997; Wu, 1996).

\section{Surface precipitation}

As discussed in Section 1.2, crude oils vary widely in their ability to act as solvents for their asphaltenes. If the oil is a poor solvent for its asphaltenes, the tendency for wetting alteration is enhanced, as illustrated in Fig. 24b. Measurements of amounts of adsorbed material (Akhlaq et al, 1996), contact angles (Buckley et al., 1997), and the rate of imbibition into Berea sandstone cores (Tang et al., 1996) all indicate that more adsorption and less water-wet conditions are achieved as the oil becomes a poorer solvent for its asphaltenes.

\section{Acid/base interactions}

Water plays several important roles in mediating oil/solid interactions. In the presence of water, both the solid and oil interfaces become charged. Polar functional groups belonging to both the mineral and crude oil phases can behave as acids (giving up a proton and becoming negatively charged) and bases (gaining a proton and thus producing a positive charge) (Cuiec, 1975). There are two major ways in which the phenomenon of surface charge impacts interactions between crude oils, brine, and solid surfaces. 
Net Charge Affects Water Film Stability: The influence of DLVO forces in stabilizing a thin film of water between mineral and oil is most significant when the brine phase salinity is low. For a given oil or solid surface, surface charge depends on the extent of acid/base dissociation reactions which, in turn, depend on $\mathrm{pH}$ at the surface. For some brine compositions, both oil/water and solid/water interfaces will have like charge. The resulting repulsion stabilizes the intervening water film. If the water film is stable, strongly water-wet conditions can be maintained. If not, the collapse of the water film allows wettability altering interactions to proceed.

Ionized Acidic and/or Basic Sites Influence Adsorption: Collapse of the water film is only the first step in wetting alteration. At this stage, crude oil components at the oil/brine interface can adsorb on the solid surface. Silica surfaces are negatively charged above $\mathrm{pH} 2$; positively charged nitrogen bases can adsorb, as illustrated in Fig. 24c. Calcite surfaces are more complex, but may be positively charged below a $\mathrm{pH}$ of about 9.5 , enhancing adsorption of acidic species.

\section{Ion binding}

When present, $\mathrm{Ca}^{2+}$ ions mask the purely acid/base interactions. Several interactions are possible:

$$
\text { oil- } \mathrm{Ca}-\text { oil } \quad \text { mineral- } \mathrm{Ca}-\text { mineral } \quad \text { oil- } \mathrm{Ca}-\text { mineral }
$$

The first two can limit wettability alteration, while the last can promote it, as illustrated in Fig. 24d.

\subsubsection{Interactions with glass surfaces}

Polar Interactions: Figure 25 shows the results of contact angle measurements for water advancing against decane $\left(\theta_{A}\right)$ on glass surfaces. These measurements were made after the surfaces had been treated with one of four different crude oils. $\theta_{\mathrm{A}}$ is shown for shorter ( 1 day) and longer ( $\sim 20$ days) aging times in oil and for two aging temperatures, $25^{\circ}$ and $80^{\circ} \mathrm{C}$. For all of these oils, aging in crude oil changes wetting from strongly water-wet to intermediate. Aging time and aging temperature have only small effects on the measured values of $\theta_{\mathrm{A}}$. Intermediate 
values of $\theta_{\mathrm{A}}$ have also been reported for glass surfaces aged in varying concentrations of asphaltene dissolved in toluene (Buckley et al., 1997).

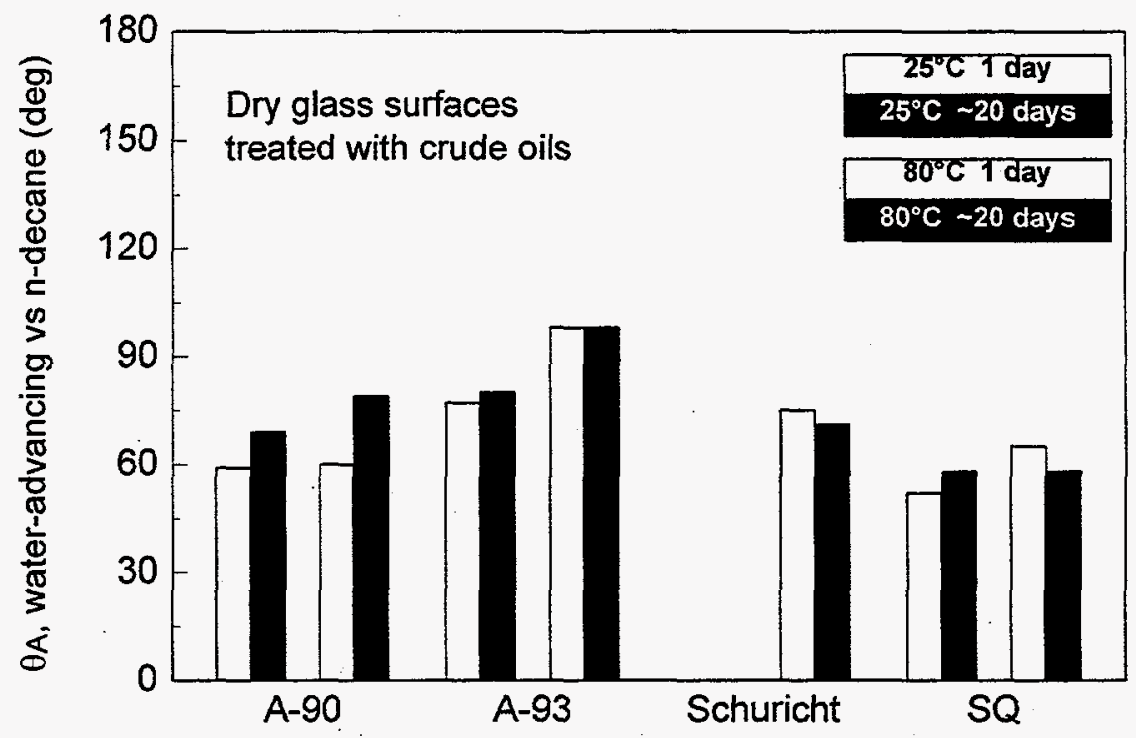

Figure 25. Glass surfaces, treated with crude oils in the absence of water. Polar interactions result in intermediate in wetting.

Surface Precipitation: As discussed in Section 1.2, if the oil is a poor asphaltene solvent, asphaltenes can precipitate. Even before precipitate can be detected in the oil, however, there can be an effect on wetting. Surfaces become increasingly oil-wet as the oil approaches the point of precipitation, as shown in Figs. 26a and b. Water/decane contact angles on surfaces treated with a synthetic reservoir brine, then aged in A-93 crude oil for three weeks at $80^{\circ} \mathrm{C}$ are shown. Washing with a precipitant (decane) produces an oil-wet surface with high advancing and receding angles. Rinsing with better solvents (toluene or cyclohexane) results in high advancing angles, but much lower receding angles (Fig. 26a). Similarly, aging in oil mixtures of $40 \%$ crude oil and $60 \%$ precipitant (isooctane) produced more oil-wet surfaces than aging in the oil alone or in oil to which similar amounts of solvents (toluene or $\alpha$-methylnaphthalene) were added (Fig. 26b). 
a) effect of rinsing agents

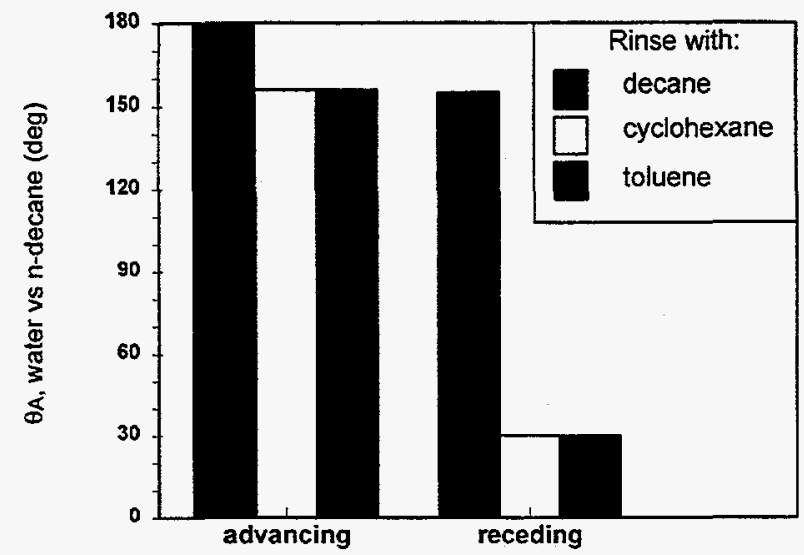

b) effect of fluids added to aging oil

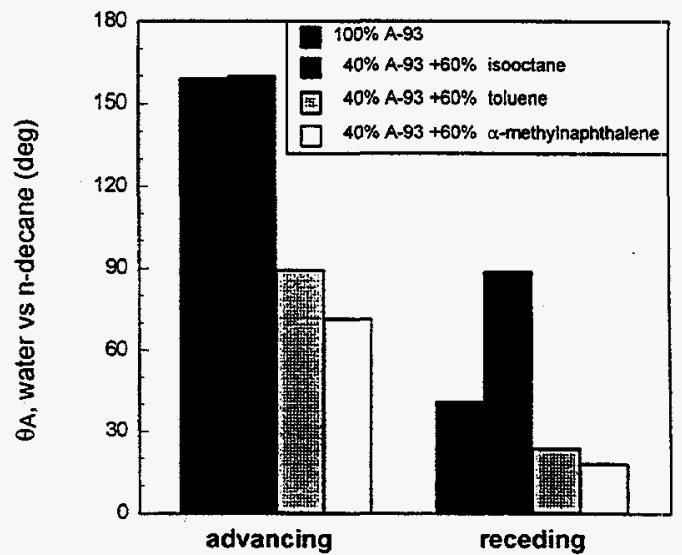

Figure 26. Contact angles (measured on glass surfaces treated with synthetic reservoir brine and A-93 crude oil) show that oil mixtures with poorer solvent quality have greater wettability altering tendency.

As discussed in the previous section, $\Delta_{\mathrm{RI}}$ is an indicator of an oil's ability to serve as a solvent for its asphaltenes. In Fig. 27, oils are ranked by API gravity (a measure of density) and by $\Delta_{\mathrm{Rl}}$. The rankings are similar, but with some important differences. The Sulimar Queen oil is a better solvent than its density would suggest, whereas Tensleep is poorer than would be predicted on the basis of density. Lagrave, by any measure, is a poor solvent for its asphaltenes.

a) comparison of oils by API gravity

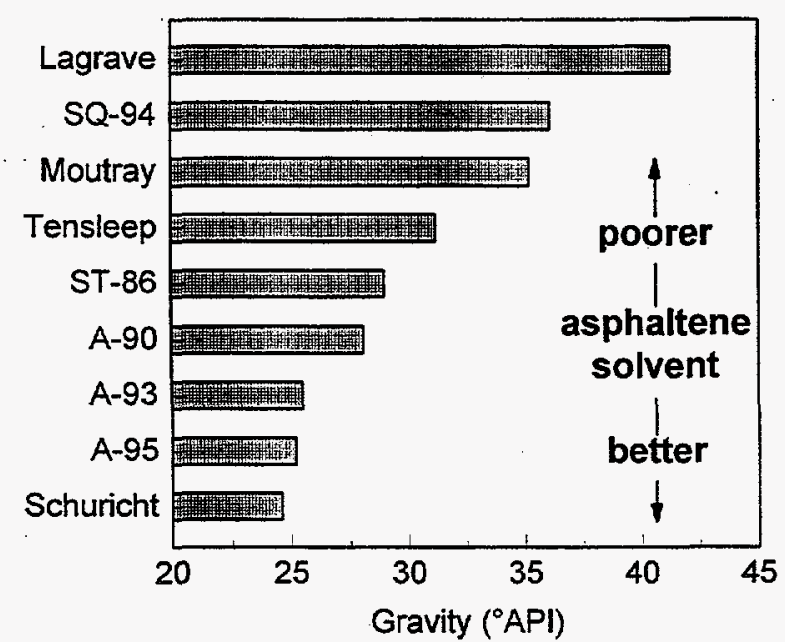

b) comparison of oils by $\Delta R I$

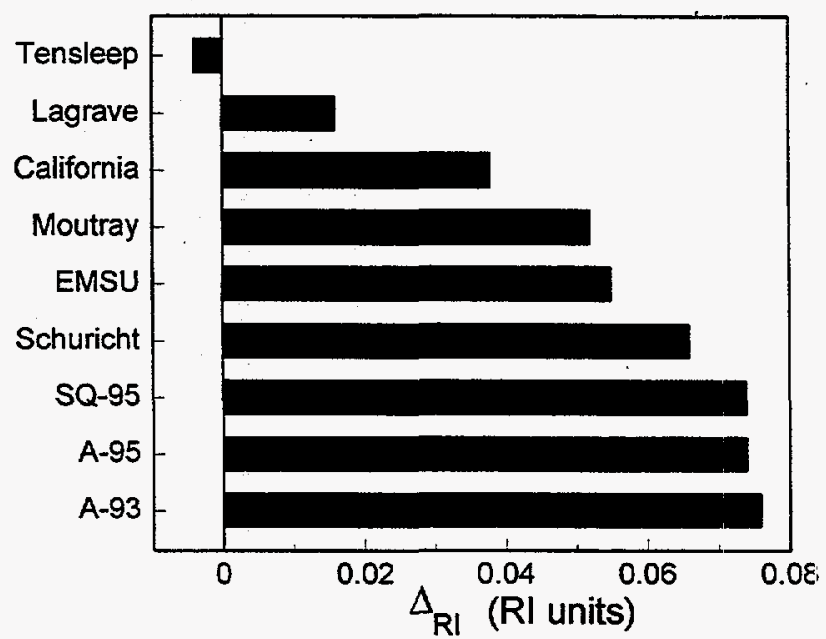

Figure 27. Density and RI are both rough measures of an oil's solvent power. Rankings by API gravity (a) and $\Delta_{\mathrm{RI}}$ (b) are similar, with some significant differences for SQ-95 and Tensleep. 
Acid/Base Interactions: Adhesion maps with $\mathrm{NaCl}$ brines show interactions between oil, brine, and solid as a function of brine composition. These tests highlight acid/base interactions. Fig. 28 shows the effects of adsorption during longer exposures of glass to oil. In these tests, too, the results depend strongly on brine composition. The water advancing angles can be quite water-wet or fairly oil-wet for the same oil and solid, aged under exactly the same conditions. The only difference is the $\mathrm{pH}$ and ionic strength of the brine.

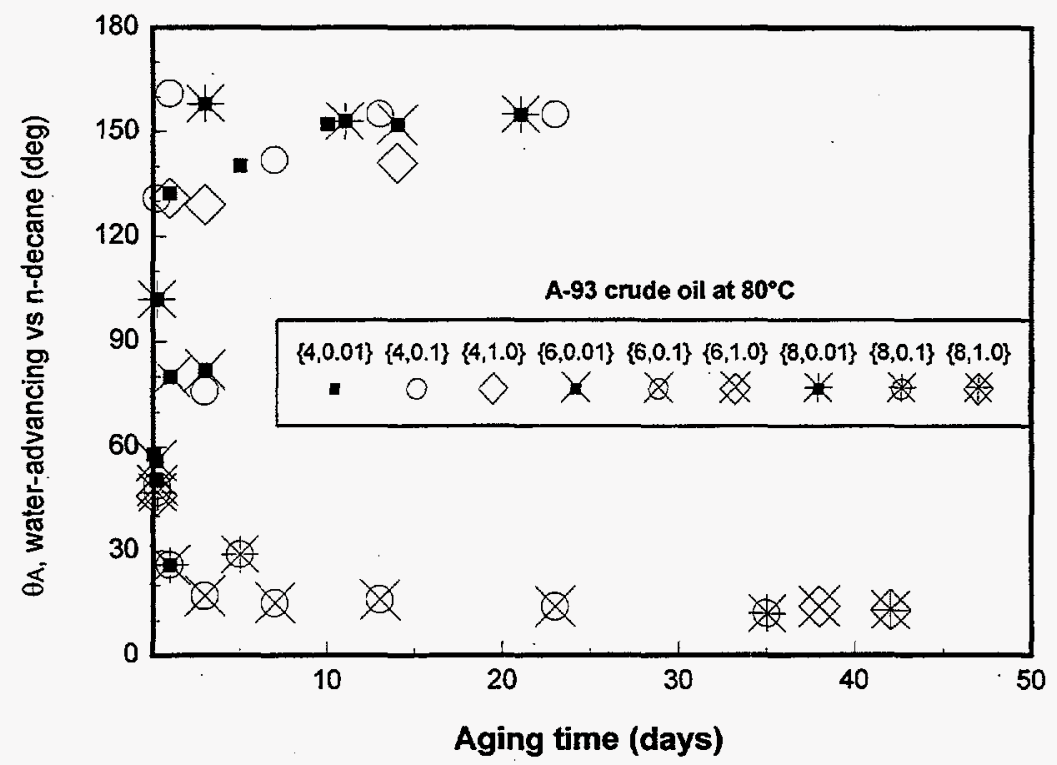

Figure 28. Brine composition can have a dominant effect on oil/solid interactions by the acid/base mechanism (after Liu and Buckley, 1997).

The dependence on brine composition is different for every crude oil, since each oil has different acidic and basic components available for interfacial interactions. Acid and base numbers were listed in Table 1 and compared in Fig. 18. Moutray has the highest acid number and A-93 the highest base number of the oils in this group. It is probably also significant that the corresponding base number for Moutray and acid number for A-93 are relatively low. These two oils are thus at opposite ends of the spectrum with regard to their acid/base properties.

Ion Binding. When the brine phase contains dissolved salts of divalent or multivalent ions, the interactions become more complicated. $\mathrm{pH}$ is not directly a major determining factor in adhesion experiments (Buckley and Morrow, 1992), nor is adhesion a good indicator of 
adsorption interactions that occur with longer exposure times. The examples shown in Fig. 26 are for slides that were contacted with a synthetic reservoir brine that contains $\mathrm{Ca}^{2+}$ and $\mathrm{Mg}^{2+}$ in addition to $\mathrm{Na}^{+}$and $\mathrm{K}^{+}$cations before aging in crude oil. Interactions can be very dependent on temperature. High hysteresis, similar to that observed for acid/base interactions, has been observed. Interactions via ion binding appear to be somewhat more resistant to desorption than the acid/base interactions are for the same crude oil.

Summary. Some of the general characteristics identified for the four major categories of interaction are illustrated in Fig. 29. The arrows indicate typical rates at which decane/water contact angles might increase on surfaces aged in oil. Solid lines indicate aging at elevated temperature and dotted lines are for room conditions. Similar diagrams have been drawn for each of the four mechanisms of interaction to summarize general features of many measurements of contact angles on brine and oil treated glass surfaces. These are collected in Table 4.

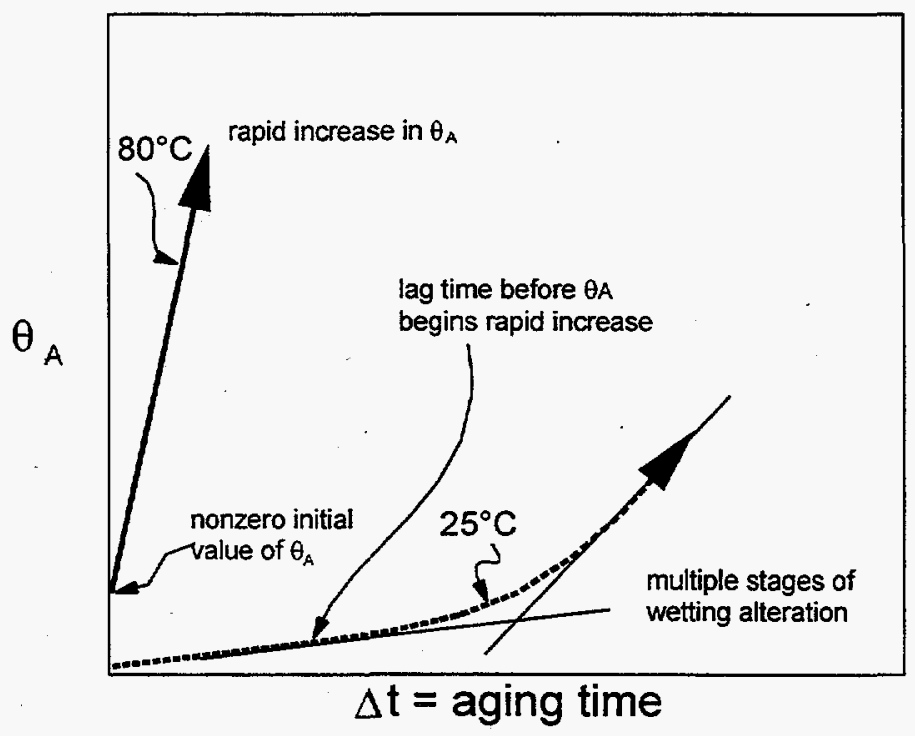

Figure 29. Illustration of the summary notation used in Table 4. 


\begin{tabular}{|c|c|c|c|c|c|}
\hline Type & Description & $\theta_{\mathrm{A}}$ & $\begin{array}{l}\text { Hysteresis } \\
\left(\theta_{A}-\theta_{R}\right)\end{array}$ & Effects of Aging Con & ditions \\
\hline Polar & $\begin{array}{l}\text { If there is no water present, the strongest } \\
\text { interactions are between polar atoms }(\mathrm{N}, \mathrm{S}, \mathrm{O}) \\
\text { and polar surface sites }\end{array}$ & $\sim 90$ & moderate & $\theta_{\mathrm{A}}$ & $\Delta \mathrm{t}$ \\
\hline $\begin{array}{l}\text { Surface } \\
\text { precipi- } \\
\text { tation }\end{array}$ & $\begin{array}{l}\text { Occurs when oil is a poor solvent for its } \\
\text { asphaltenes; changes in } \mathrm{T}, \mathrm{P} \text {, and in oil } \\
\text { composition affect solvent properties }\end{array}$ & $\sim 180$ & low & & $\Delta t$ \\
\hline $\begin{array}{l}\text { Acid/ } \\
\text { base }\end{array}$ & $\begin{array}{l}\text { Coulombic interactions between ionized acidic } \\
\text { and basic sites; for monovalent salt solutions at } \\
\text { low concentration, } \mathrm{pH} \text { is the dominant variable }\end{array}$ & $\begin{array}{l}\text { depends } \\
\text { on oil \& } \\
\text { brine }\end{array}$ & high & & gh pH \\
\hline $\begin{array}{c}\text { Ion } \\
\text { binding }\end{array}$ & $\begin{array}{l}\text { Coulombic interactions; divalent and multivalent } \\
\text { ions can bind at both oil and solid/water } \\
\text { interfaces and/or bridge between them }\end{array}$ & $\begin{array}{l}\text { depends } \\
\text { on oil \& } \\
\text { brine }\end{array}$ & high & $\theta_{A}$ & \\
\hline
\end{tabular}

\subsubsection{Interactions in porous media}

Wetting in porous media can be inferred from observations of spontaneous imbibition. A standard method first described by Amott (1959) compares the amount of fluid that imbibes spontaneously with forced displacements. The results are Amott indices for water $\left(\mathrm{I}_{\mathrm{w}}\right)$ and oil $\left(I_{o}\right)$. Each index ranges from 0 (no spontaneous imbibition) to 1 (strongly wetted). The rate of spontaneous imbibition can also used to compare wetting in cores. Imbibition times can be scaled to account for differences in core length, porosity, permeability, fluid viscosities, and interfacial tension (Zhang et al., 1995).

It is probable that more than one mechanism at a time contributes to crude oil/brine/rock interactions. Nevertheless, by comparing acidic and basic oils and oils of varying solvent quality, it is possible to see differences in wetting alteration that are consistent with the outlined mechanisms. Polar interactions that occur between oil and dry surfaces are not likely to be important in most core studies since water is always the first fluid occupying the pore space. 
Surface Precipitation: The best known example of wettability alteration by destabilizing the asphaltenes in a crude oil is the work of Salathiel (1973). In order to induce wettability alteration in cores, the crude oil was diluted with $n$-heptane. It is likely that surface precipitation contributed to the mixed-wet conditions observed.

Another example is the high gravity Lagrave crude oil. Lagrave readily alters wetting on silica and in sandstone cores (Gauchet, 1993; Morrow et al., 1994) despite having only an intermediate acid number and low base number.

Acid/Base Interactions: The effect of aging Aerolith-10 (a synthetic porous medium that is composed primarily of silica) in A-93 crude oil has been shown to vary depending on brine $\mathrm{pH}$ (Buckley et al., 1996). Low $\mathrm{pH}$, favoring positive charge of basic functional groups, produced weakly water-wet conditions $\left(\mathrm{I}_{\mathrm{w}}=0.5\right)$, whereas at higher $\mathrm{pH}$, with the same crude oil and aging conditions, strongly water-wet conditions $\left(\mathrm{I}_{\mathrm{w}}=1\right)$ were maintained.

Ion Binding-Three Crude Oils in Berea Sandstone: In natural sandstones, the interactions are more complex than in Aerolith. Acid/base interactions may still be important, but they cannot readily be isolated from the more complex contributions of the ion-binding mechanism. Ion binding provides an alternative mechanism for wetting alteration by which ions of the same sign as the solid surface can contribute. The details of this mechanism are undoubtedly complex and have yet to be worked out, but its consequences can be observed.

In Fig. 30, scaled imbibition rates show that wetting of Berea sandstone cores varies with oil composition for cores aged in three crude oils (Jadhunandan, 1990; Yildiz, 1995). The composition of the brine phase influences wetting alteration, especially for Moutray crude oil (Fig. 30a). The extent of wetting alteration does not correlate with the concentration of calciurn ions in the brine nor with its total ionic strength (plotted as the gray bars in the legend). 
(a) Moutray $\left(26^{\circ} \mathrm{C}\right)$
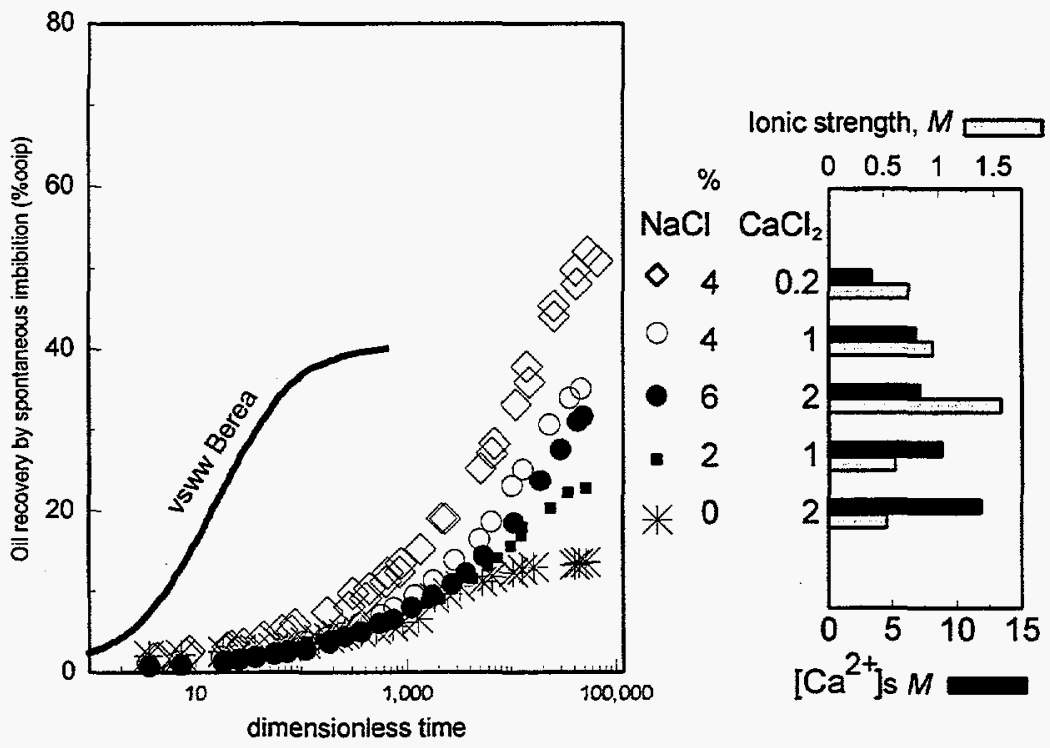

(b) Alaska-92 $\left(25^{\circ} \mathrm{C}\right)$

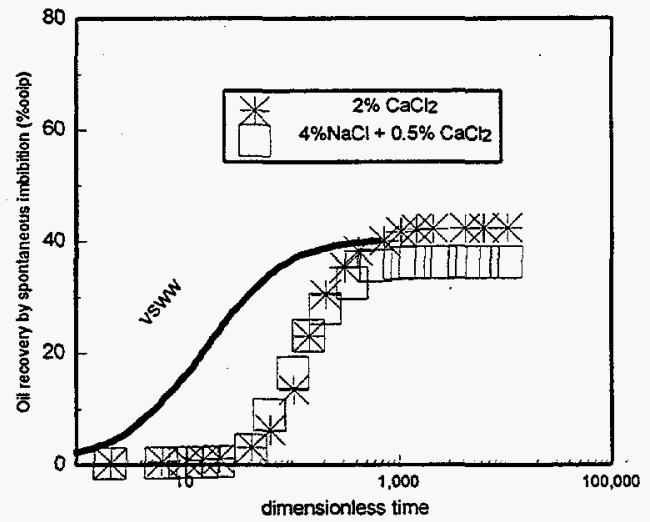

(c) ST-86 $\left(25^{\circ} \mathrm{C}\right)$

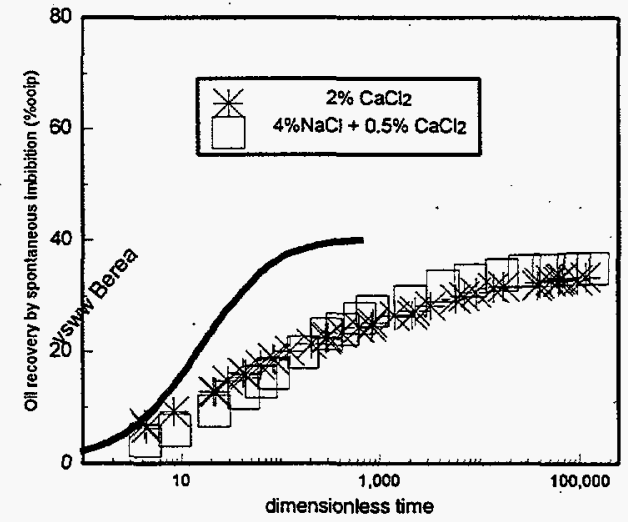

Figure 30. Rate of imbibition of brine into Berea sandstone cores after they were aged for 9-12 days with three different crude oil samples.

Counter ions $\left(\mathrm{Na}^{+}\right.$and $\left.\mathrm{Ca}^{2+}\right)$ are concentrated in the double layer near a negatively charged surface. Calculated values of calcium ion concentration near a negatively charged solid surface $\left(\left[\mathrm{Ca}^{2+}\right]_{\mathrm{s}}\right)$ are shown in the bar graph in Fig. 30a. These values were calculated assuming a negative surface charge density of $-0.2 \mathrm{C} / \mathrm{m}^{2}$. The rate of imbibition decreases systematically with these calculated values of $\left[\mathrm{Ca}^{2+}\right]_{s}$, suggesting that calcium ions are specifically involved in the interaction mechanism. Moutray, with a high acid number (Fig. 18a), has many negatively charged interfacial sites and depends on the ion-binding mechanism for its wettability altering behavior. 
Less acidic crude oils and those with different interfacial ratios of bases to acids respond differently than Moutray to changes in calcium ion concentration in the brine. For A-92, higher $\left[\mathrm{Ca}^{2+}\right]_{\mathrm{s}}$ increases the amount of oil produced by spontaneous imbibition (Fig. 30b) (Yildiz, 1995). Acid and base numbers are not available for A-92, but it is probably a fairly basic oil, judging by the other samples that have been tested from the same reservoir (A-90, A-93, and A-95). Wetting alteration by ST-86 (intermediate acid and base numbers) is almost completely insensitive to brine composition (Fig. 30c) (Jadhunandan, 1990).

\subsubsection{Effect of crude oil composition onwettability alteration}

From the preceding discussion, it is clear that crude oils influence wetting of mineral surfaces by more than one mechanism. Evaluation of the potential for a given oil must therefore consider a balance of several contributing factors. In Fig. 31, the $I_{w}$ data from Table 2, first plotted in Fig. 18, are replotted. Two changes have been made. First, the oils are grouped according to API gravity to take into account their asphaltene solvent properties. Then the ratio of base number to acid number is indicated. Oils, including those from Prudhoe Bay, with high base number and low acid number can alter the wetting of silicate surfaces by acid/base interactions. Those with higher acid number and low base number, of which Moutray is an example, can alter wetting by ion-binding interactions. Poor solvent oils, the best example of which in this group is Lagrave, alter wetting by surface precipitation. 


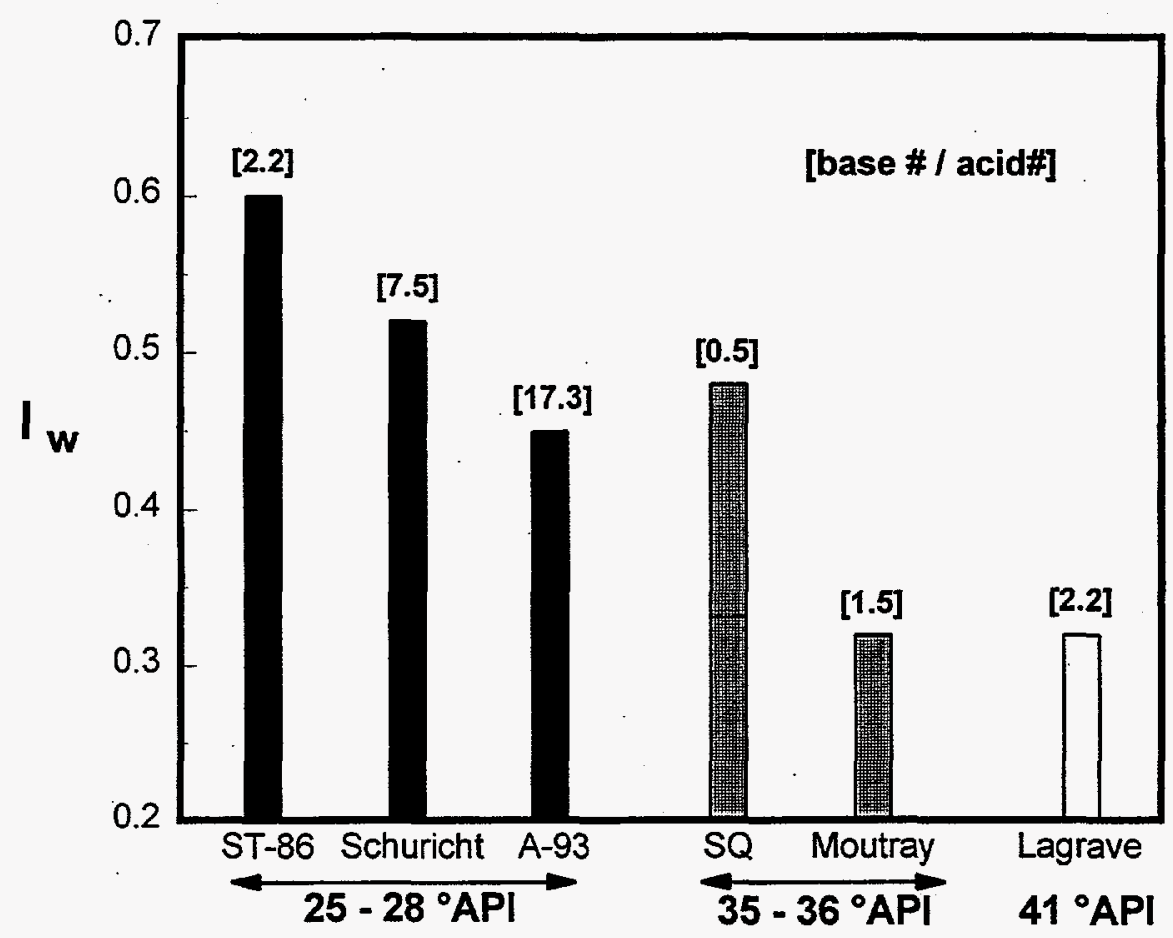

Figure 31 . When crude oils are grouped by API gravity, trends in wetting alteration that depend on acid and base numbers can be differentiated from the effects of oil solvent properties.

Approaching crude oil wetting studies from a mechanistic point of view will help to improve predictive evaluation of the potential for wetting alteration. It will not always be possible to identify individual mechanisms as we have done here for the fairly extreme cases of high acid or base number and poor solvency (i.e., Moutray, Prudhoe Bay, and Lagrave crude oils, respectively). Nonetheless, this mechanistic approach will improve the design of experiments for evaluation of crude oil wetting properties.

\subsection{Asphaltene Precipitation-Onset at Controlled Temperature and Pressure}

Testing oils for asphaltene precipitation at ambient conditions is useful, but it is limited to those oils whose asphaltenes precipitate with a relatively non-volatile precipitant. Fig. 32 shows a series of measurements of $P_{R I}$ with $n$-paraffins of varying chain length. The minimum for $n$ heptane cannot be considered reliable because the rate of evaporation for shorter-chain paraffins is high in these tests at ambient conditions. 


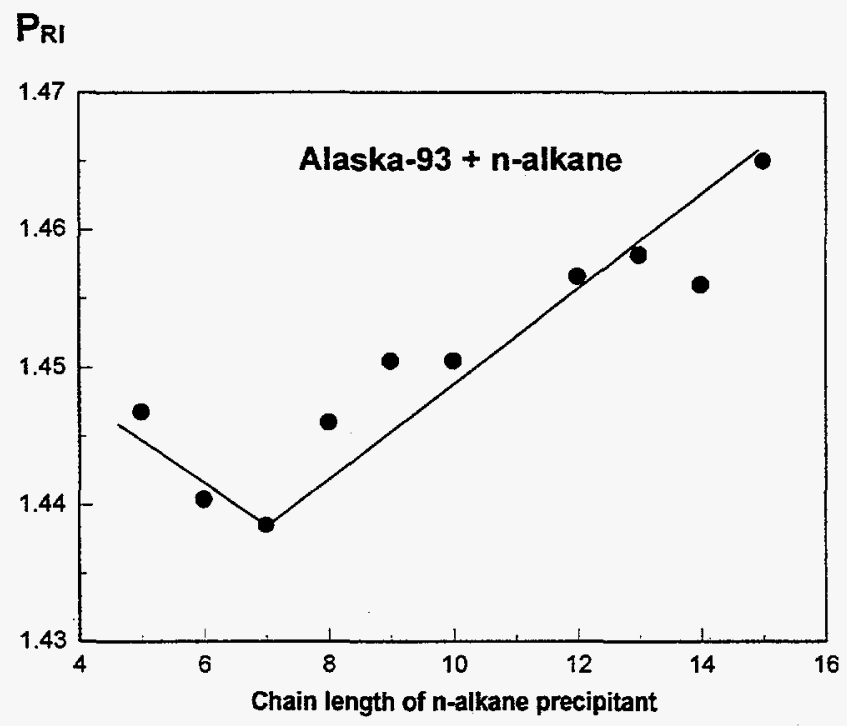

Figure 32. $\mathrm{P}_{\mathrm{RI}}$ of A-93 varies with carbon chain length of $n$-paraffin precipitants. Tests at ambient conditions show a minimum value for $n$-heptane.

More realistic studies, at elevated temperatures and pressures, with volatile components in the oil, are needed. In this section, a study is presented using a specially designed optical cell for observing precipitation onset and a commercially available PVT apparatus for controlling temperature, pressure, and fluid volumes. Volume fractions have been used to calculate approximate RI's by linear interpolation.

\subsubsection{PVT and optical cell design and operation}

A Ruska 2370 mercury-free system was used with minor modifications (Fig. 33). An optical cell with a very small spacing between two parallel glass plates was designed for viewing samples under controlled conditions of temperature and pressure. Details of the optical cell are shown in Fig. 34. The path length is controlled with shims and was estimated to be about 0.010 inches in these tests. The cell was tested to $10,000 \mathrm{psi}$. 


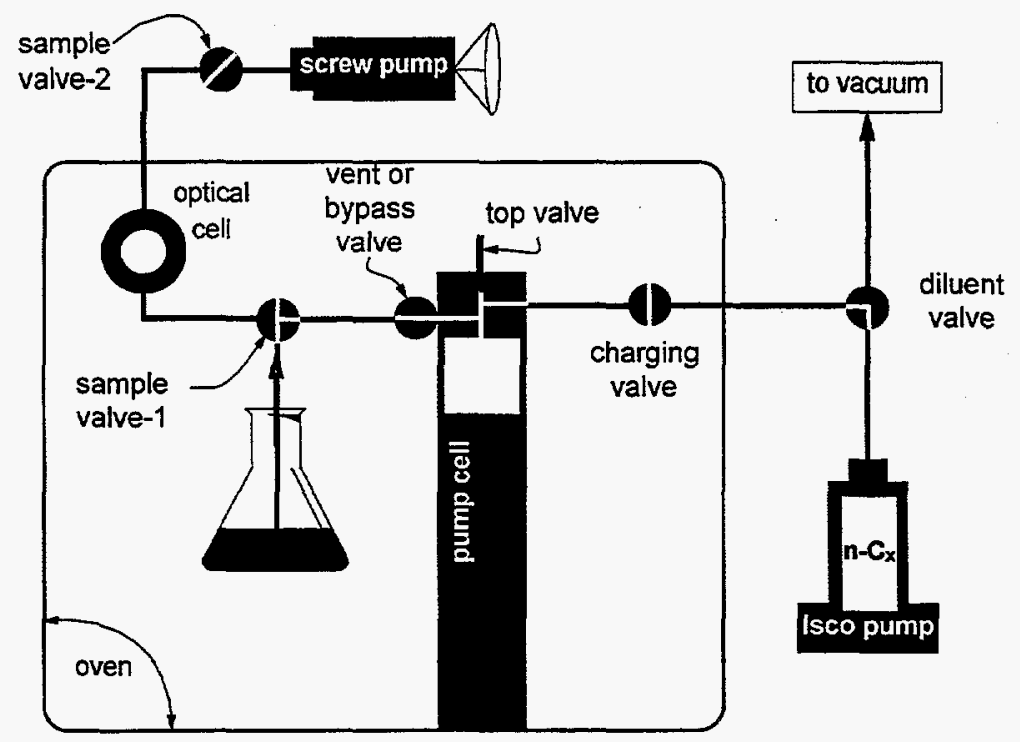

Figure 33. Adapted Ruska 2370 PVT apparatus configured for charging the pump cell with oil. Volume is controlled by movement of the pump cell piston.

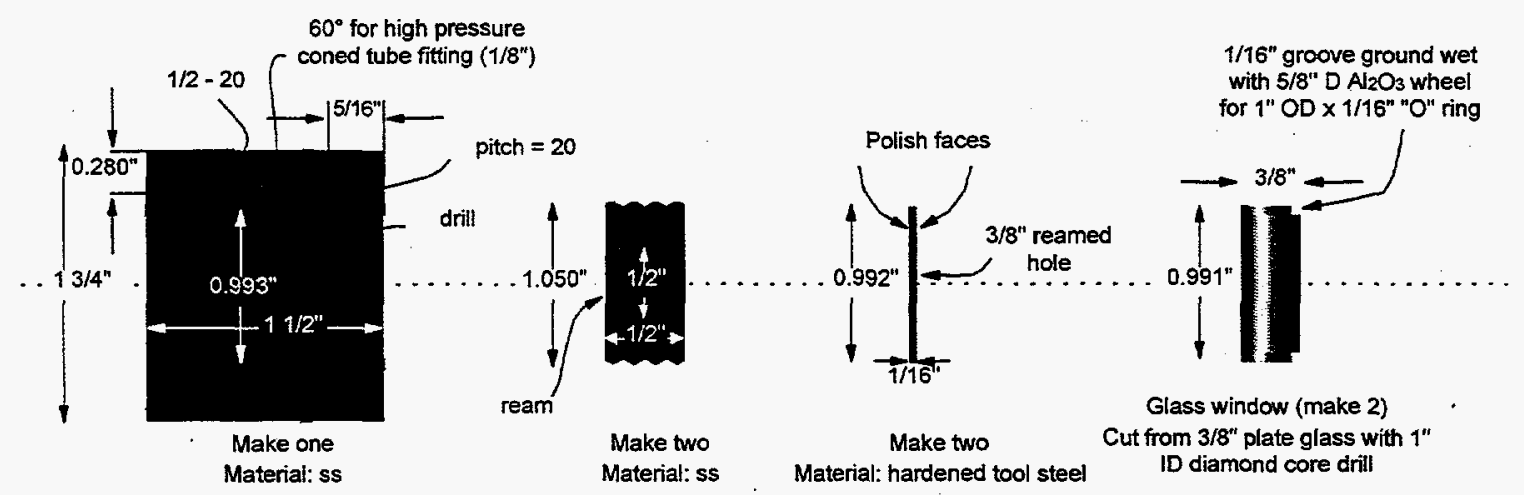

Figure 34. Optical cell designed for observation of oil samples for detection of onset of asphaltene precipitation.

With strong transmitted light, provided by the built-in optic fiber mounted behind the optical cell, adequate visibility was obtained with a $45 \mathrm{X}$ microscope (Edmund Scientific) with a $6.3 \mathrm{~mm}$ field of view and $65 \mathrm{~mm}$ working distance. The optical cell and fiber optic light were mounted on a removable frame just inside the oven door, while the microscope was mounted on a tripod, outside the oven door.

Dead volume calibration: With the pump cell cleaned and at its minimum volume and the top valve open, the cell was charged with nitrogen to an initial pressure $P_{\mathrm{o}}$. The top valve 
was then closed. Using PRESET pump mode, the cell volume was increased in small increments. The volume at the top of the pump cell was found to be $2.23 \mathrm{ml}$.

Charging the pump cell with sample and precipitant: The cell was charged with crude oil (A-93) or with stable mixtures of oil and normal alkanes at ambient temperature and pressure. With the bypass valve and sample valve-1 open, the volume in the pump cell was increased by a predetermined amount. With about $50 \mathrm{ml}$ of oil in the pump cell, the volume was decreased to expel air, the vent valve was closed, pressure was increased to about $100 \mathrm{psi}$, and the volume of oil recorded.

Precipitant was added through the charging valve using a metering pump. Pressure in the pump cell was reduced below that of the Isco pump (i.e. to about 20 to $40 \mathrm{psi}$ ) and the desired amount of precipitant delivered. With the pump cell isolated, the pressure was again increased to $100 \mathrm{psi}$ and a second volume reading was taken. Pressure was then reduced to create a head space of about 5 to $10 \mathrm{ml}$. The contents of the pump cell were mixed for about 20 minutes using the magnetic stirrer included in the PVT apparatus. This mixing procedure was adopted after preliminary tests showed inadequate mixing near the top of the pump cell that resulted in premature appearance of asphaltene particles.

In preliminary tests with A-93 and $n$-pentane $\left(f_{\mathrm{V}, \text { oil }}=0.32\right)$, a bubble point was reached at $\mathrm{T}=93^{\circ} \mathrm{C}$ and $\mathrm{P}=57$ psi. Pressure was raised to about $100 \mathrm{psi}$ after the initial mixing of oil and precipitant and before sampling.

Withdrawal of a sample for observation: The screw pump pressure was matched to the pump cell pressure with both at about $100 \mathrm{psi}$ during the sampling process. This pressure is above the bubble point and compresses any precipitant in the line to the charging valve so that dilution does not occur at the point of sampling. The screw pump can be backed off very slowly. Each turn of the handle corresponds to about $0.4 \mathrm{ml}$ of sample removed from the pump cell, through the optical cell. Four turns $(1.6 \mathrm{ml})$ are required to replace fluids in the sampling lines completely. After sampling and observation, additional precipitant was added, as described above. 
Recharging the pump cell: When a new crude oil sample was to be used, the pump cell and all the lines were completely cleaned. Since all the tests reported here were made with A-93 crude oil, rinsing the pump cell with fresh A-93 was sufficient to reduce the previously used alkane precipitant to trace levels. To accomplish this, the cell was rinsed before recharging by filling and expelling three successive $20 \mathrm{ml}$ aliquots of A-93 crude oil. The pump cell was then recharged with $50 \mathrm{ml}$ of A-93 for the next series of tests.

Time and temperature dependence: The first samples of oil/precipitant mixtures contained no precipitated material. As the volume of precipitant increased, the point of onset was reached. The effect of increased temperature was explored near the onset of precipitation. Temperature was increased until the precipitate disappeared, then decreased and the volume fraction of precipitant was further increased. Appearance and disappearance of precipitated material required as much as several hours to reach a stationary state.

\subsubsection{Results at controlled temperature and pressure}

The results of this study confirm that the onset of asphaltene precipitation can be quantified under controlled conditions of temperature and pressure by microscopic observation. Experimental measurements have been made with one crude oil sample (A-93), three alkanes ( $n$ pentane, $n$-hexane, and $n$-heptane), and temperatures varying from 10 to $60^{\circ} \mathrm{C}$. The volume fractions at the onset of precipitation at ambient temperature and $100 \mathrm{psi}$ are summarized in Table 5:

Table 5. Onset of Precipitation from A-93 Crude Oil and Paraffinic Precipitants

\begin{tabular}{|c|c|}
\hline precipitant & $\mathrm{f}_{\mathrm{V}, \text { oil }}$ at onset \\
\hline$n$-pentane & 0.439 \\
$n$-hexane & 0.435 \\
$n$-heptane & 0.428 \\
\hline
\end{tabular}

\subsubsection{Comparison to ambient conditions tests}

The onset of precipitation for A-93 crude oil with $n$-heptane at ambient conditions was observed at a volume fraction of oil, $\mathrm{f}_{\mathrm{V}, \mathrm{oil}}=0.431$ and $\mathrm{RI}$ at the onset, $\mathrm{P}_{\mathrm{RI}}=1.446$. Using the 
PVT apparatus, $\mathrm{f}_{\mathrm{V} \text {,oil }}=0.428$ at the onset of precipitation with the same fluids. This shows excellent agreement, with a difference in the volume fractions of only 0.003 .

RI can be calculated by linear interpolation using the RI values of the $n$-paraffins and the volume fractions at onset. These calculated values are shown in Fig. 35 for comparison with the results shown previously (Fig. 32) for A-93 crude oil precipitation induced by $n$-paraffins of varying carbon chain length. The PVT results show that the previously observed minimum in $\mathrm{P}_{\mathrm{PU}}$ at $n$-heptane was an artifact caused by increasing volatility of the precipitants as carbon chain length decreases. When evaporation does not occur, $P_{R I}$ is shown to be an increasing function of precipitant molecular weight.

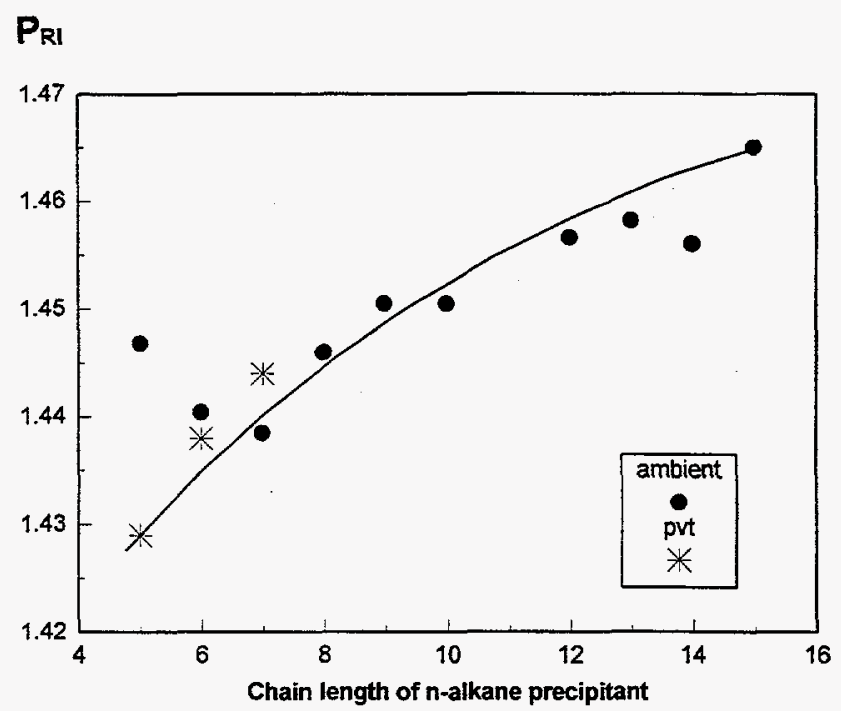

Figure 35. Comparison of ambient and PVT results for onset of precipitation from A-93 crude oil as a function of carbon chain length of the precipitant.

\subsubsection{Rate and reversibility of asphaltene precipitate formation}

Asphaltenes do not appear or disappear immediately. Recommended procedures (ASTM, 1980) recognize that some period of time must be specified, and there are other reports in the literature that demonstrate time-dependent effects. Whether or not precipitation is reversible is a matter of considerable debate. The adapted PVT apparatus is well suited for observations over extended periods of time at constant composition, temperature, and pressure. Some observations near the onset of precipitation have been made to establish the temperature at which the precipitate disappears. The main results are summarized in Table 6 and plotted in Fig. 36. This 
study has thus demonstrated that the appearance of asphaltenes is reversible, at least near the onset.

\begin{tabular}{|cc|cc|cc|}
\hline \multicolumn{6}{|c|}{$\begin{array}{c}\text { Table 6. Disappearance Temperatures for Mixtures of } \\
\text { Paraffins and A-93 Near Onset of Precipitation }\end{array}$} \\
\hline \multicolumn{2}{|c|}{$n$-pentane } & \multicolumn{2}{|c|}{$n$-hexane } & \multicolumn{2}{c|}{$n$-heptane } \\
$\mathrm{f}_{\mathrm{V}, \text { oil }}$ & $\mathrm{T}^{\circ} \mathrm{C}$ & $\mathrm{f}_{\mathrm{V}, \text { oil }}$ & $\mathrm{T}^{\circ} \mathrm{C}$ & $\mathrm{f}_{\mathrm{V}, \text { oil }}$ & $\mathrm{T}^{\circ} \mathrm{C}$ \\
\hline 0.439 & 37 & 0.435 & 31 & 0.428 & 32 \\
0.430 & 46 & 0.425 & 42 & 0.419 & 41 \\
0.425 & 51 & 0.410 & 50 & 0.409 & 48 \\
0.414 & 59 & & & 0.398 & 52 \\
\hline
\end{tabular}

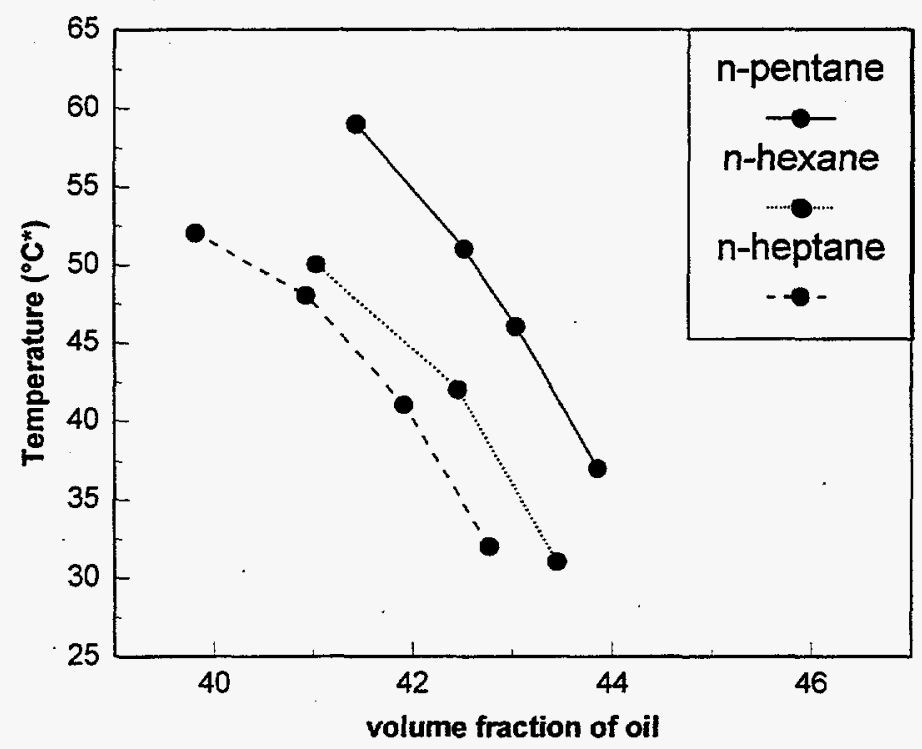

Figure 36. Asphaltene precipitation is reversible near the onset point. Temperatures at which particles disappear depends on composition and on precipitant.

The first line of data in Table 6 shows the mixtures that are closest to onset at room temperature for each precipitant. These were sampled after 20 minutes of mixing, then allowed to age overnight. At the beginning of the aging period, very small particles were generally visible. After ten hours of aging, more elaborate, extensive structures had developed. At this point, the oven temperature was increased incrementally until the precipitate disappeared completely. 
The remaining data points were obtained by cooling the sample to room temperature (or even lower, 10 to $20^{\circ} \mathrm{C}$ ), adding another aliquot of precipitant, then completing the process by mixing, and aging. When precipitation is observed, the incremental heating steps are resumed. In all cases, the temperature required to produce a precipitate-free solution increased as the amount of precipitant in the mixture increased. It also appears that range of temperature over which asphaltenes disappear increases. The final temperature appeared to be influenced by the aging time during which asphaltenes continued to form.

As the composition and temperature change, so does the rate of asphaltene precipitation. When the RI of the mixture is well below $\mathrm{P}_{\mathrm{RI}}$, precipitation can proceed more quickly. In that case, particles can be seen while the mixture is moving through the visual cell, but they aggregate and settle rapidly under the influence of gravity in the vertically oriented optical cell. In mixtures closer to the onset, particles do not settle to the bottom of the cell.

The trends shown in Fig. 36 can be compared with the results of similar studies reported by Fuhr et al. (1991) on the onset of precipitation from a waxy North Sea crude oil. Asphaltenes were detected using a fiberoptics near-infrared probe. Precipitant was added to a $25 \mathrm{~g}$ sample of oil at a rate of $2 \mathrm{ml} / \mathrm{min}$. A minimum in absorbance was judged to indicate the onset of precipitation.

Fuhr et al. report that the volume of precipitant required to reach the onset of precipitation decreased with increasing temperature. Our results show the opposite: at higher temperatures, larger volumes of precipitant are required for precipitate to be observed. Addition of precipitant at a fixed rate of roughly $10 \%$ of the sample volume per minute probably does not allow sufficient time for asphaltene aggregates to grow to detectable size. This method would tend to overestimate the volume of precipitant required to initiate precipitation.

If aggregation occurs more rapidly at higher temperature, the tendency to overshoot the onset point might be less serious, and thus may account for the decrease in volume observed at higher temperatures. If so, the lower temperature results reported by Fuhr et al. substantially overestimate the stability of the oil (i.e. the amount of precipitant required to initiate precipitation is overestimated). 
The effect of pressure is another question that can be studied by the experimental methods described here. Only one such test was conducted in this preliminary series of tests: a mixture of $40 \%$ oil and $60 \% n$-pentane at $78^{\circ} \mathrm{C}$ that was clear of any asphaltene precipitate at 100 psi was examined at elevated pressures. Pressure increments from 1000 psi up to 3000 psi were sustained for $20 \mathrm{~min}$, followed by further incremental increases to 4000 and 5000 psi for $10 \mathrm{~min}$ each. The solution in the optical cell became much darker at the highest pressures; no aggregation was observed. The results of Carnahan et al. (1993) showed that aggregate size decreases with increasing pressure in near-critical mixtures. It would be of interest to determine whether disappearance of the aggregate would be observed with increasing pressure. Further tests are underway using more volatile precipitants at higher pressures and temperatures. 


\section{PART 2. WETTABILITY ASSESSMENT}

\subsection{Interactions of Prudhoe Bay Crude Oil with Mica Surfaces}

\subsubsection{Mica surfaces}

Micas are a group of silicate minerals that have planar structures and are characterized by perfect basal cleavage. One such mineral, muscovite, has a three-layered aluminosilicate structure in which two tetrahedral silicate layers condense onto the $\mathrm{AlO}_{6}$ octahedral layer (Fig. 37). The mica group is divided into subgroups on the basis of the octahedrally coordinated cations. If all three octahedra are occupied by cations at their centers, the sheet is said to belong to the trioctahedral group. If only two of the three available octahedral sites are filled and the third octahedron is vacant, the mineral is a member of the dioctahedral group (Bailey, 1984).

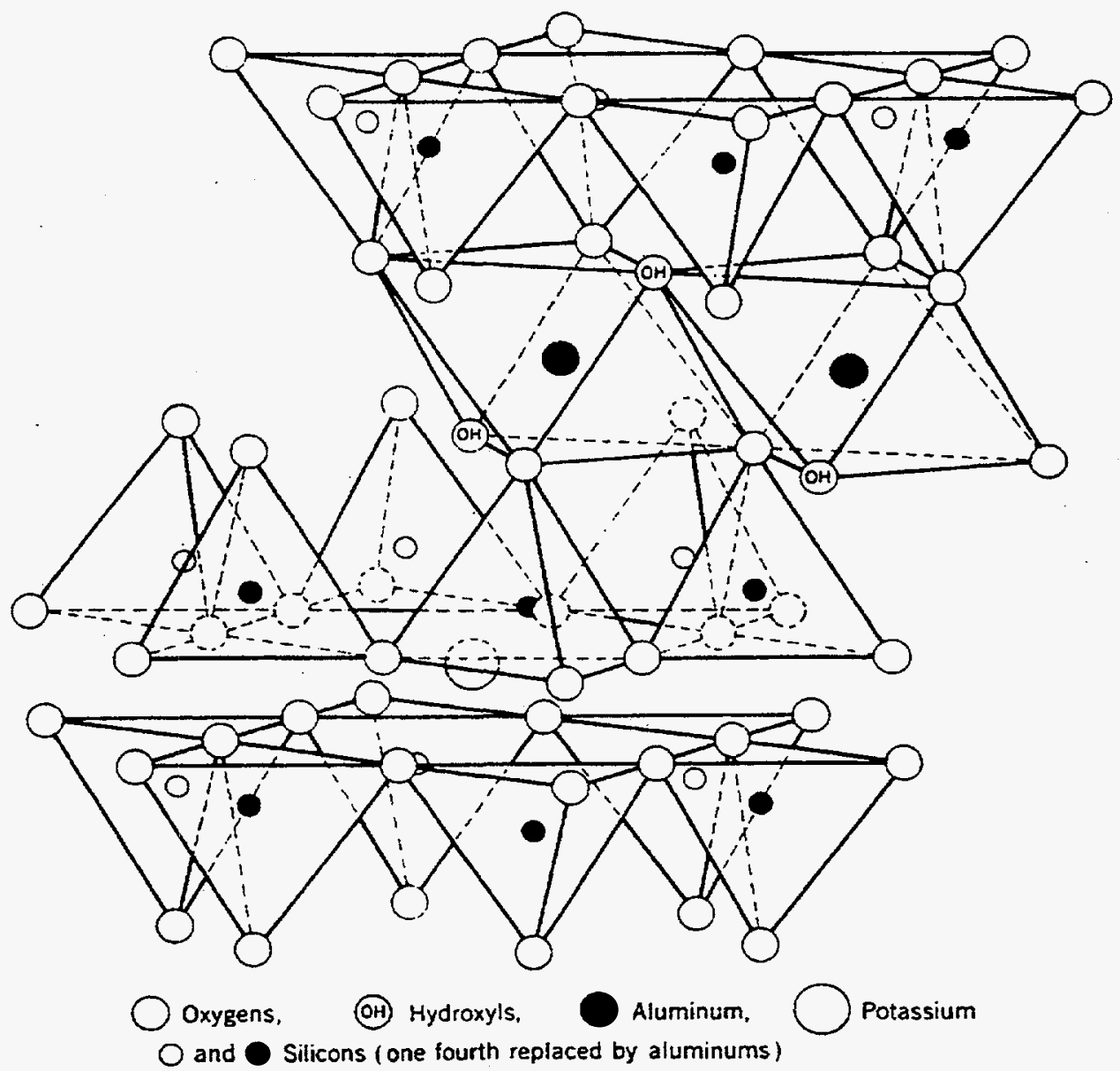

Figure 37. Layered structure of muscovite (after Grim, 1953). 
Various isomorphous replacements can occur in the mica framework. Substitution of $\mathrm{Al}^{3+}$ for $\mathrm{Si}^{4+}$ is the main mechanism by which the mica structure becomes charged (with one negative charge for each $\mathrm{Al}^{3+}$ ). Additional substitution can occur, as in biotite, where $\mathrm{Al}^{3+}$ is replaced by $\mathrm{Fe}^{3+}$ in the tetrahedral layers. In addition, small cations, such as $\mathrm{Mg}^{2+}$ and $\mathrm{Fe}^{2+}$ may replace $\mathrm{Al}^{3+}$ in the octahedral layer-with no alteration in framework charge-to change dioctahedral micas (e.g., muscovite) to trioctahedral ones (e.g., biotite). Solid solution from muscovite toward biotite follows the reaction $2 \mathrm{Al}^{3+}=3\left(\mathrm{Mg}^{2+}, \mathrm{Fe}^{2+}\right)$ (Griffen, 1992).

The resultant negative charge of the triple mica sheets is high. A surface charge density of $2.1 \times 10^{18}$ sites $/ \mathrm{m}^{2}$ has been reported for muscovite (Chen et al., 1992). In muscovite, the negative charge is neutralized by potassium ions between pairs of sheets. These interlayer ions have a very high exchange capacity with electrolyte ions in aqueous solution.

\subsubsection{Experimental materials and methods}

\section{$\underline{\text { Materials }}$}

Crude oil: Table 7 summarizes the properties of the Alaska-93 crude oil sample used in this study.

\begin{tabular}{|c|c|c|c|c|c|c|}
\hline \multicolumn{7}{|c|}{ Table 7. Crude Oil Properties } \\
\hline Oil & $\begin{array}{c}\text { Gravity } \\
\text { (API) }\end{array}$ & $\begin{array}{c}\text { Base \# } \\
(\mathrm{mg} \mathrm{KOH} / \mathrm{g})\end{array}$ & $\begin{array}{c}\text { Acid \# } \\
(\mathrm{mg} \mathrm{KOH} / \mathrm{g})\end{array}$ & $\begin{array}{c}\text { Density at } \\
25^{\circ} \mathrm{C} \\
(\mathrm{g} / \mathrm{ml})\end{array}$ & $\begin{array}{c}\text { Viscosity } \\
\text { at } 25^{\circ} \mathrm{C} \\
(\mathrm{mPa} . \mathrm{s})\end{array}$ & $\begin{array}{c}\text { Asphaltenes } \\
\text { ppt with } n \text { - } \mathrm{C}_{5} \\
(\%)\end{array}$ \\
\hline $\begin{array}{c}\text { Alaska-93 } \\
\text { (Prudhoe Bay) }\end{array}$ & 25.5 & 2.42 & 0.14 & 0.8945 & 26.7 & 10.9 \\
\hline
\end{tabular}

Brines: The chemicals used for buffer preparation were $\mathrm{NaC}_{2} \mathrm{H}_{3} \mathrm{O}_{2} \cdot 3 \mathrm{H}_{2} \mathrm{O}$ and glacial acetic acid for $\mathrm{pH} 4, \mathrm{Na}_{2} \mathrm{HPO}_{4} \cdot 7 \mathrm{H}_{2} \mathrm{O}$ and $\mathrm{NaH}_{2} \mathrm{PO}_{4} \cdot \mathrm{H}_{2} \mathrm{O}$ for $\mathrm{pH} 6$ and $\mathrm{pH} 8$ solutions. $\mathrm{NaCl}$ was used for salinity adjustment, and $100 \mathrm{ppm}$ sodium azide were added to all buffered solutions to prevent bacterial growth. High salinity $(2 M)$ solutions were not buffered; $\mathrm{pH}$ was adjusted with acetic acid and sodium hydroxide. The measured $\mathrm{pH}$ for buffer solutions of varying salinity are summarized in Table 8. 
Table 8. pH and Salinity of Aqueous Solutions

\begin{tabular}{|c|c|c|c|c|}
\hline Nominal $\mathrm{pH}$ & {$\left[\mathrm{Na}^{+}\right]=0.01 M$} & {$\left[\mathrm{Na}^{+}\right]=0.1 M$} & {$\left[\mathrm{Na}^{+}\right]=1.0 M$} & $\begin{array}{c}{\left[\mathrm{Na}^{+}\right]=2.0 M} \\
\text { (unbuffered) }\end{array}$ \\
\hline 4 & 4.19 & 4.08 & 3.86 & 3.98 \\
6 & 6.30 & 6.12 & 5.59 & 5.46 \\
8 & 8.17 & 8.10 & 7.65 & 7.90 \\
10 & - & - & - & 9.82 \\
\hline
\end{tabular}

Mica surfaces: Two mica minerals, muscovite and biotite, were used in this study. Characteristics of the samples (from Ward's Natural Science Establishment, Inc.) are shown in Table 9.

\begin{tabular}{|c|c|c|c|c|}
\hline \multicolumn{5}{|c|}{ Table 9. Properties of Mica Samples } \\
\hline Mineral & Composition & Crystallography & Physical Description & Deposit \\
\hline Muscovite & $\mathrm{KAl}_{2}\left(\mathrm{Si}_{3} \mathrm{Al}\right) \mathrm{O}_{10}(\mathrm{OH}, \mathrm{F})_{2}$ & Monoclinic, 2/m & $\begin{array}{c}\{001\} \text { perfect cleavage } \\
\text { colorless, transparent }\end{array}$ & Stoneham Maine \\
\hline Biotite & $\begin{array}{c}\mathrm{K}\left(\mathrm{Mg}_{2} \mathrm{Fe}^{2+}\right)_{3}\left(\mathrm{Al}, \mathrm{Fe}^{3+}\right) \\
\mathrm{Si}_{3} \mathrm{O}_{10}(\mathrm{OH}, \mathrm{F})_{2}\end{array}$ & Monoclinic, 2/m & $\begin{array}{c}\{001\} \text { perfect cleavage } \\
\text { dark, smoky color } \\
\text { transparent to translucent }\end{array}$ & Bancroft Ontario \\
\hline
\end{tabular}

Figure 38 shows the X-ray diffraction patterns of samples of muscovite and biotite. Comparison with the JADE-PDF Card shows that the mica sheets exhibit very strong c-axis orientation, indicating that the sheets cleave parallel to the $\{001\}$ cleavage plane. 

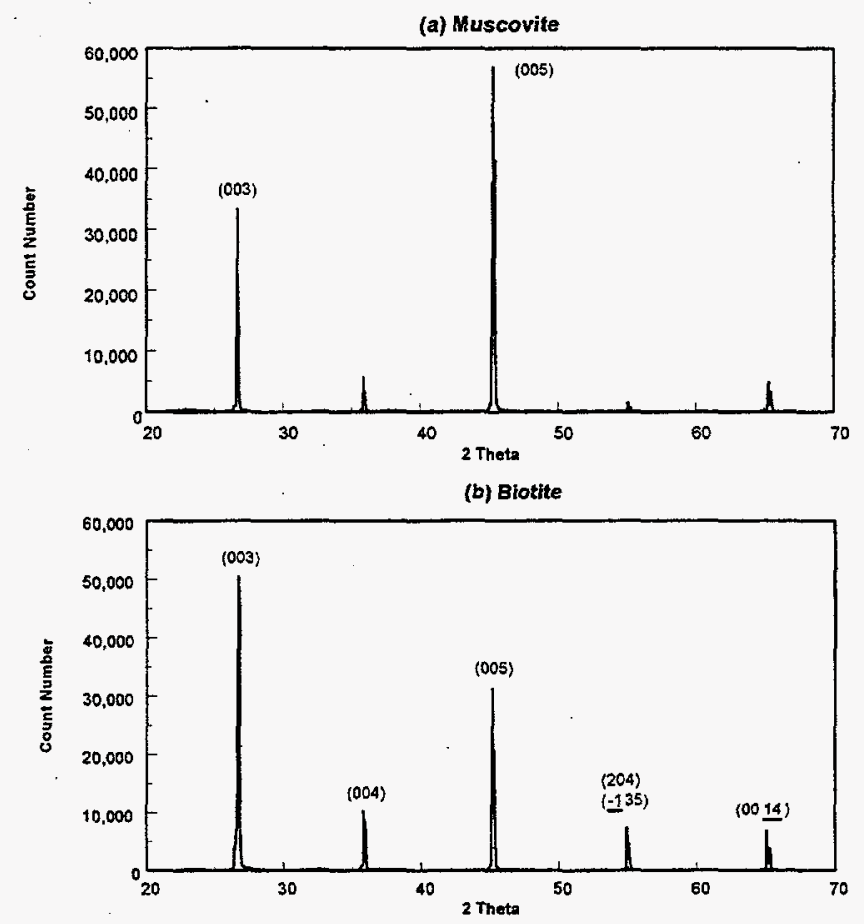

Figure 38. X-ray diffraction patterns of muscovite and biotite.

Although natural mica sheets are theoretically homogeneous and smooth, they do not always appear to be perfect. In the case of muscovite, some pieces look very smooth and highly transparent; others are not completely transparent. Some of the biotite samples are curved. Individual mica samples can appear to be rough, although whether the macroscopic roughness extends to the microscopic level is not clear. X-ray diffraction patterns comparing smooth and rough samples show no obvious differences. Macroscopically smooth surfaces have been selected for wetting measurements, except where noted.

Selected mica pieces were carefully cleaved and rinsed with double-distilled water immediately prior to use. The freshly cleaved and washed mica pieces were immersed in selected brines at room temperature and soaked for 12 to 48 hours. During this period, $\mathrm{K}^{+}$ exchanges with cations in the aqueous phase.

\section{Characterizing crude oil-treated surfaces}

Previously developed adhesion and adsorption test procedures have been used to evaluate the effects of adsorption from crude oil on mica surfaces (Liu, 1993). Figure 39 summarizes the steps involved in treating and testing mica surfaces. 


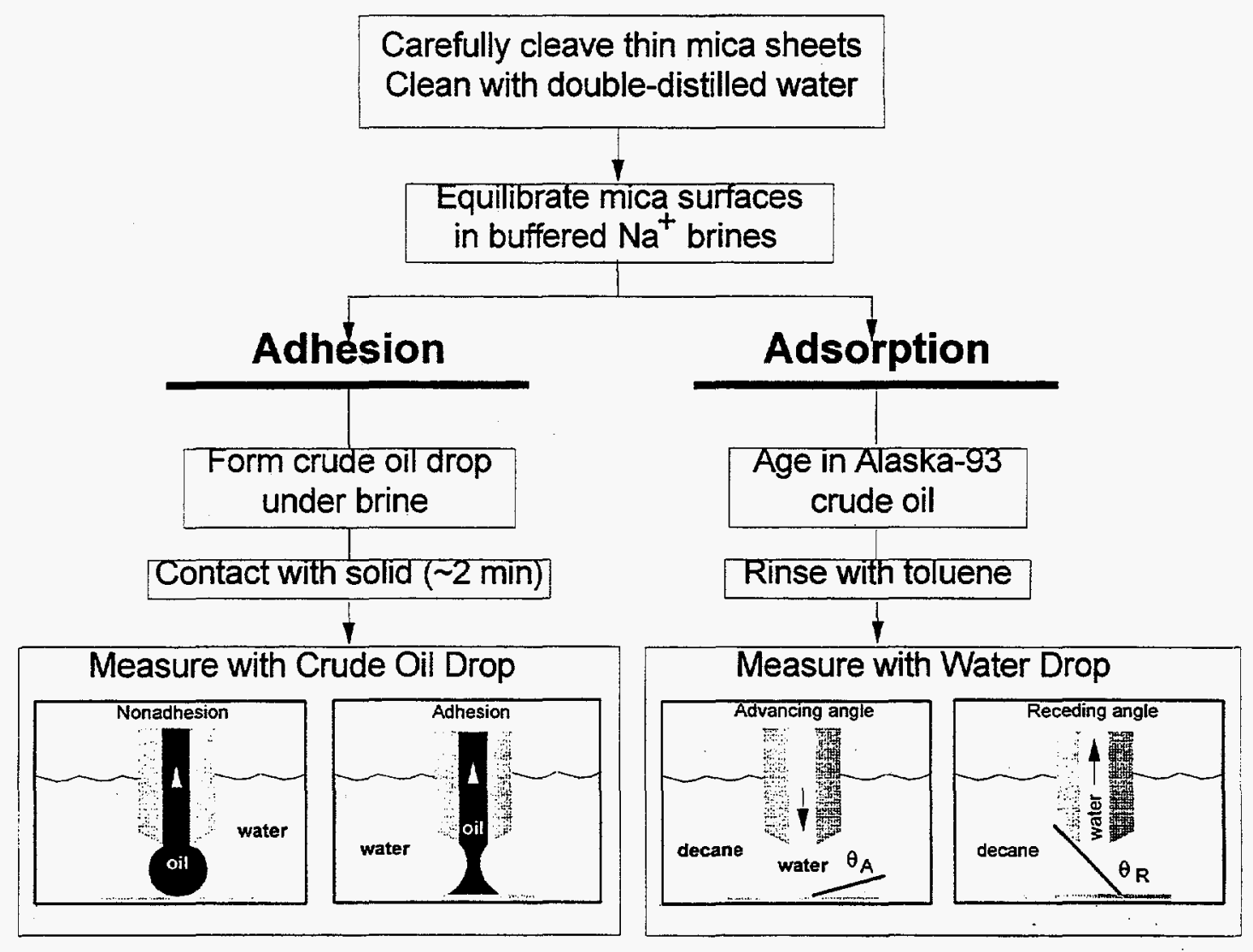

Figure 39. Adhesion and adsorption test sequences.

For the adhesion tests, ion-exchanged mica surfaces were transferred to a quartz glass cuvette filled with brine of the same composition as that used in the preequilibration step. A microburet filled with the Alaska-93 crude oil was used to form captive drops of oil which were in contact with the brine-covered mica surface. After two minutes of contact, the drop was retracted and adhesion observations recorded according to standard procedures.

Longer exposure times were also studied with freshly prepared, ion-exchanged mica surfaces. In these experiments, selected pieces of mica were removed from the brine and immersed wet into the crude oil. The aging period under oil varied from one hour to 48 days at aging temperatures of 25 and $80^{\circ} \mathrm{C}$. After aging, mica samples were removed from the oil, rinsed with toluene, and immersed in decane. Contact angles measured with distilled water are reported for the average of at least two mica sheets with 4 to 10 measurements per sheet. 


\subsubsection{Results and discussion}

\section{Standard adhesion tests}

Adhesion was measured with a standard set of brines ( $\mathrm{pH} 4$ to $8, \mathrm{I}=0.01$ to $1.0 \mathrm{M}$ ) at 25 and $80^{\circ} \mathrm{C}$. Drops of Alaska-93 crude oil adhere to the mica surface mainly at low $\mathrm{pH}$, as shown in Fig. 40. No differences were observed between muscovite and biotite mica samples in the adhesion tests. The results in Fig. $\mathbf{4 0}$ were obtained for both of these mineral surfaces.

(a) A-93/NaCl brine/mica adhesion map at $25^{\circ} \mathrm{C}$

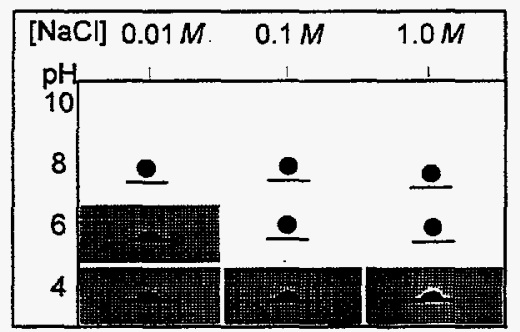

(b) A-93/ $\mathrm{NaCl}$ brine/mica adhesion map at $80^{\circ} \mathrm{C}$

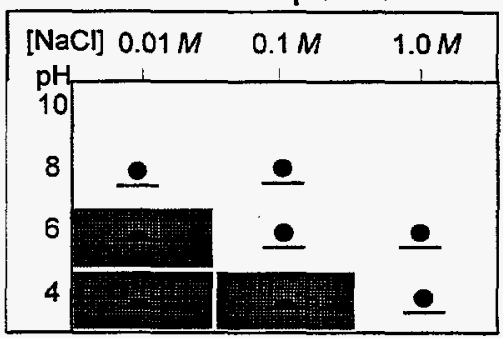

Figure 40. Adhesion of Alaska-93 crude oil on mica surfaces.

The adhesion of Alaska-93 on mica as a function of $\mathrm{pH}$, ionic strength, and temperature can be compared to previously reported tests on glass surfaces with the same conditions (Fig. 41). A comparison of Figs. $\mathbf{4 0}$ and $\mathbf{4 1}$ shows that adhesion on mica is similar to adhesion on glass. The adhesive regions are somewhat smaller for the mica surfaces at both temperatures. The tendency is for the lowest $\mathrm{pH}$ and lowest ionic strengths to be adhesive on both surfaces. Only $\mathrm{pH} 4, \mathrm{I}=1 \mathrm{M}$ changed from adhesive to nonadhesive with increasing temperature in the mica tests; the size of the adhesive region on glass was substantially reduced with increasing temperature.

(a) A-93/NaCl brine/glass adhesion map at $25^{\circ} \mathrm{C}$

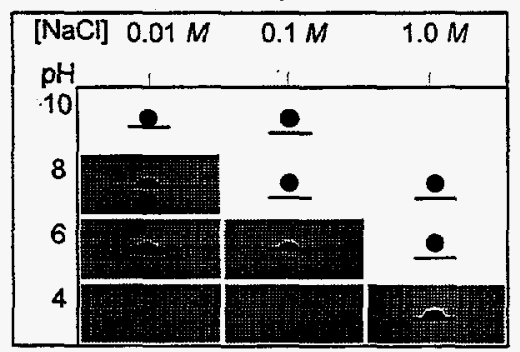

(b) A-93/NaCl brine/glass adhesion map at $80^{\circ} \mathrm{C}$

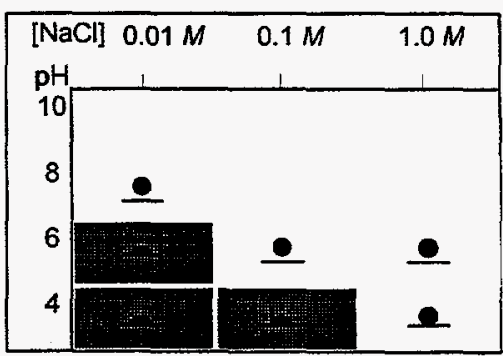

Figure 41. Adhesion of Alaska-93 crude oil on glass surfaces (after Buckley et al, 1997). 


\section{Changing wetting by adsorption}

Contact angles between water and decane were measured on mica surfaces (both muscovite and biotite) treated with the standard range of $\mathrm{NaCl}$ brines ( $\mathrm{pH} 4$ to 8 , ionic strengths from 0.01 to $1 \mathrm{M}$ ) and after aging times in oil as short as one hour and as long as 48 days. The samples were aged at temperatures of 25,60 , or $80^{\circ} \mathrm{C}$.

\section{Reproducibility of contact angle measurements}

There is considerable scatter in contact angle measurements on mica, as has been observed previously for glass surfaces (Liu, 1993). Figure 42 shows advancing and receding contact angles between decane and distilled water on muscovite surfaces. These surfaces were treated first with a pH 4, $0.1 \mathrm{M} \mathrm{NaCl}$ solution for 8 hours, then aged in Alaska-93 crude oil at room temperature for times ranging from 1 hour to 34 days. The shaded areas indicate the standard deviations of the contact angle measurements. These large standard deviations quantify the scatter in the measured angles from one point to another on each piece of mica exarnined. Figure 43 shows the same data plus a second, replicate test. In the second test, the preequilibration time was increased to 24 hours; otherwise, the tests were identical. Good agreement was obtained between these two tests, especially after about 3 weeks of aging in oil.

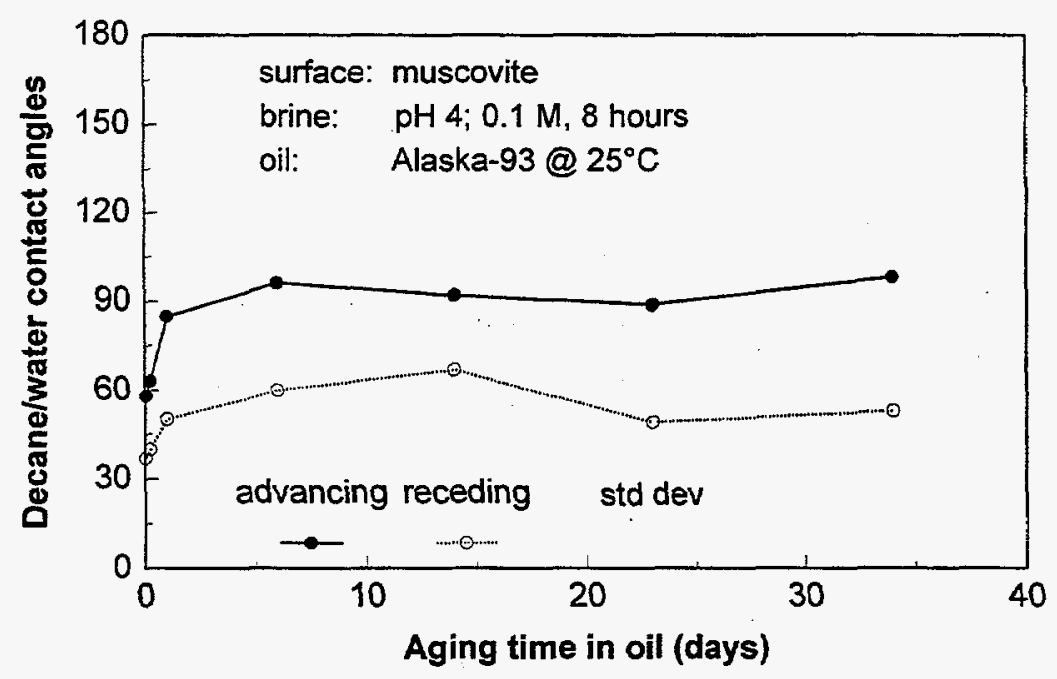

Figure 42. Decane/water advancing and receding contact angles measured on brine and crude oiltreated muscovite. 


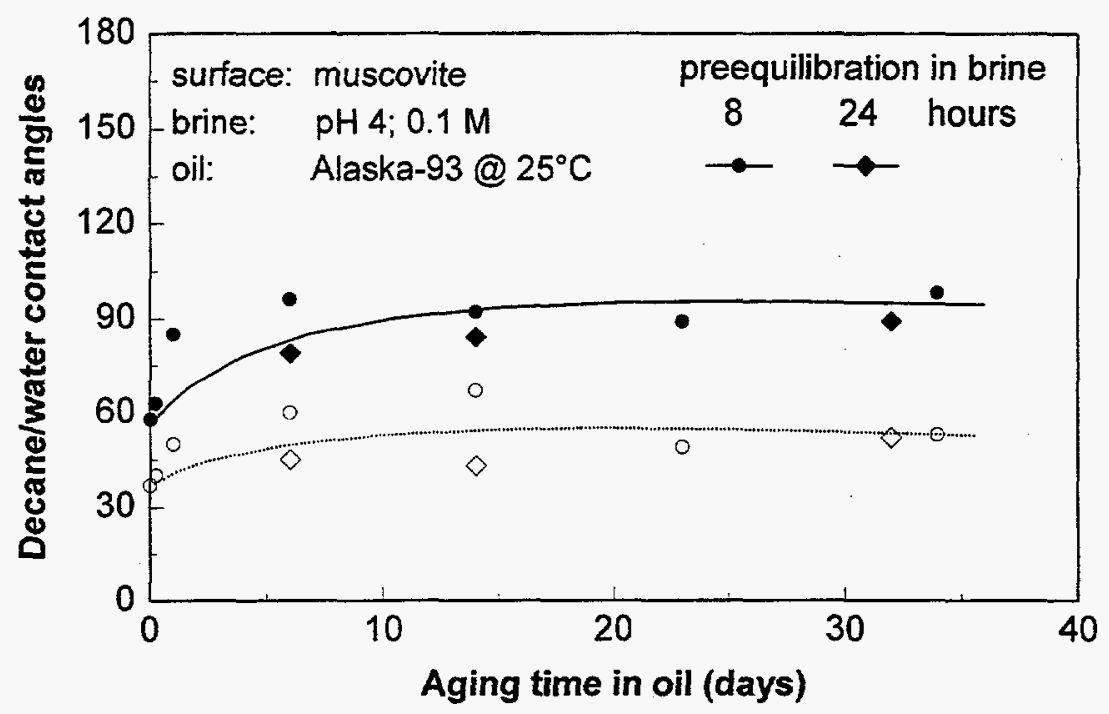

Figure 43. Repeatability of treatments.

\section{Adsorption on two mica minerals: muscovite and biotite}

Decane/water contact angles on muscovite and biotite mica surfaces after pretreatment with $\mathrm{pH} 4,0.1 \mathrm{M} \mathrm{NaCl}$ and aging in Alaska-93 at $25^{\circ} \mathrm{C}$ are shown in Fig. 44. The results are similar for the two types of mica surface, with consistently higher angles measured for biotite. Given the scatter in individual measurements, it is difficult to say whether this difference is really significant. No measurable differences were observed in adhesion properties for the muscovite and biotite samples.

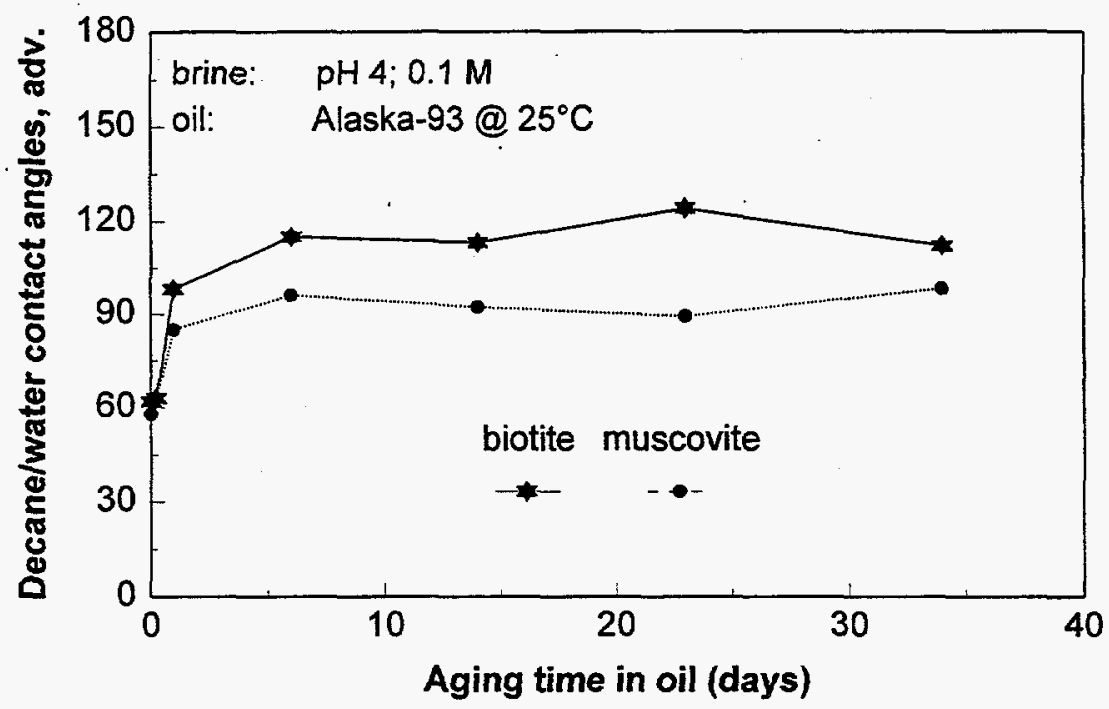

Figure 44. Comparison of contact angles on treated muscovite and biotite surfaces. 


\section{Effect of aging time in crude oil}

Changes in decane/water contact angles with aging time appear to follow the two-stage: evolution reported previously for glass surfaces, similarly treated with brine and oil (Liu and Buckley, 1997). In Fig. 45, the data shown in Fig. 44 are replotted as a function of the log of aging time in oil, to show more clearly the early time measurements. There is an immediate increase from initial water-wetting to about 60 degrees. Further changes occur more slowly until. a plateau value is reached. During the slower stage, contact angles may either increase, as in Fig. 45, or decrease as shown in Fig. 46.

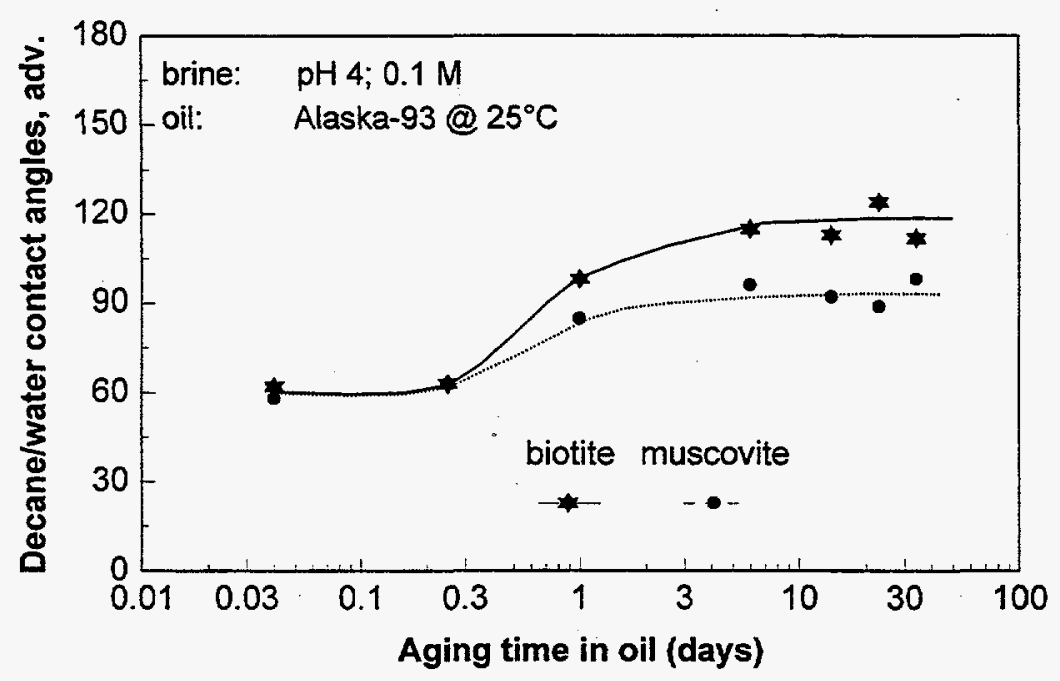

Figure 45. Effect of aging time for surfaces aged at $25^{\circ} \mathrm{C}$.

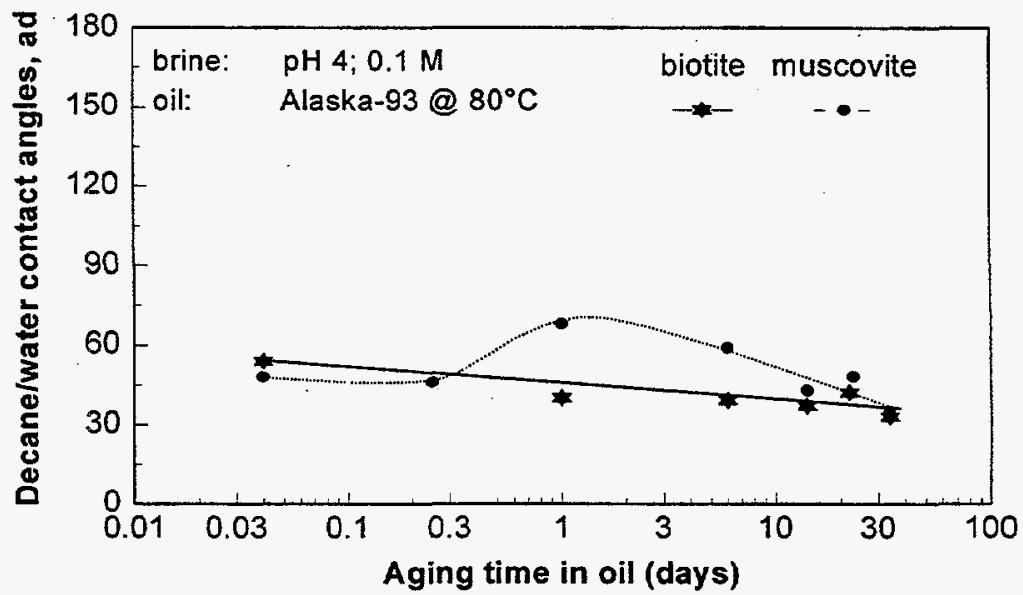

Figure 46. Effect of aging time for surfaces aged at $80^{\circ} \mathrm{C}$. 


\section{Effect of macroscopic surface roughness}

As mentioned in the experimental section, the apparent smoothness of individual mica samples varied. This was particularly true of the biotite samples. In general, samples that appeared to be smooth were selected for testing, but the question of the effect of macroscopic roughness was also investigated by deliberately choosing some rough samples for direct comparison. Figure 47 shows no consistent difference in contact angles between smooth and rough surfaces for either muscovite or biotite using surfaces pretreated with $\mathrm{pH} 4,0.1 \mathrm{M} \mathrm{NaCl}$, then aged at 25 or $80^{\circ} \mathrm{C}$ in crude oil.
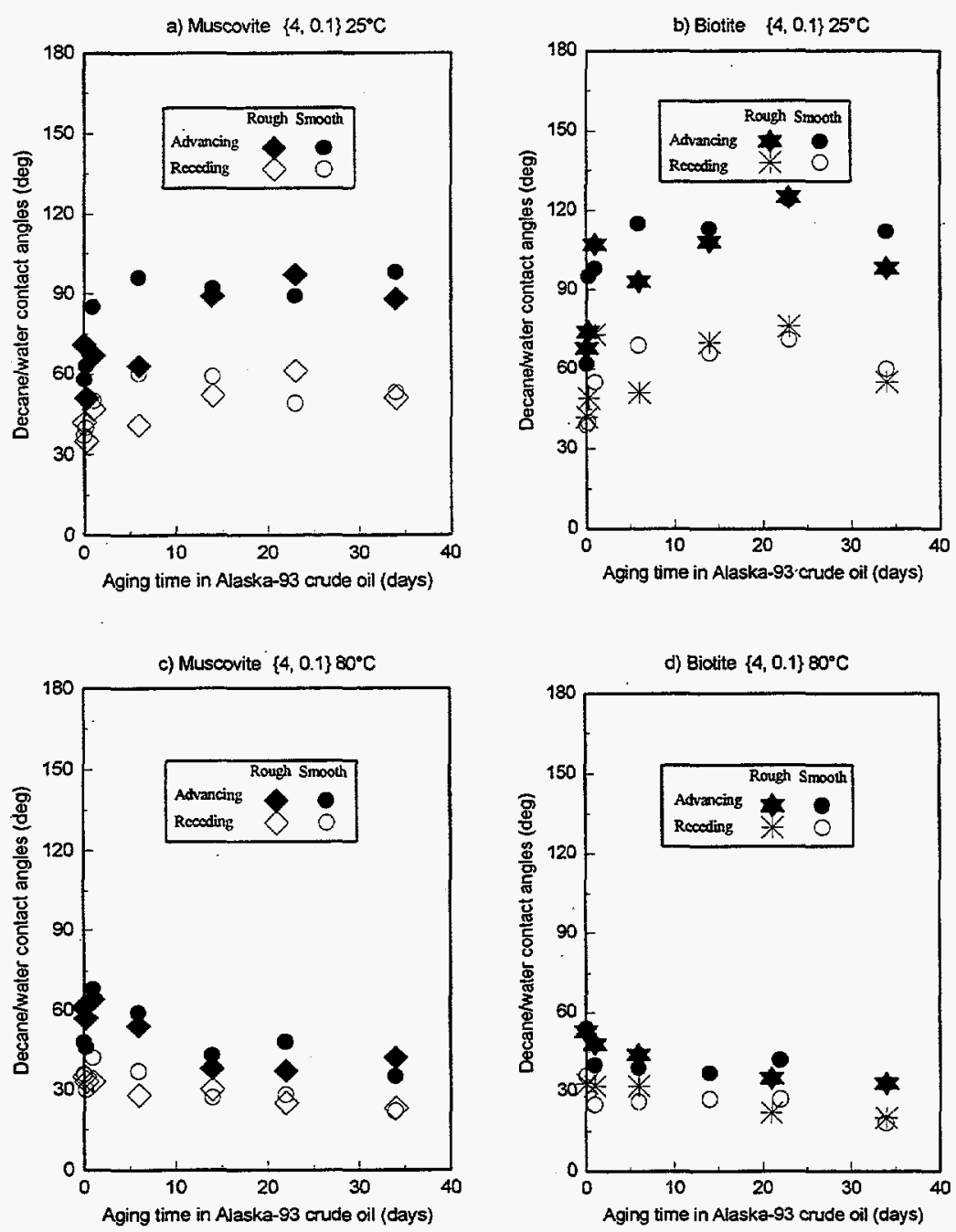

Figure 47. Effects of macroscopic roughness on contact angles. 


\section{Brine composition effects}

The effects of both $\mathrm{pH}$ and ionic strength are summarized in Fig. 48. For each brine, two aging times are shown, 1 hour and approximately 20 days. Several observations can be made from the data shown in Fig. 48. Higher advancing angles are generally found on surfaces pretreated with $\mathrm{pH} 4$ brines, especially at the lowest ionic strength; this agrees well with previous results on glass surfaces. There are few differences of any significance between muscovite and biotite samples. For most brine pretreatments, interactions occur quickly. Differences between the 1-hour and 20-day data are generally less than have been observed for glass surfaces.
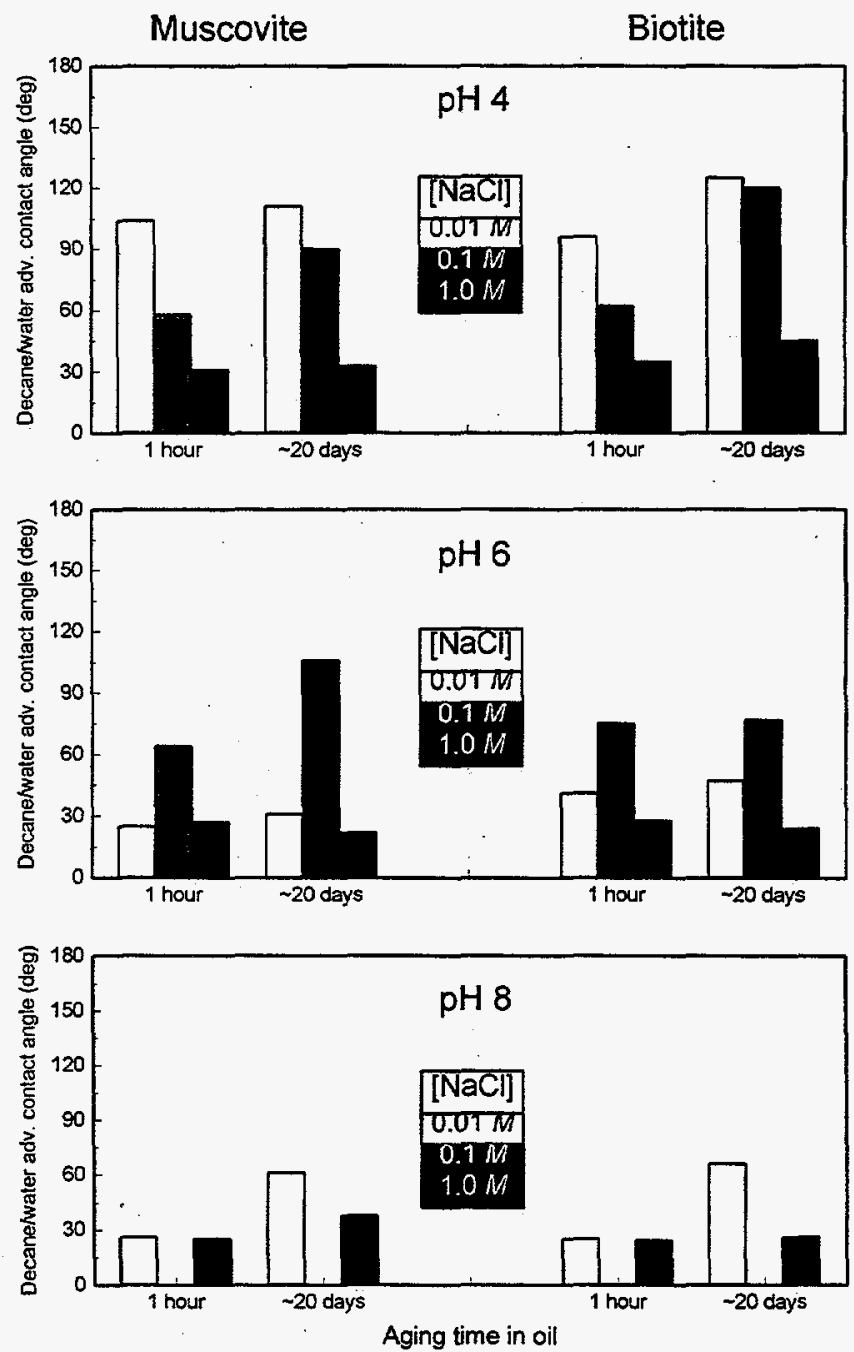

Figure 48. Wettability alteration by Alaska- 93 crude oil aged at $25^{\circ} \mathrm{C}$-effects of brine composition. 
An unexpected feature of the interactions summarized in Fig. 48 is the trend of consistently higher water-advancing angles produced by pretreatment with $\mathrm{pH} 6,[\mathrm{NaCl}]=0.1 \mathrm{M}$ solutions. Previous studies with Alaska-93 crude oil have indicated that interactions were strongest for the lowest ionic strength brines for $\mathrm{pH}$ values from 4 to 8 .

\section{Effect of aging temperature on COBR interactions}

The temperature at which solids are exposed to crude oil can affect the resulting interactions in more than one way. Kinetics of interaction may be accelerated at higher temperature, but desorption as well as adsorption may be occurring (Liu and Buckley, 1997). Increasing temperature also decreases the size of asphaltene aggregates and thus may reduce their interactions with solid surfaces (Buckley et al., 1997). Figure 49 shows water-advancing data for muscovite and biotite surfaces pretreated with $\mathrm{pH} 4,[\mathrm{NaCl}]=0.1 \mathrm{M}$ brine, then aged in Alaska-93 crude oil at three different temperatures. The highest advancing angles are produced by aging at the lowest temperature $\left(25^{\circ} \mathrm{C}\right)$. Increasing to $60^{\circ} \mathrm{C}$ decreases the contact angles on the aged mica surfaces. There may be a small increase in $\theta_{\mathrm{A}}$ if the temperature is increased from 60 to $80^{\circ} \mathrm{C}$, although the difference is small and may not be significant.

a) Muscovite

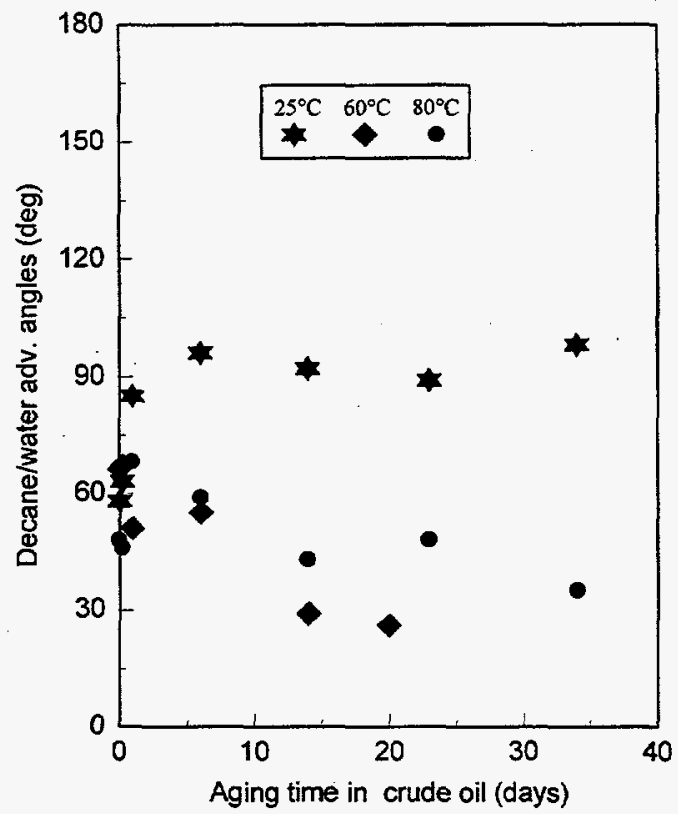

b) Biotite

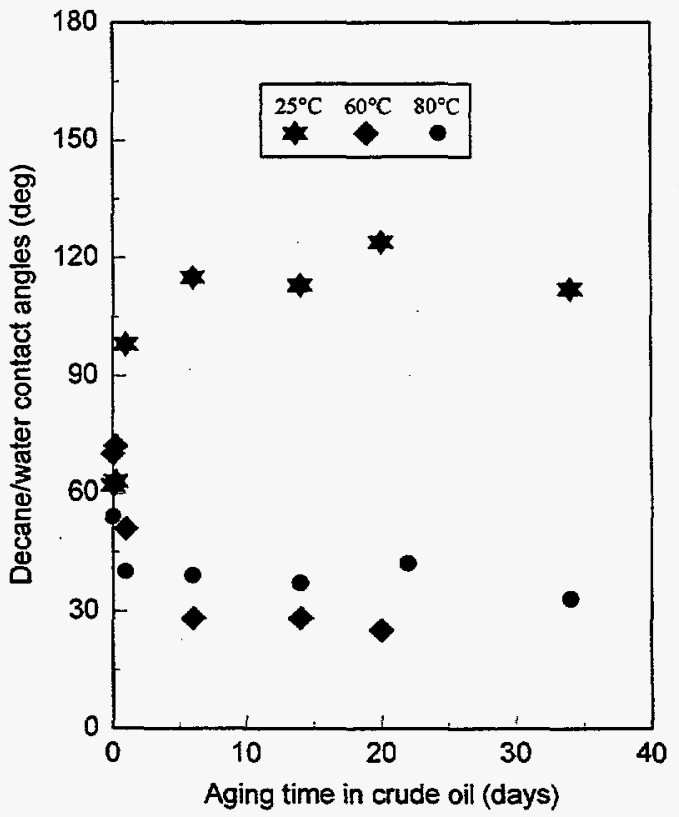

Figure 49. Advancing angles measured on mica surfaces aged in Alaska-93 at 25,60 , and $80^{\circ} \mathrm{C}$. 
Previous studies with glass surfaces have suggested that some of the mechanisms by which crude oils alter wetting are accelerated by increasing temperature, as illustrated in Fig. $\mathbf{5 0 .}$ Water advancing angles are compared for glass surfaces aged at 25 and $80^{\circ} \mathrm{C}$ with two oil samples from Prudhoe Bay and two different pretreating brines. In all cases, the higher the aging temperature, the higher the contact angles on the resulting surface. In the case of Alaska-93 with synthetic reservoir brine, the difference is especially dramatic.

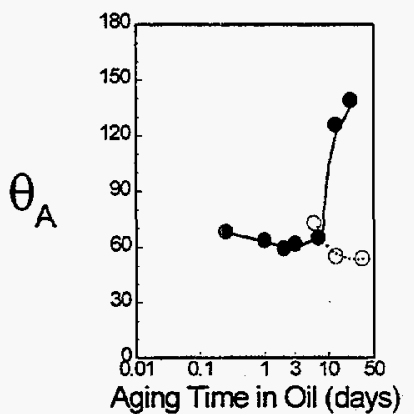

(a) Alaska-90, $\mathrm{NaCl}$ brine $\mathrm{pH} 4,0.01 \mathrm{M}$

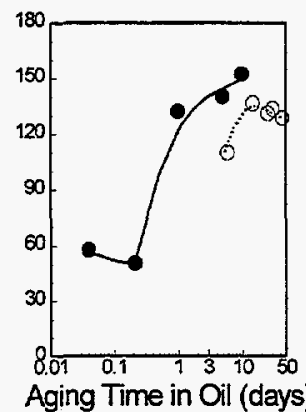

(b) Alaska-93, $\mathrm{NaCl}$ brine

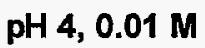

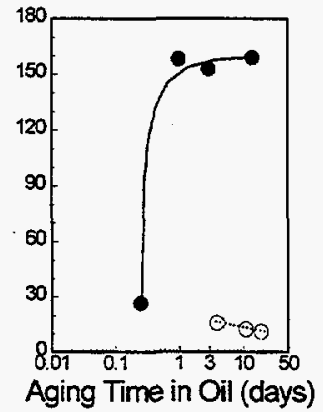

(c) Alaska-93, synthetic reservoir brine

$$
\begin{aligned}
& \text { glass surfaces aged in crude oil at: } \\
& \qquad \rightarrow \cdots,-25^{\circ} \mathrm{C}
\end{aligned}
$$

Figure 50. Effects of aging temperature on glass surfaces (after Buckley, 1996).

For mica surfaces, the effect of temperature is quite different. As illustrated in Fig. 49, increasing the temperature can substantially decrease the advancing contact angles on mici surfaces aged in crude oil. Two cases where direct comparisons to glass have been made are shown in Fig. 51. All surfaces were pretreated with $\mathrm{pH} 4$ brine $([\mathrm{NaCl}]=0.01$ or $0.1 M)$. Figure 51a shows the results of aging in Alaska-93 at $25^{\circ} \mathrm{C}$. Advancing angles are comparable for glass and biotite surfaces. The principal difference is that higher values are measured for the receding angles on mica. The situation is quite different, however, when the aging temperature is raised to $80^{\circ} \mathrm{C}$ (Fig. 51b). Advancing angles on the mica surface are much lower than those measured on similarly treated glass surfaces. 
a) $25^{\circ} \mathrm{C}$

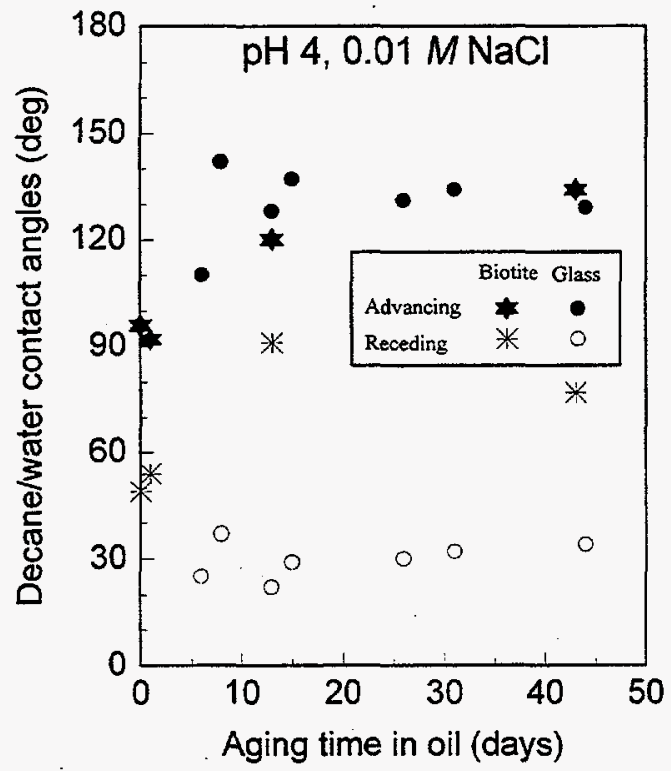

b) $80^{\circ} \mathrm{C}$

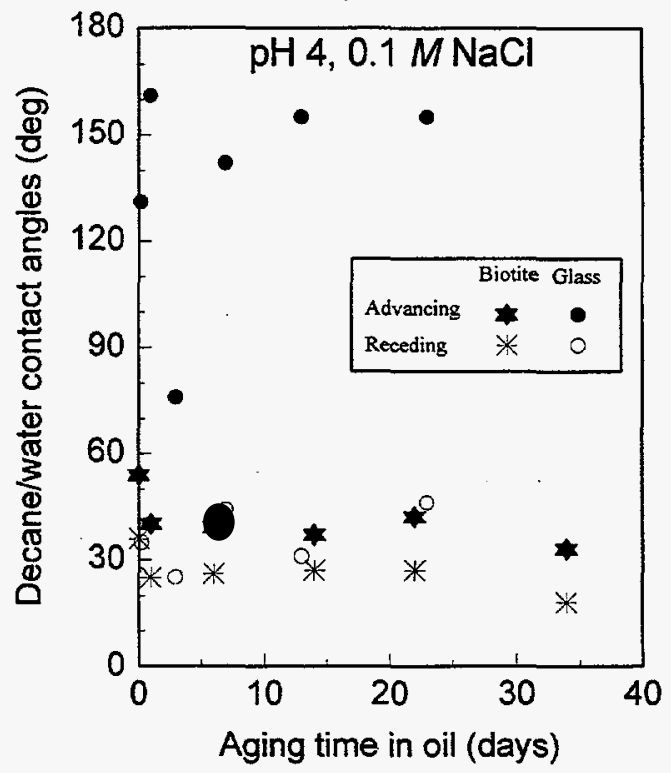

Figure 51. Glass and mica interactions are similar for aging at $25^{\circ} \mathrm{C}$, but not at $80^{\circ} \mathrm{C}$.

Increasingly water-wet conditions in core tests at higher temperatures have been reported. A recent example is the increase in rate and amount of imbibition in Berea sandstone core studies reported by Tang et al. (1996). While there is a great deal yet to explain, this observation suggests that mica/crude oil interactions may be more representative of wetting alteration in Berea than glass used in previous surface surfaces.

\subsubsection{Conclusions of wettability study on mica surfaces}

Surface properties of different mica minerals can be very similar, despite differences within their framework structures. The fact that biotite has some iron substitution does not exert a major influence on the surface interactions between solid and crude oil components. Muscovite provides consistently smoother, more transparent samples.

Macroscopic surface roughness may contribute to some scatter in the contact angle measurements, but it does not appear to bias the results significantly.

There are many similarities between interactions with mica and either borosilicate or quartz glass for the same brines and crude oil. In both cases adhesion occurs with low $\mathrm{pH}$, low ionic strength brines. Increasing temperature decreases the area of brine compositions over 
which adhesion occurs. The adhesive region is smaller for mica than for glass, and changes with temperature are less pronounced.

Changes in surface properties by adsorption appear to occur in stages; there is an initial jump in the advancing angles to about 60 degrees, followed by slower equilibration over days or weeks. This pattern of wetting alteration is similar to that reported for glass surfaces.

Temperature has a much different effect on COBR interactions with mica than had been observed previously on glass. The trend is toward more water-wet surfaces at higher temperature for mica treated with low $\mathrm{pH}$ brine and Alaska-93 crude oil. 


\section{CONCLUSIONS AND FUTURE WORK}

During the first year of this project advances have occurred on several fronts. Work has focused on characterization of crude oils and relating specific aspects of their chemical composition to the mechanisms by which they interact with mineral surfaces to alter wetting. We have also conducted an extensive baseline study of mica as an alternative to glass surfaces for future wettability testing.

\section{Part 1. Chemical Evaluation of Crude Oils}

Survey of acid and base numbers: We have demonstrated that acid and base numbers can be measured with reasonable precision and reproducibility by standard nonaqueous potentiometric titrations. Spiking solutions with a known oil-soluble acid or base helps to produce a well-defined equivalence point.

A ranking of oils with respect to their acidic and basic properties has emerged from our comparison of acid and base numbers for 22 different oil samples. Samples from Prudhoe Bay are among the highest in base number and lowest in acid number, while the opposite end of the spectrum (i.e. low base number and high acid number) is occupied by Moutray crude oil. The wettability altering properties of both of these oils have been widely studied in this laboratory and others. Both can alter the wetting of smooth glass surfaces and Berea sandstone, but by different mechanisms. General trends relating acid and/or base numbers to wetting alteration, as measured by Amott indices to water and oil were not obvious, however, without further consideration of the asphaltenes and their solvent envirnment.

Asphaltene precipitation-onset at ambient conditions: Recent developments relating refractive index to the onset of asphaltene precipitation were applied to characterize nine oil samples. Several other oils were tested, but produced no precipitate at ambient conditions in any mixture with $n$-heptane. Linearity of the relationship between mixture RI and volume fraction of oil was demonstrated, as was the validity of extrapolation to $\mathrm{RI}_{\text {oil }}$, for samples that are too opaque to be measured directly. 
The difference between $\mathrm{RI}_{\text {oil }}$ and $\mathrm{P}_{\mathrm{RI}}$ (the $\mathrm{RI}$ of the mixture in which asphaltene precipitate is first observed) is a relative measure of the stability of asphaltenes in their respective stock-tank oils. Tensleep and Lagrave were the two least stable samples among the oils tested at ambient conditions.

Mechanisms of COBR interactions: Since there are many components in crude oils that can adsorb on solid surfaces and since different components adsorb by different mechanisms, it is impossible to isolate the contributions of different components or mechanisms for many real crude oils. If, however, we choose oils with the extremes of high acid number, high base number, and poor solvency, we can identify cases where one or another of the possible interaction mechanisms dominates wetting behavior. Using this approach, four main categories of interaction mechanisms have been identified. These include:

- polar interactions involving oil components with heteroatoms in the absence of water,

- surface precipitation from oils that are poor solvents for their asphaltenes,

- acid/base interactions with organic acids and bases in the presence of water, and

- ion-binding interactions that occur when divalent and multivalent ions are present in the aqueous phase.

Since surface precipitation is greatest for oils like Lagrave that are very poor solvents for their asphaltenes, it makes sense to consider the wettability altering tendencies of oils grouped by their solvent quality. When oils of similar API gravity are compared, the effects on wetting alteration of bases and acids become more apparent.

Onset of asphaltene precipitation-controlled temperature and pressure: Studies of the relationship between solvency of the oil and the onset of asphaltene precipitation have been extended from ambient conditions to higher temperatures and 
pressures and more volatile precipitants. The feasibility of optical identification of the onset of precipitation at elevated temperature and pressure has been demonstrated. A trend of decreasing $\mathrm{P}_{\mathrm{Rr}}$, established with non-volatile paraffins was shown to extend to more volatile, lower molecular weight paraffins.

Reversibility of precipitation was tested by increasing and decreasing temperature. For the conditions of these tests, asphaltene precipitation appeared to be reversible, especially near the onset of precipitation. In contrast to reports in the literature, more precipitant was required to initiate precipitation at elevated temperature than at room temperature.

\section{Part 2. Wettability Assessment}

Interactions of Prudhoe Bay crude oil with mica surfaces: Two mica minerals have been tested. Interactions are similar to those reported for glass surfaces, but some interesting differences have also been found.

Tests with muscovite and biotite showed only minor differences between the two. Depending on brine composition and aging temperature, contact angles could change with aging time in oil toward either higher or lower angles. Macroscopic roughness of mica surfaces did not significantly influence adsorption tests.

Similarities between glass and mica include the trends of adhesion under the lowest ionic strength and lowest $\mathrm{pH}$ brines, non-adhesion for higher ionic strength and higher $\mathrm{pH}$ brines, and intermediate results between these two extremes. The primary difference between mica and glass surfaces was apparent when they were aged in oil at elevated temperature. In some cases, mica surfaces aged at high temperature were more water-wet than comparably treated surfaces aged at room temperature. These results are different than those previously reported comparisons where higher temperature aging of glass surfaces resulted in more oil-wet conditions. 


\section{Future Work}

Work will continue in both the chemical characterization of crude oils and in the wetting assessment areas. Oils are added to our data base of chemical properties as they become available. In addition, we are investigating some new tools.

- The capability to observe the onset of precipitation at high temperature and pressure will be used to extend those studies to lower molecular weight precipitants, including propane and $\mathrm{CO}_{2}$, and to continue investigations of the effects of temperature and pressure.

- FT-IR techniques will be used to quantify differences between crude oils and the materials that adsorb from them.

- Assessment of surface wetting is being extended to elevated temperatures and pressures.

Visualization of spontaneous imbibition into non-circular capillary tubes will be studied. How fluids are distributed and how rapidly they imbibe will be investigated for tubes that are treated with brine and crude oil to generate mixed-wet conditions.

In cores, we will study the effects of mixed wetting on end-point fluid saturations and relative permeabilities. 


\section{NOMENCLATURE}

$\left[\mathrm{Ca}^{2+}\right]_{\mathrm{s}}$ concentration of $\mathrm{Ca}^{2+}$ at a charged surface $(M)$

COBR crude oil/brine/rock

DLVO Derjaguin-Landau-Verwey-Overbeek

$\mathrm{E}$ equivalence point of sample (ml)

$\mathrm{F}$ equivalence point of blank (ml)

I ionic strength $(M)$

Io Amott index to oil

$I_{w}$ Amott index to water

$\mathrm{I}_{\mathrm{w}-\mathrm{o}}$ Amott-Harvey index

$\mathrm{N}_{\mathrm{a}}$ normality of $\mathrm{HClO}_{4}$ solution (equivalents $/ \mathrm{L}$ )

$\mathrm{N}_{\mathrm{A}}$ acid number (mg KOH/g of oil)

$\mathrm{N}_{b}$ normality of $\mathrm{KOH}$ solution (equivalents/L)

$\mathrm{N}_{B}$ base number (mg KOH/g of oil)

$P_{c}$ capillary pressure

$\mathrm{pH}$ - $\log$ of hydrogen ion concentration

$\mathrm{pK}_{\mathrm{a}} \quad \mathrm{pH}$ at equivalence point

$P_{R T}$ refractive index at onset of asphaltene precipitation

PVT pressure-volume-temperature

RI refractive index

$\mathrm{RI}_{\text {oil }}$ refractive index of oil

$\mathrm{S}$ sample size in measurements of acid and base numbers (g)

$\mathrm{S}_{\#}$ water saturations, as indicated in Fig. 11

$\mathrm{S}_{\mathrm{w}}$ saturation of water

$\mathrm{S}_{\mathrm{wi}}$ initial water saturation

$\mathrm{T}$ temperature $\left({ }^{\circ} \mathrm{C}\right)$

SARA saturates-aromatics-resins-asphaltenes

USBM United States Bureau of Mines

$\mathrm{V}$ calculated volume $\left(\mathrm{nm}^{3}\right)$

$V_{f, \text { oil }}$ oil volume fraction

$\Delta_{\mathrm{RI}}=\mathrm{RI}_{\text {oil }}-\mathrm{P}_{\mathrm{RI}}$

$\theta$ contact angle through water (deg)

$\theta_{\mathrm{A}}$ water-advancing contact angle (deg)

$\theta_{\mathrm{R}}$ water-receding contact angle (deg) 


\section{REFERENCES}

Akhlaq, M.S., Kessel, D., and Dornow, W.: "Separation and Chemical Characterization of Wetting Crude Oil Compounds," J. Colloid Interface Sci. (1996) 180, 309-314.

Amott, E.: "Observations Relating to the Wettability of Porous Rock," Trans., AIME (1959) 216, 156-162.

Anderson, W.G.: "Wettability Literature Survey-Part 1: Rock/Oil/Brine Interactions and the Effects of Core Handling on Wettability," JPT (Oct. 1986) 38, No. 11, 1125-1144.

Anderson, W.G.: "Wettability Literature Survey_Part 2: Wettability Measurement," JPT (Nov. 1986) 38, No. 12, 1246-1262.

Anderson, W.G.: "Wettability Literature Survey-Part 3: The Effects of Wettability on the Electrical Properties of Porous Media," JPT (Dec. 1986) 38, No. 13, 1371-1378.

Anderson, W.G.: "Wettability Literature Survey-Part 4: Effects of Wettability on Capillary Pressure," JPT (Oct. 1987) 39 , No. 10, 1283-1300.

Anderson, W.G.: "Wettability Literature Survey_Part 5: The Effects of Wettability on Relative Permeability," JPT (Nov. 1987) 39, No. 11, 1453-1468.

Anderson, W.G.: "Wettability Literature Survey_Part-6: The Effects of Wettability on Waterflooding," JPT (Dec. 1987) 39, No. 12 , 1605-11621.

ASTM D664-89: "Standard Test Method for Acid Number of Petroleum Products by Potentiometric Titration," $\operatorname{ASTM}(1989)$.

ASTM D2007-80: "Standard Test Method for Characteristic Groups in Rubber Extender and Processing Oils by the Clay-Gel Adsorption Chromatographic Method," ASTM (1980).

ASTM D2896-88: "Standard Test Method for Base Number of Petroleum Products by Potentiometric Perchloric Acid Titration, ASTM(1988).

Bailey, S.W.: "Classification and Structures of the Micas," in Micas, S.W. Bailey, ed., Mineralogical Society of America, 1984.

Brown, R.J.S. and Fatt, I.: "Measurements of Fractional Wettability of Oilfield Rocks by the Nuclear Magnetic Relaxation Method," Trans., AIME (1956) 207, 262-64.

Buckley, J.S.: "Microscopic Investigation of the Onset of Asphaltene Precipitation," Fuel Sci. \& Tech. Internat.(1996) 14, 55-74.

Buckley, J.S.: "Mechanisms and Consequences of Wettability Alteration by Crude Oils," PhD Thesis, Heriot-Watt University, Edinburgh, Scotland (1996).

Buckley, J.S., Liu, Y., Xie, X., and Morrow, N.R.: "Asphaltenes and Crude Oil Wetting-The Effect of Oil Composition," SPEJ (June, 1997) 107-119. 
Buckley, J.S., Bousseau, C., and Liu, Y.: "Wetting Alteration by Brine and Crude Oil: From Contact Angles to Cores," SPEJ (Sept. 1996) 1, No. 3, 341-350.

Buckley, J.S. and Morrow, N.R.: "An Overview of Crude Oil Adhesion Phenomena," in Physical Chemistry of Colloids and Interfaces in Oil Production, H. Toulhoat and J. Lecourtier, eds., Éditions Technip, Paris, 1992, 3945 .

Buckley, J.S., Takamura, K., and Morrow, N.R.: "Influence of Electrical Surface Charges on the Wetting Properties of Crude Oils," SPEFE (August 1989) 332-340.

Carnahan, N.F., Quintero, L., Pfund, D.M., Fulton, J.L., Smith R.D., Capel, M., and Leontaritis, K.: "A Small Angle X-ray Scattering Study of the Effect of Pressure on the Aggregation of Asphaltene Fractions in Petroleum Fluids under Near-Critical Solvent Conditions," Langmuir (1993) 9, No. 8, 2035-2044.

Chen, Y.L., Chen, S., Frank, C., and Israelachvili, J.: "Molecular Mechanisms of Kinetics during the Self-Assembly of Surfactant Layers," J. Coll. Interface Sci. (1992) 153, No. 1, 244-265.

Christenson, H.K. and Israelachvili, J.N.: "Direct Measurements of Interactions and Viscosity of Crude Oils in Thin Films between Model Clay Surfaces," J. Colloid Interface Sci. (1987).119, 194.

Cimino, R., Correra, S., Del Bianco, A., and Lockhart, T.P.: "Solubility and Phase Behavior of Asphaltenes in Hydrocarbon Media," Asphaltenes: Fundamentals and Applications, E.Y. Sheu and O.C. Mullins (eds.), NY: Plenum Press (1995) 97-130.

Clementz, D.M.: "Interaction of Petroleum Heavy Ends with Montmorillonite," Clays and Clay Minerals (1976) 24 312-319.

Clementz, D.M.: "Alteration of Rock Properties by Adsorption of Petroleum Heavy Ends: Implications for Enhanced Oil Recovery," paper SPE/DOE 10683 presented at the 1982 SPE/DOE Joint Symp. on EOR, Tulsa, Apr 4-7.

Craig, F.F., Jr.: The Reservoir Engineering Aspects of Waterflooding, SPE Monograph, Dallas (1971) 141 pp.

Cuiec, L.: "Restoration of the Natural State of Core Samples," paper SPE 5634 presented at the 1975 ATCE, Dallas, Sept. 28 - Oct. 1.

Cuiec, L.: "Wettability and Rock/Crude-Oil Component Interactions," paper presented at the 21st Intersociety Energy Conversion Engineering Conference, San Diego, Aug. 25-29, 1986.

Cuiec, L.: "Evaluation of Reservoir Wettability and Its Effects on Oil Recovery," in Interfacial Phenomena in Oil Recovery, N.R. Morrow, ed., Marcel Dekker, Inc., New York City (1991), 319-375.

Czarnecka, E. and Gillott, J.E.: "Formation and Characterization of Clay Complexes with Bitumen from Athabasca Oil Sand," Clay and Clay Minerals (1980) 28, No. 3, 197-203.

Denekas, M.O., Mattax, C.C., and Davis, G.T.: "Effect of Crude Oil Components on Rock Wettability," Trans., AIME (1959) 216, 330-333.

Dubey, S.T. and Doe, P.H.: "Base Number and Wetting Properties of Crude Oils," SPERE (Aug. 1993) 195-200.

Dubey, S.T. and Waxman, M.H.: "Asphaltene Adsorption and Desorption from Mineral Surfaces," SPERE (Aug. 1991) 389-395. 
Espinat, D. and Ravey, J.C.: "Colloidal Structure of Asphaltene Solutions and Heavy-Oil Fractions Studied by Small-Angle Neutron and X-Ray Scattering," paper SPE 25187 presented at the 1993 SPE International Symposium on Oilfield Chemistry, New Orleans, March 2-5.

Fuhr, B.J., Cathrea, C., Coates, L., Kalra, H., and Majeed, A.I.: "Properties of asphaltenes from a waxy crude," Fuel (1991) 70, 1293-1297.

Garland, E.: "The Asphaltic Properties of an Apparently Ordinary Crude Oil May Lead to Re-Thinking of Field Exploitation," paper SPE 19731 presented at the 1989 SPE Annual Technical Conference and Exhibition, San Antonio, Oct. 8-11.

Gauchet, R.: "Waterfloodings on Intermediate Wet Porous Media: New Considerations on Two Phase Flow Proerties Determination," Adv. in Core Evaluation, Reservoir Management, Proc. Eurocas III, Gordon and Breach Science Publ. (1993) 251-273.

Gaudin, A.M., Witt, A.F., and Biswas, A.K.: "Hysteresis of Contact Angles in the System Organic Liquid-WaterRutile," Trans., SME (March 1964) 1-5.

Griffen, D. T., "The Systematic Crystal Chemistry of Silicates - Mica," in Silicate Crystal Chemistry, (1992) Oxford University Press, pl 10.

Grim, R.E.: Clay Mineralogy, McGraw Hill, NY (1953) 384 pp.

Jadhunandan, P.P.: "Effects of Brine Composition, Crude Oil, and Aging Conditions on Wettability and Oil Recovery," PhD dissertation, New Mexico Institute of Mining and Technology, Socorro, NM (1990).

Liu, Y.: "Wetting Alteration by Adsorption from Crude Oils," Master's thesis, New Mexico Institute of Mining and Technology, Socorro, NM (1993).

Liu, Y. and Buckley, J.S.: "Evolution of Wetting Alteration by Adsorption from Crude Oil," SPEFE (Mar. 1997) 511.

Long, R.B.: "The Concept of Asphaltenes," Chemistry of Asphaltenes, J.W. Bunger and N.C. Li (eds.), ACS, Washington, DC (1981) 17-27.

Morrow, N.R.: "Wettability and Its Effect on Oil Recovery," JPT (Dec. 1990) 1476-1484.

Morrow, N.R., Lim, H.T., and Ward, J.S.: "Effect of Crude-Oil-Induced Wettability Changes on Oil Recovery," SPEFE (Feb. 1986) 89-103.

Morrow, N.R., Ma, S., Zhou, X., and Zhang, X.: "Characterization of Wettability and the Effects of Initial Water Saturation and Aging Time on Wettability and Oil Recovery by Waterflooding," Proc. Third Intn'l. Symp. on Evaluation of Reservoir Wettability and Its Effect on Oil Recovery, Sept. 21-23, 1994, Laramie, WY.

Nellensteyn, F.I.: "The Colloidal Structure of Bitumens," The Science of Petroleum, A.E. Dunstan (ed.), Oxford U. Press, London (1938) 4.

Peck, A.S., Raby, L.H., and Wadsworth, M.E.: "An Infrared Study of the Flotation of Hematite with Oleic Acid and Sodium Oleate," Soc. Mining Eng. Trans. (Sept. 1966) 301-307.

Pfeiffer, J.P. and Saal, R.N.: "Asphaltic Bitumen as Colloid System," Phys. Chem. (1940) 44, 139-149.

Salathiel, R.A.: "Oil Recovery by Surface Film Drainage in Mixed-Wettability Rocks," J. Pet. Tech. (Oct. 1973) 1216-24; Trans., AIME, 255. 
Speight, J.G.: The Chemistry and Technology of Petroleum, 2nd ed., M. Dekker, New York (1991), 760 pp.

Speight, J.G., Wernick, D.L., Gould, K.A., Overfield, R.E., Rao, B.M.L., and Savage, D.W.: "Molecular Weight and Association of Asphaltenes: A Critical Review," Revue De L'Institut Français du Pétrole (Jan.-Feb. 1985) 40, No. 1, 51-61.

Tang, G.Q. and Morrow, N.R.: "Effect of Temperature, Salinity and Oil Composition on Wetting Behavior and Oil Recovery by Waterflooding," paper SPE 36680 presented at the 1996 ATCE, Denver, 6-9 Oct.

Thiyagarajan, P., Hunt, J.E., Winans, R.E., Anderson, K.B., and Miller, T.: "Temperature-Dependent Structural Changes of Asphaltenes in 1-Methylnaphthalene," Energy \& Fuels (1995) 9, 829-833.

Villard, J.-M., Buckley, J.S., Morrow, N.R.., and Gauchet, R.: "Wetting and Waterflood Recovery of a Moderately Viscous Crude Oil," paper SCA 9323 presented at the 1993 Ann. Tech. Conf., Houston, TX, August 9-11.

Wu, Y.: "Crude Oil-Related Surface Wetting Study," Master's thesis, New Mexico Institute of Mining and Technology, Socorro, NM (1996).

Yildiz, H.Ö.: "Effect of Brine Composition on Oil Recovery by Waterflooding," Ph.D. Thesis, New Mexico Institute of Mining and Technolgy, Socorro, NM (1995).

Zhang, X., Morrow, N.R., and Ma, S.: "Experimental Verification of a Modified Scaling Group for Spontaneous Imbibition," paper SPE 30762 presented at the 1995 ATCE, Dallas, Oct. 22-25. 